\title{
Breakthroughs in the fabrication of electrospun-nanofiber-sup- ported thin film composite/nanocomposite membranes for the forward osmosis process: A review
}

\author{
M. OBAID ET AL.
}

CRITICAL REVIEWS IN ENVIRONMENTAL SCIENCE AND TECHNOLOGY

\section{[AQ0]}

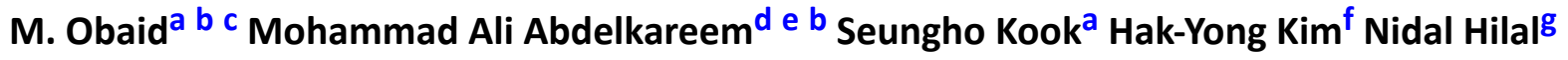 \\ Noreddine Ghaffour ${ }^{\mathrm{C}}$ In S. Kim ${ }^{\mathrm{a}}$
}

a. Global Desalination Research Center (GDRC), School of Earth Sciences and Environmental Engineering, Gwangju Institute of Science and Technology (GIST), Gwangju, Republic of Korea;

${ }^{b}$. Chemical Engineering Department, Faculty of Engineering, Minia University, Minia, Egypt;

c. Division of Biological \& Environmental Science \& Engineering (BESE), King Abdullah University of Science and Technology (KAUST), Water Desalination and Reuse Center (WDRC), Thuwal, Saudi Arabia;

d. Department of Sustainable and Renewable Energy Engineering, University of Sharjah, Sharjah, United Arab Emirates;

e. Center of Advanced Materials Research, University of Sharjah, Sharjah, United Arab Emirates;

f. Department of Organic Materials and Fiber Engineering, Chonbuk National University, Jeonju, Republic of Korea;

g. Centre Advanced Technologies and Environmental Research (CWATER), College of Engineering, Swansea University, Swansea,

CONTACT In S. ....... skim@gist.ac.kr; Mohammad Ali Abdelkareem mabdulkareem@sharjah.ac.ae[AQ2]

\begin{abstract}
Research on membrane technology to provide fresh water while considering inextricably linked energy issues has resulted in remarkable accomplishments in the production of membranes, such as thin film composite (TFC) membranes, for relatively lowenergy desalination and wastewater reclamation via the forward osmosis (FO) process. Exhaustive and continuous efforts in the enlargement of TFC membranes to achieve an excellent combination of flux and selectivity have revealed a considerable need to fabricate an appropriate substrate. Electrospinning, as a cheap, scalable, and simple technique, is capable of producing electrospun mats with distinctive features. These features make electrospun nanofibers (ENs) a promising substrate for TFC-FO membranes, resulting in tremendous achievements in enhancing membrane performance. Since 2011, rapid progress has been made in applying electrospinning to fabricate ENs substrates for TFC-FO membranes. This paper reviews progress in the fabrication and modification of TFC membranes supported by ENs substrates for FO applications. The theoretical background of FO, discussing the main problems associated with the use of conventional substrates, progress in applying electrospinning to overcome these problems, including breakthrough achievements in ENs substrates for FO, the synthesis and characterization of such substrates, and a comparison of energy consumption between FO and other desalination techniques were covered.
\end{abstract}

Keywords: Commercial membranes ; forward osmosis ; desalination ; electrospinning ; energy consumption ;FO ;membrane ; nanofiber ; osmosis ; phase inversion ; structural parameter ; TFC ; TFN ; water

\section{FUNDING}

Korea Environment Industry \& Technology Institute (KEITI)10.13039/501100003654Industrial Facilities \& Infrastructure Research ProgramKorea Ministry of Environment (MOE)1485016274This work was supported by the Korea Environment Industry \& Technology Institute (KEITI) through the Industrial Facilities \& Infrastructure Research Program, funded by the Korea Ministry of Environment (MOE) (1485016274). AQ21 


\section{Introduction}

Clean water and energy scarcity, which are inextricably linked, are two of the biggest global crises threatening humanity. Because these issues should be considered together, the search for a unique technology that simultaneously addresses water and energy shortages has been invigorated, resulting in the emergence of more effective membranebased technology for low-energy desalination and wastewater reclamation (Bui, Lind, Hoek, \& McCutcheon, 2011; Chung, Zhang, Wang, Su, \& Ling, 2012; Shannon et al., 2008). The forward osmosis (FO) process was introduced as an effective process for desalination (Chun, Mulcahy, Zou, \& Kim, 2017; Chung, Zhang, et al., 2012; Ge, Ling, \& Chung, 2013; Kong, Yang, Wu, Wang, \& Xie, 2015; Qasim, Darwish, Sarp, \& Hilal, 2015; Shaffer, Werber, Jaramillo, Lin, \& Elimelech, 2015; Tan \& Ng, 2010), wastewater treatment (Achilli, Cath, Marchand, \& Childress, 2009; Cath, Adams, \& Childress, 2005; Han et al., 2016; Lutchmiah, Verliefde, Roest, Rietveld, \& Cornelissen, 2014), liquid food processing (Dova, Petrotos, \& Lazarides, 2007; Kim, Choi, \& Hong, 2018; Rastogi, 2016; Shalini \& Nayak, 2016), energy harvesting (Qin \& He, 2014; Yuan, Abu-Reesh, \& He, 2015; Zhang, Brastad, \& He, 2011), and pharmaceutical applications (Huang, Chen, Huang, Sun, \& Crittenden, 2015; Kong et al., 2015). Unlike hydraulic-pressure-driven processes (i.e., reverse osmosis, RO), FO relies on the osmotic pressure difference between two solutions with different concentrations that are separated by a semipermeable membrane (McGinnis \& McGurgan, 2012). The difference in concentration results in the natural movement of water through the membrane from the low to the high concentration solution. Thus, FO systems consist of three main parts: a feed solution (FS, low osmotic pressure), a draw solution (DS, high osmotic pressure), and a semipermeable membrane (Figure 1).

Figure 1. Schematic setup for FO system.

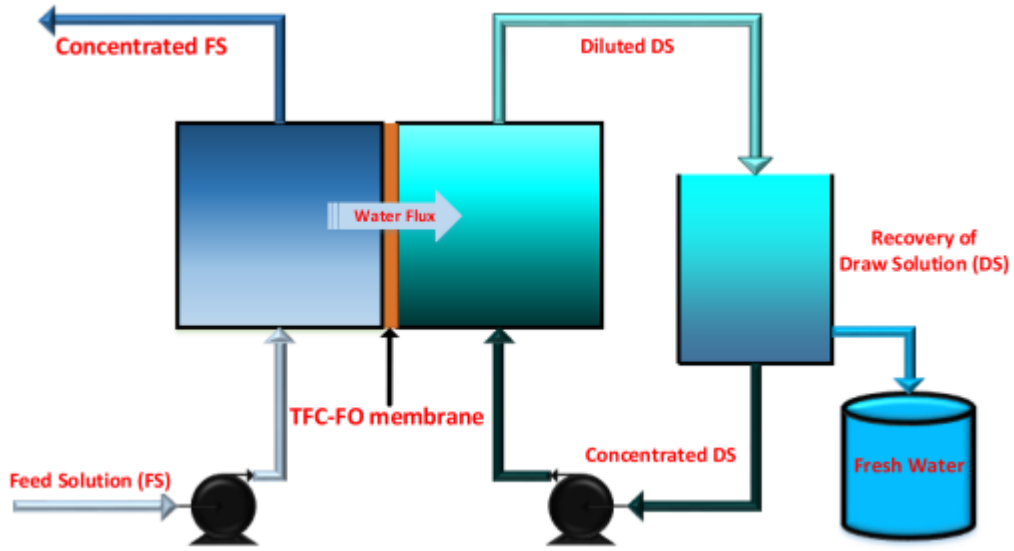

In general, the semipermeable membrane allows the transportation of water from the FS (low osmotic pressure) to the DS (high osmotic pressure), resulting in dilution of the DS and concentration of the FS, as shown in Figure 1. Thus, the water drawn through the FO membrane is not ready-for-use as product water but a diluted DS (a mixture of the DS and passed water). As a result, a second separation step (regeneration or recovery step) must be applied to produce freshwater and simultaneously reconcentrate (regenerate) the DS (Figure 1). Furthermore, the second step (regeneration) is an energy-intensive process, which has hindered the exploration of industrial FO processes. Thus, many efforts have been focused on the introduction of new nontoxic DSs that can be easily recycled with low energy requirements and low reverse solute fluxes (Ge, Fu, \& Chung, 2014; Ge \& Chung, 2015; Gwak \& Hong, 2017; Park, Ahn, Chung, \& Kwak, 2016).

Membranes are the heart of the FO process, and any semipermeable dense membrane can be used for FO. The membranes commonly used for FO can be classified into three main types: modified thin-film composite (TFC)-RO membranes, asymmetric cellulose triacetate (CTA) membranes, and TFC-FO membranes (Klaysom, Cath, Depuydt, \& Vankelecom, 2013; McCutcheon \& Elimelech, 2008; Wei, Qiu, Tang, Wang, \& Fane, 2011). Conventional TFCRO membranes are not suitable for FO owing to the thickness of the constituent layers (cast layer and nonwoven fabric layer, Figure 2 (Wei, Qiu, et al., 2011)), which decreases the FO water flux (Arena, McCloskey, Freeman, \& McCutcheon, 2011; Yip, Tiraferri, Phillip, Schiffman, \& Elimelech, 2010). For a long time, asymmetric CTA membranes (CTA-FO) from Hydration Technologies Inc. (HTI, Albany, OR) have been used (Cath, Childress, \& Elime- 
lech, 2006) (a cross-section of this type of membrane is shown in Figure 2 (Wei, Qiu, et al., 2011)). Although, CTAFO membranes show better performance in FO processes than TFC-RO membranes (Cath et al., 2013; Tiraferri, Yip, Straub, Castrillon, \& Elimelech, 2013), they generally exhibit low solute rejection, low FO water flux, and low chemical stability (membrane degradation occurs on exposure to some chemical DSs) (Yip et al., 2010).

Figure 2. A cross-sectional SEM images of commercial FO and RO membranes; Where SW30 XLE represents TFC-RO membranes from DowFilmtec, BW30 is a TFC membrane supported by a non-woven fabric, BW-GE is cellulosic brackish water RO from GE Osmonics, HTI-EM is HTI embedded mesh forward osmosis (CA) membrane from HTI, and CTA-W and CTA-NW are CTA supported by a polyester woven and nonwoven fabric, respectively. The images are adopted from (Wei, Qiu, Tang, Wang \& Fane 2011, McCutcheon \& Elimelech 2008, Puguan, Kim, Lee \& Kim 2014).
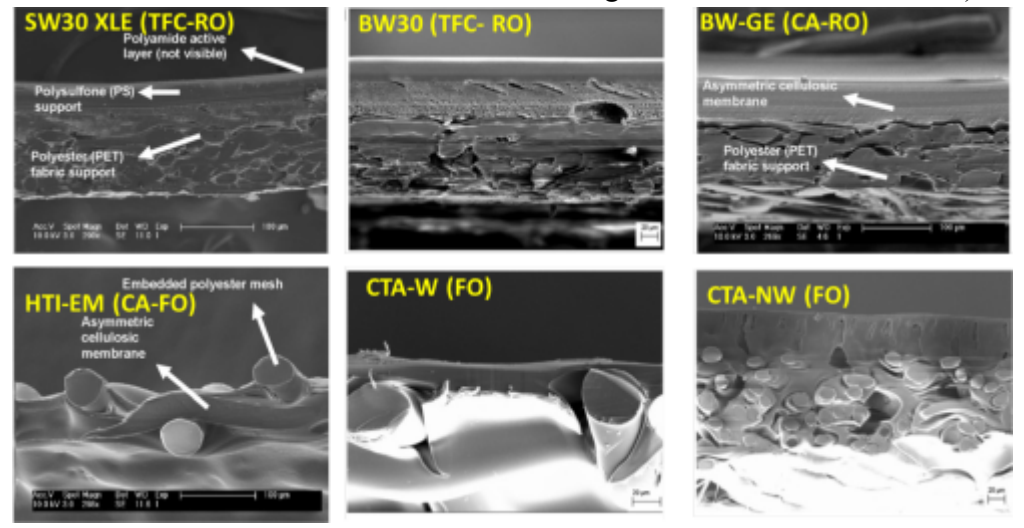

Furthermore, TFC-FO membranes have become more popular because of their superior perm-selectivity and the feasibility of optimizing the support layer and the active layer separately (Wang et al., 2010). As different fabrication techniques result in different structures for the same type of support layer, as shown in Figure 3, the fabrication method can play an important role in the performance of the support, as will discuss in detail in the following section.

Figure 3. 3D schematic of TFC membranes with various substrate structures; fingerlike and sponge-like pore structure of PI substrate, and scaffold ENs substrate. The SEM and TEM 2 D images were adapted from (Klaysom, Cath, Depuydt \& Vankelecom 2013, Wei, Qiu, Tang, Wang \& Fane 2011, Jeong, Hoek, Yan, Subramani, Huang, Hurwitz, Ghosh \& Jawor 2007).

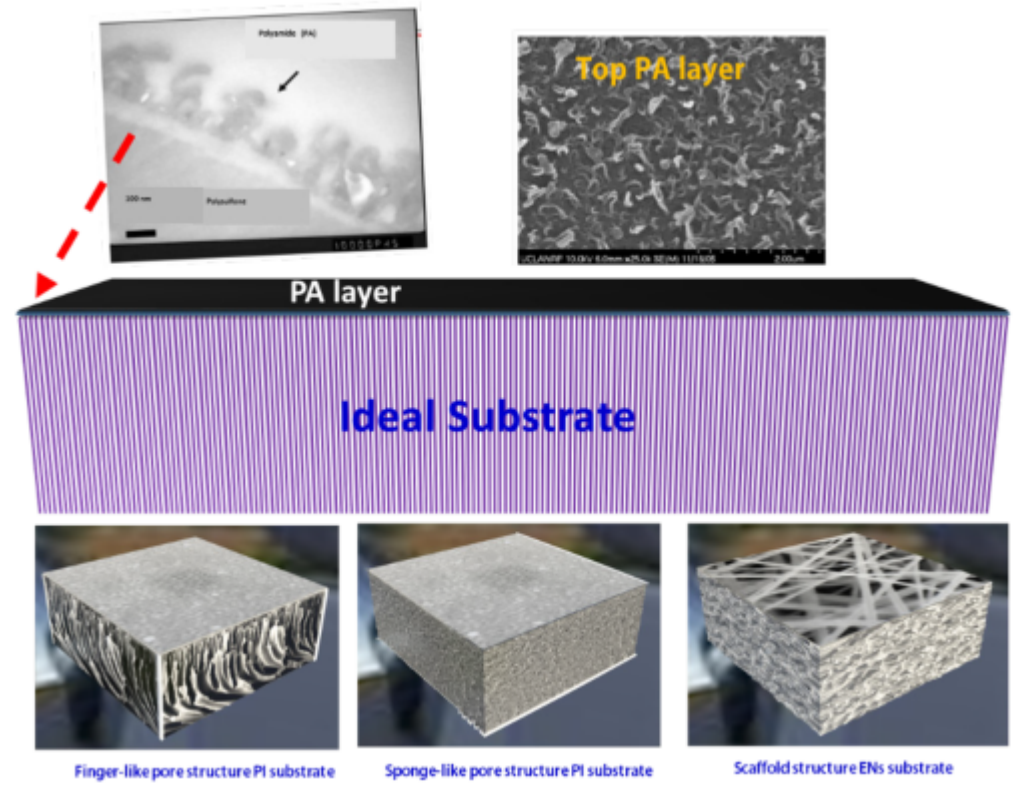

Although several review articles have been published on TFC membranes (Gohil \& Ray, 2017; Ismail, Padaki, Hilal, Matsuura, \& Lau, 2015; Lau, Ismail, Misdan \& Kassim 2012; Lau et al., 2015) and FO membranes (Cath et al., 2006; Chung, Li, et al., 2012; Lutchmiah et al., 2014; Qasim et al., 2015), in addition to many reviews on electrospun 
membranes for water applications (Ahmed, Lalia, \& Hashaikeh, 2015; Feng, Khulbe, Matsuura, Tabe, \& Ismail, 2013; Ray, Chen, Li, Nguyen, \& Nguyen, 2016; Sarbatly, Krishnaiah, \& Kamin, 2016; Shirazi et al., 2017; Wang, Yu, Sun, \& Ding, 2016), none of these articles focused on or discussed electrospun nanofibers (ENs)-supported TFC-FO membranes. As a result, there is a crucial need for a review showing the progress in these types of membranes.

For the first time, this review focuses on studies related to TFC-FO membranes based on ENs substrates. The history and progress of this candidate (ENs-based TFC-FO membranes), polymers used for fabrication, modification methods, and FO performance evaluation are discussed. To provide critical information about the obstacles facing this candidate, the challenges of using ENs substrate for TFC-FO membranes are also discussed. Moreover, this review also includes the mechanism of FO, practical considerations for implementing FO membranes in large scale and the main challenges facing its commercialization, as well as a discussion of the electrospinning process and the main parameters affecting the morphology and other properties of the prepared electrospun substrates.

\section{TFC membranes}

TFC membranes are composed of a very thin dense layer that is deposited upon a porous sublayer (for RO, membranes are mechanically reinforced with a nonwoven or woven fabric polyethylene terephthalate (PET) support) (Figure 2). These composite membranes exhibit higher water flux and salt rejection than CTA/CA membrane, as well as good stability over wide $\mathrm{pH}(2-12)$ and temperature $\left(30-70{ }^{\circ} \mathrm{C}\right)$ ranges (Baker, 2004). Moreover, this asymmetric structure allows individual optimization of the different layers to achieve the required criteria for the substrate (support layer) and the thin dense layer (Gohil \& Ray, 2017).

The possibility of independent optimization and control of thin dense and porous substrate layers attracts the membrane scientists' attention to develop and optimize the TFC membrane. Where some researches went to enhance the substrate and the other care with the improvement of the dense layer.

The porous substrates ((mostly UF membranes), of TFC membrane, can be prepared using several techniques, such as track change, stretching, electrospinning, and phase inversion; PI (phase separation; PS) (Lalia, Kochkodan, Hashaikeh, \& Hilal, 2013). Of these, PI is indeed the most used technique for fabricating the substrates, in which a homogenous system (polymeric solution having a polymer, solvent, and additives) is separated into two different phases namely; polymer-rich phase (solid) which forms the substrate (membrane) matrix and polymer-lean phase (solvent-rich liquid) which produces the pores of substrate (membrane). This separation (demixing or precipitation) process can be induced by; decreasing the temperature (Temperature-induced PS; TIPS) (Liu et al., 2017), adsorbing a non-solvent from a vapor phase (vapor-induced PS; VIPS) (Kao et al., 2008), evaporating of a volatile solvent from the casting solution (evaporation-induced PS; EIPS) (Zhao, Luo, Wu, \& Xia, 2013), or immersing into a non-solvent bath (non-solvent-induced or diffusion-induced PS; NIPS or DIPS) (Wang \& Lai, 2013). To fabricate the NIPS substrate (abbreviated as PI from now on), the homogenous polymeric (casting) solution is casted in the desired shape, then it immediately immersed in a non-solvent (coagulation) bath, and finally the resulted substrate (membrane) is well washed to remove the remaining solvent, as shown in Figure 4. Numerous studies have been done to fabricate effective and modified PI substrates, to assist in the synthesis of high-performance TFC membranes. In these modified fabrication process; organic, inorganic, or nanoparticles (NPs) additives were added to the casting solution. It was found that the modified substrate, supported TFC-FO, fabricated from the addition of hydrophilic nanomaterials, such as carbon nanotube (MWCNT) (Wang, Ou, Ge, Wang, \& Xu, 2013), porous zeolite NPs (Ma et al., 2013), titanium dioxide NPs $\left(\mathrm{TiO}_{2} \mathrm{NPs}\right)$ (Emadzadeh, Lau, Matsuura, Rahbari-Sisakht, \& Ismail, 2014), and graphene oxide (GO) (Park et al., 2015), to the casting solution revealed higher hydrophilicity and porosity, and lower structural parameter (S) than those pristine (without nanomaterials) substrates. Also, adding polyvinyl pyrrolidone (PVP), polyethylene glycol (PEG), as hydrophilic organic additive, to the casting solution enhanced the PSf substrate hydrophilicity (Ghosh \& Hoek, 2009), and improved the wettability, pore size, and surface properties of the PES substrate supported TFC-RO membrane (Fathizadeh, Aroujalian, \& Raisi, 2012). Furthermore, the casting solution conditions, including polymer types, concentration, viscosity, solvent types, and temperature, showed a significant effect on the substrate morphology, structure, and properties (Misdan, Lau, Ismail, \& Matsuura, 2013; Yeow, Liu, \& Li, 2004). Additionally, change the conditions and compositions of the coagulation bath can greatly influence the structure and the morphology of the substrates, where the existence of solvent in the coagulation bath has two opposite effects; (1) limits the outflow diffusion (delay demixing process) of solvent from the casted substrate, giving rise to formation of substrate with top-dense layer and sponge-like structure (cross-section morphology), and (2) decreases the polymer 
concentration at the surface, tending to more open pores on the top layer (Hilal, Ismail, \& Wright, 2015). While increasing of the coagulation bath temperature results in increasing the porosity and thinning the skin-layer (Peng et al., 2010).

Figure 4. Substrate fabrication: the schematic shows the fabrication steps of PI and ENs substrates, where the SEM images of PI substrate were adapted from (Widjojo, Chung, Weber, Maletzko \& Warzelhan 2011). PA layer synthesis: the photograph images illustrate the general (basic) protocol steps to prepare the PA layer to form TFC membranes, where (a) porous substrates are prewetted for a certain time, (b) then amine (i.e. MPD) aqueous solution is poured into the top surface and allowed to contact the porous substrate for a certain time before draining the excess MPD solution, (c) The residual MPD solution is removed using rubber roller (or air knife), (d) acid chloride (i.e. TMC) in organic solution is poured into the membrane surface, (e) After a certain time, the organic solution is drained from the membrane surface, and the TFC membrane is rinsed with organic solvent (i.e. hexane) and (f) Finally, the TFC prepared membrane is cured in oven at a certain temperature for a certain time. The photographic images (a-f) was adapted from (Xie, Geise, Freeman, Lee, Byun \& McGrath 2012). Where the suggested schematic diagram by Richard Baker (Baker 2000) for machinery used to make TFC membrane via interfacial composite membranes for large scale was presented in the right corner.

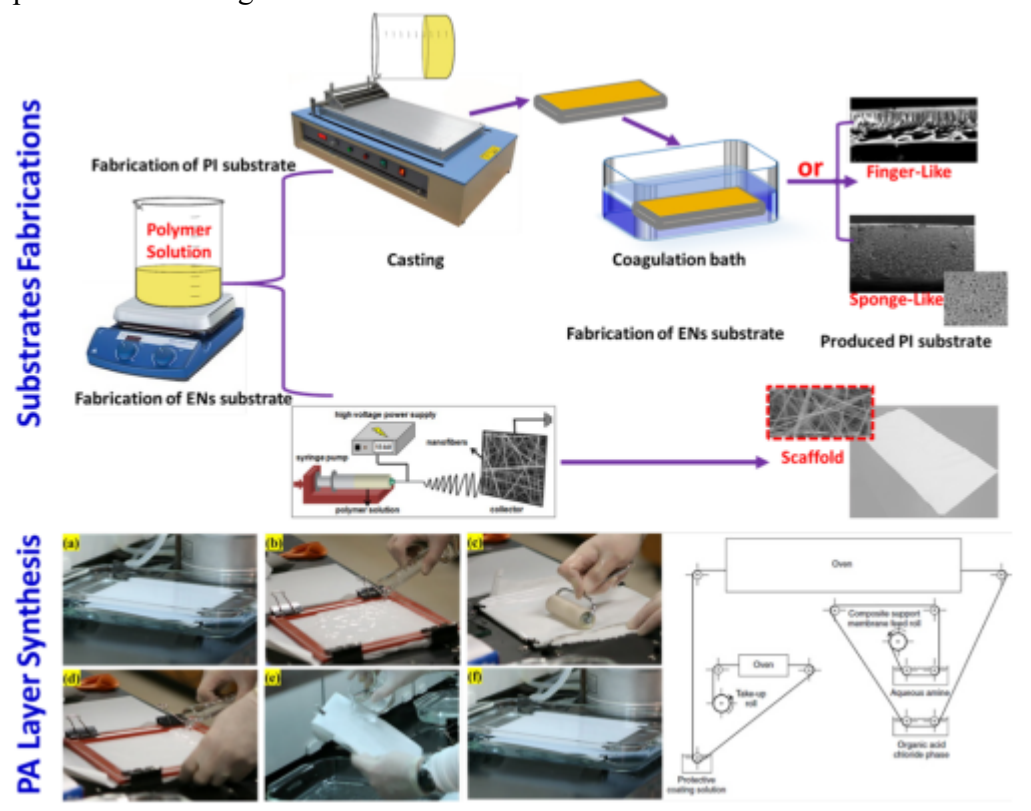

On the other hand, several techniques have been used to deposit the thin layer (PA layer) upon a porous substrate; including spray coating, dip coating, photo-grafting, plasma-initiated polymerization, and interfacial polymerization (IP) (Li, Fane, Ho, \& Matsuura, 2011). Of these, the IP is the most used technique for preparing TFC membrane, in which a reaction at the interface between two reactive monomers (an amine in the aqueous phase and an acid chloride in the organic phase) occurs on the surface of the porous substrate, resulting in a polyamide (PA) (active/rejection/ selective) layer (Gohil \& Ray, 2017; Vyas \& Ray, 2015). However, the general steps to fabricate PA layer on the top of a porous substrate to form TFC membrane are presented in Figure 4.

The properties of the obtained PA layer (TFC membrane) depends on the IP conditions and parameters, such as monomer molecular structure, solvent types, monomers concentration, reaction conditions (time, $\mathrm{pH}$, temperature, etc...), and curing temperature (Ismail et al., 2015; Lau, Ismail, Misdan \& Kassim, 2012). When MPD and TMC monomers (in immiscible aqueous and organic media, respectively) reacted, a fully aromatic PA layer is obtained, for RO and FO, while a semi-aromatic PA, for NF, can be achieved when piperazine (PIP) is used instead of MPD (Kong, Koushima, et al., 2011; Lau et al., 2015). Decreasing the MPD concentration or increasing the TMC concentration results in a looser (less cross-linked) PA layer or looser TFC with high water permeability and low salt rejection (Wei, Liu, Qiu, Wang, \& Tang, 2011). In addition to MPD, PIP, and TMC, various derivatives of amines and acyl chloride monomers were applied to fabricate PA layers (TFC) with different properties (Lau, Ismail, Misdan \& Kassim, 2012). However, NPs were mixed with MPD aqueous or TMC organic phase to fabricate thin-film nanocomposite (TFN) membranes, where GO was incorporated into the PA layer via the mixing with TMC (TMC/GO mixed organic solution) (Yin, Zhu, \& Deng, 2016) or MPD (MPD/GO mixed aqueous solution) (Shen, Xiong, \& Wang, 
2016) to enhance the TFN wettability and water permeability. In addition to this, NaY zeolite NPs and hydrophilic functionalized titanate nanotubes $\left(\mathrm{NH}_{2}\right.$-TNTs) were mixed with the TMC organic phase, to modify the PA layer. It was found that embedding $0.1 \mathrm{wt} . \%$ of NaY zeolite NPs into the PA enhanced the water permeability of the TFN-FO membrane by $80 \%$, compared to the pristine TFC membrane (Ma, Wei, Liao, \& Tang, 2012), while the FO water flux of the TFN was increased by two times, compared with the TFC membrane, when 0.05 wt. $\%$ of $\mathrm{NH}_{2}-\mathrm{TNT}_{\mathrm{s}}$ was incorporated into the PA layer (Emadzadeh et al., 2015).

Overall, during the fabrication of TFC membranes, it is important to fabricate the PA layer that has a high crosslinking degree (for high salt rejection), thin thickness, and hydrophilic (for high water permeability) in case of TFC membranes for $\mathrm{RO}$ and $\mathrm{FO}$, while there is distinguish in the requirements for the substrates for TFC-FO membrane rather than that for TFC-RO membrane. Thin, hydrophilic, highly porous substrates are required for TFC-FO membrane, while the high mechanical properties to withstand the high hydraulic pressure is the most important features for the support of TFC-RO membranes.

Although the high potential revealed by the TFC-FO, so far, FO for industrial- or large-scale applications has rarely been reported (Haupt \& Lerch, 2018). Owing to several challenges, including high reverse salt flux, internal and external concentration polarization, and limitations in the efficient recovery of the DS (Lutchmiah et al., 2014). The recovery of DS has required an additional process (hybrid system), thus FO cannot work as a stand-alone system which mainly limiting its commercialization. For successful and broadly commercialization implementation of FO, all of these challenges must be resolved. The important features towards successful FO are the enhancement of the operation parameters and conditions, membrane properties, selection and regeneration of draw solution, and hybridization. The concentration polarization (CP) is considered a key aspect in FO and it affects the water flux or water passing through the membrane, thus in the following section, we provide a brief background on $\mathrm{CP}$.

\subsection{Concentration polarization}

$\mathrm{CP}$ is one of the challenges of the FO process and it occurs on both sides of the FO membrane and can be classified as external concentration polarization (ECP) on the outer surfaces and ICP inside the substrate (Gao, Wang, Li, \& Tang, 2014; Tang et al., 2011; Wang, Zhang, Liu, Xiao, \& Xu, 2016). For ECP, during the FO process, water passes from the feed side through the active layer (PA), leaving the solute on the PA layer surface, resulting in the formation of a boundary layer and a concentration gradient (AL-FS mode, where the active layer faces the FS). This phenomenon, called concentrative ECP (CECP), is shown in Figure 5a. In contrast, dilutive ECP (DECP), which occurs when the PA layer faces the DS (AL-DS mode), is shown in Figure 5b (Gray, McCutcheon, \& Elimelech, 2006; Wang et al., 2014; Wang, Zhang, Liu, Xiao \& Xu, 2016). ECP reduces the net driving force owing to increase (ALFS) or decrease (AL-DS) the osmotic pressure at the PA layer $\left(C_{F, m}\right)$ compared with that of the bulk FS $\left(C_{F, b}\right)$ or DS $\left(C_{D, b}\right)$, respectively (Figure $5 \mathrm{a}$ and $\mathrm{b}$ ). However, the increase in turbulence and the shear rate can effectively mitigate both types of ECP (Lay et al., 2012). Various models are available to understand and describe ECP in FO processes (McCutcheon \& Elimelech, 2006; Tan \& Ng, 2008, 2013).

Figure 5. Illustration of $\mathrm{CP}$ phenomenon; external concentration polarization (ECP) exists at the membrane surfaces and internal concentration polarization (ICP) which occurs within the substrates. (a) Shows AL-FS mode including DICP and CECP, (b) Shows AL-DS mode including CICP and DECP, (c) shows the real AL-FS mode considering ECEP, DICP, and CECP in 2D and 3D schematic, and (d) shows all CP phenomena. [a, b and d adopted from (Suh \& Lee 2013; Tan \& Ng 2008)]. 

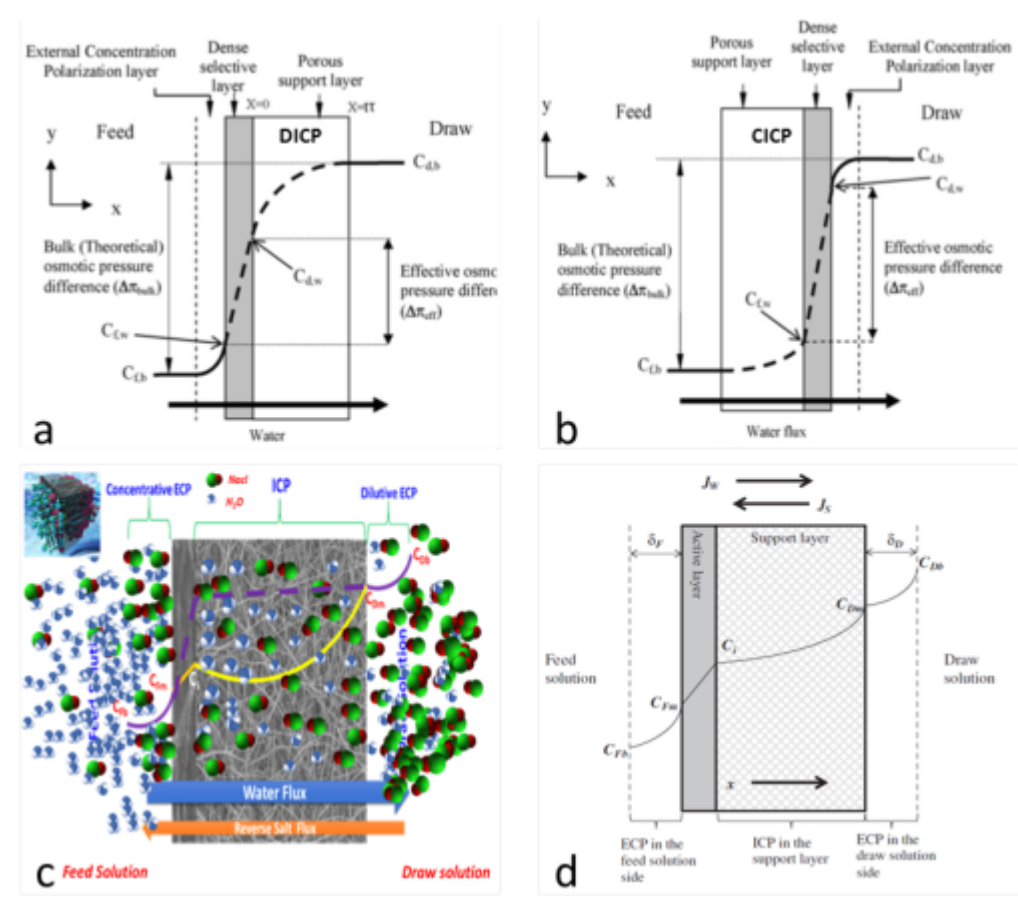

While ECP occurs near the FO membrane surface, ICP occurs inside the substrate. When water moves from the FS across the PA to meet the DS (AL-FS mode) at the interface (inner or back-side of the PA layer facing the substrate, $C_{i}$, the DS at the interface become diluted. Hence, this causes a decrease in the effective osmotic pressure difference (gradient) across the PA layer. As a result, the DS concentration at the interface is lower than its concentration at the membrane surface and bulk, and this phenomenon is called ICP, as shown in Figure 5c and d (Gray et al., 2006; Liu, Li, Zhou, Xie, \& Lee, 2016; McCutcheon \& Elimelech, 2006; Tang, She, Lay, Wang, \& Fane, 2010). Two types of ICP can arise within the support layer, namely, dilutive ICP (DICP) and concentrative ICP (CICP), depending on the membrane orientation, as demonstrated in Figure 5a and b. When the feed is placed against the PA layer (AL-FS), DICP will occur within the substrate (Figure 5a), whereas CICP occurs when the PA layer is facing the DS (AL-DS, Figure 5b). Unlike ECP, because ICP occurs inside the support layer, it cannot be mitigated by changing the hydrodynamic conditions. Thus, ICP has a more severe influence than ECP on the decrease in FO water flux. Numerous studies have investigated the mechanism of ICP, and ICP models have been developed (Gray et al., 2006; Loeb, Titelman, Korngold, \& Freiman, 1997; McCutcheon \& Elimelech, 2006; Tang et al., 2010; Zhao \& Zou, 2011).

Based on these models, FO water flux equations have been developed by taking into consideration the influence of ICP and ECP, as follow (McCutcheon \& Elimelech, 2006, 2007):

$J_{w}=\boldsymbol{A}\left[\pi_{D, b} \exp \left(-J_{w} K\right)-\pi_{F, b} \exp \left(\frac{J_{w}}{\boldsymbol{k}_{F}}\right)\right]($ AL-FS mode $)(1)$

$\boldsymbol{J}_{\boldsymbol{w}}=\boldsymbol{A}\left[\boldsymbol{\pi}_{\mathrm{D}, \boldsymbol{b}} \boldsymbol{e x p}\left(-\frac{\boldsymbol{J}_{\boldsymbol{w}}}{\boldsymbol{k}_{\boldsymbol{D}}}\right)-\boldsymbol{\pi}_{\boldsymbol{F}, \boldsymbol{b}} \boldsymbol{e x p}\left(\boldsymbol{J}_{\boldsymbol{w}} \boldsymbol{K}\right)\right](\mathrm{AL}-\mathrm{DS} \text { mode })^{(2)}$

where $J_{w}$ is the FO water flux, $A$ is the water permeability coefficient of the membrane, $\pi_{D, b}$ and $\pi_{F, b}$ are the osmotic pressures of the bulk DS and FS, respectively, $K$ is the diffusion resistivity of the solute inside the substrate, and $k_{D}$ and $k_{F}$ are the mass transfer coefficients in the DS and FS, respectively.

It is worth mentioning that these equations are based on some assumptions, namely, (1) the membrane has a high flux with excellent salt rejection (the salt permeability coefficient, B, is negligible), (2) DECP is negligible in AL-FS mode, and (3) CECP is negligible in AL-DS mode. In fact, both DECP and CECP, as well as the ICP, can occur in the same orientation, as shown in Figure 5c. Thus, there is a critical need for modified models that predict the FO water 
flux accurately when considering both CECP and DECP with ICP. Interestingly, for the AL-FS mode, CECP and DECP on the PA layer (FS side) and the substrate (DS side), respectively, as well as ICP, were considered to develop an accurate FO model that predicts the reverse salt flux $\left(J_{\mathrm{S}}\right)$ (Suh \& Lee, 2013; Wang, Zhang, et al., 2016).

$J_{s}=B\left[\frac{C_{D, b}+J_{s} / J_{w}}{\exp \left(J_{w} / k_{D}\right) \exp \left(J_{w} K\right)}-\left(C_{F, b}+J_{s} / J_{w}\right) \exp \left(J_{w} / k_{F}\right)\right](\text { AL-FS mode })^{(3)}$

where $C_{D, b}$ and $C_{F, b}$ are the solute concentrations of the bulk DS and FS, respectively.

From the above equations, it was observed that $K$ (solute resistivity for diffusion within the substrate) is present in both the water and solute flux equations. This parameter is defined in Eq. (4) (McCutcheon \& Elimelech, 2006).

$K=\frac{t \tau}{D}=\frac{S}{D}(4)$

where $t, \tau$, and are the thickness, tortuosity, and porosity of the substrate, respectively, which can be expressed as the structural parameter of the substrate, $S(\underline{\boldsymbol{t} \tau})$, and $D$ is the solute diffusion coefficient.

Based on the above equations, $k_{F}$ and $k_{D}$ (mass transfer coefficients) are dependent on the hydrodynamic conditions on the membrane surface, which can be controlled by changing the operating conditions. In contrast, as $K$ is related to the structural parameter of the substrate, alteration of the properties and structure of the substrate is required to mitigate the adverse effects of ICP (Huang \& McCutcheon, 2015).

\subsection{Alteration of substrate structure to maximize water flux}

As clearly indicated by the above equations, a smaller $S$ value corresponds to less ICP, resulting in a higher FO water flux. Thus, the $S$ value is a vital parameter for controlling ICP, and it is important to characterize the $S$ values of newly fabricated membranes. Basically, thinner, less tortuous, and more porous substrates will have lower $\mathrm{S}$ values, resulting in enhanced $\mathrm{FO}$ membrane performance.

To find a simple and effective way to mitigate the effect of ICP on FO membrane performance, numerous efforts have been focused on the fabrication of low-structural-parameter (low-S) substrates (Kuang et al., 2016; Lutchmiah et al., 2014; Wei, Qiu, et al., 2011; Zirehpour, Rahimpour, \& Ulbricht, 2017). However, most studies have focused on fabricating and modifying substrates (support layers) for TFC-FO membranes, which are fabricated via the PI method, i.e., flat sheet (Sairam, Sereewatthanawut, Li, Bismarck, \& Livingston, 2011; Wei, Qiu, et al., 2011) and hollow fiber (Shi et al., 2011; Wang et al., 2010) structures. However, to address and mitigate ICP, the substrates for TFC-FO membranes should be redesigned according to specific criteria, such as high porosity $(\varepsilon)$, minimal tortuosity $(\tau)$, low thickness $(t$ ), optimum pore size, and high hydrophilicity, while also considering swelling and robustness (Huang \& McCutcheon, 2015; Tiraferri, Yip, Phillip, Schiffman, \& Elimelech, 2011; Zhao, Li, \& Liu, 2017).

To mitigate ICP phenomena, PI substrates can be enhanced by tailoring the structure (from sponge-like to fingerlike or needle-like) or enhancing the properties of the substrate (Ghanbari et al., 2016; Huang, Bui, Meyering, Hamlin, \& McCutcheon, 2013; Lau, Ismail, Misdan \& Kassim 2012; Liang et al., 2017; Liu, Li, et al., 2016; Ong, Chung, de Wit, \& Helmer, 2015; Park et al., 2015; Sahebi et al., 2016; Wang, Ou, Wang, \& Xu, 2015; Widjojo, Chung, Weber, Maletzko, \& Warzelhan, 2011, 2013; Yip, Phillip, Schiffman, \& Elimelech, 2015; Zhao et al., 2017). Owing to the big efforts, which have attempted to minimize the structural parameter $(S)$ of PI substrates for TFC-FO membranes, commercial TFC-FO membranes with small S value (less than $600 \mu \mathrm{m}$ ) were fabricated, as compared to values of $9583 \mu \mathrm{m}$ for TFC-RO (SW30, Dow Chemical Company) (Yip et al., 2010). Commercial TFC-FO and CA membranes with S values of $533 \mu \mathrm{m}$ and $465 \mu \mathrm{m}$, respectively, were fabricated by HTI (HTI, Albany, OR). It is worth mentioning that, the thickness of CA is half of the TFC membrane (100 $\mu \mathrm{m}$ vs $50 \mu \mathrm{m})$ (Ren \& McCutcheon, 2014). Also, a commercial TFC-FO with S value of $266 \mu \mathrm{m}$ was produced by Oasys Water Inc. (Boston, MA) (McGinnis, Hancock, Nowosielski-Slepowron, \& McGurgan, 2013), while Toray Industries, Korea, successfully fabricated a commercial TFC-FO flat-sheet membrane with S value of $409 \mu \mathrm{m}$ (Volpin et al., 2018), and spiral wound TFC-FO 
membranes labeled as 8"SW and $8040 \mathrm{SW}$ with very high A values of 8.9 and $5.54 \mathrm{LMH} /$ bar, respectively, but no information was provided about the S values (Kim, Phuntsho, et al., 2018; Kim et al., 2017). Also, Porifera (Porifera, Hayward, CA, USA) and Aquaporin A/S (Aquaporin A/S, Copenhagen, Denamark) provided the commercial TFCFO membranes with S values of 269 and $301 \mu \mathrm{m}$, respectively, (Lee \& Kim, 2017; Xie et al., 2018). Despite the abovementioned progress in the membrane structural parameters, thus far, the use of FO desalination process in industrial-scale is rare and scarce.

Research and development of TFC-FO membranes have been actively carried out to find an alternative solution to existing PI substrates, with the aim of overcoming the severe ICP problems that result from the high tortuosity and low porosity of PI substrates. In 2011, these efforts resulted in the development of ENs substrates, which exhibit high porosity with interconnected macropores and less tortuous paths (Song, Liu, \& Sun, 2011). These advantages make ENs substrates a promising candidate for TFC-FO membranes. However, ENs-based TFC-FO membranes are in the early stages of development. The following sections discuss the electrospinning process (Section 3) and up-to-date progress on ENs-supported TFC membranes (Section 4).

\section{Electrospinning}

Among the various nanostructure morphologies (nanofibers, nanobelts, nanorods, and nanotubes), nanofibers, which have one-dimensional nanostructures, have been extensively studied over the last two decades owing to their high aspect areas, high surface areas, mechanical robustness, and uniform pore sizes (Lee, Kim, La, Lee, \& Sung, 2002; Ray et al., 2016; Saud et al., 2017; Shao et al., 2003). There are a number of methods for nanofiber preparation, including drawing (Nain, Amon, \& Sitti, 2006; Sehaqui et al., 2012; Singh, Geng, Herrera, \& Oksman, 2018), templating (Tao \& Desai, 2007; Wang et al., 2006; Wang et al., 2018), self-assembly (Chen, Slattum, Wang, \& Zang, 2015; Liu, Fukushima, Venkataraman, Hedrick, \& Yang, 2018; Wang, Ouyang, et al., 2015), and electrospinning (Ahmed et al., 2015; Ding, Hou, Zhao, Zhu, \& Fong, 2016; Feng, Takeuchi, Abdelkareem, Tsujiguchi, \& Nakagawa, 2013; Ito, Takeuchi, Tsujiguchi, Abdelkareem, \& Nakagawa, 2013; Persano, Camposeo, Tekmen, \& Pisignano, 2013; Ramakrishna et al., 2006; Wang, Ding, \& Li, 2013; Wang, Yu, Kelkar, \& Zhang, 2017; Wang, Yu, et al., 2016; Zhang, Kang, Tarascon, \& Kim, 2016).

Electrospinning is one of the most common ways used for preparing nanofibers. Electrospinning is a simple and cost-effective process that can be operated at room temperature and applied to the preparation of a wide range of materials with different morphologies, such as nanofibers, nanotubes, and nanorods, with high productivity. Electrospinning is carried out by applying an electric field between the metallic needle of a syringe containing a polymer and a grounded metallic collector (stationary or rotating) using a high voltage power supply, as shown in Figure 6 a. By applying a high voltage between the polymer solution in the syringe and the metallic collector, an electrostatic potential difference is created between the two ends. When this potential difference is sufficient to overcome the surface tension of the polymer solution, a charged jet of the solution is formed, which then elongates to form a Taylor cone, as shown in Figure 6a. Thin fibers emerge from the tip of this cone (Garg \& Bowlin, 2011; Reneker, Yarin, Fong, \& Koombhongse, 2000), and following further elongation, the fibers are deposited on the surface of the metallic collector, which can be fixed, as shown in Figure 6a, or a rotating. In the distance between the collector and the tip, the solvent is evaporated and dry fibers are deposited on the collector.

Figure 6. (a) Schematic diagram shows the principals of electrospinning, (b) number of publications per year using keywords of "electrospinning" and the inset is the No. of publication based on the subject area [data are acquired from Scopus on 17.01.2018], (c) industrial-scale fabrication of electrospun polyimide nanofiber nonwovens/fabrics (one production line has reached $\sim 2000 \mathrm{~m}^{2}$ per day), (d) lab-scale electrospinning machine with different collector shape, (e) pilot production electrospinning machine (50 200 needles) and (f) is an electrospinning oriented industrial nanofiber production machine (production capacity of $180 \mathrm{~m}^{2} /$ day to $5.000 \mathrm{~m}^{2} /$ day nanofiber membrane coating). Where c, d, e and f adapted from (Ding, Hou, Zhao, Zhu \& Fong 2016; INOVENSO Co 2018; NanoNC 2018; TONG LI TECH 2018). 


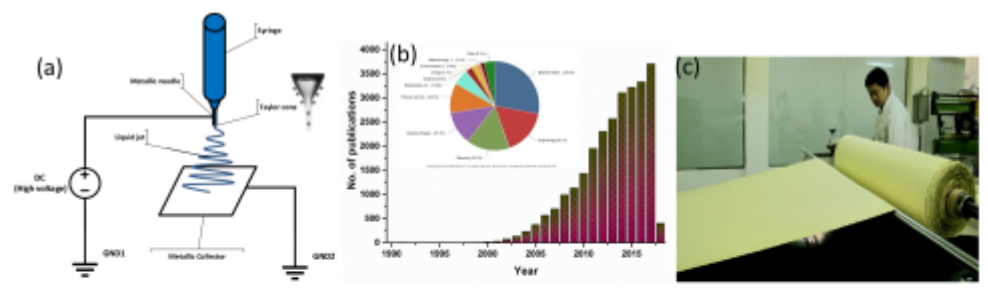

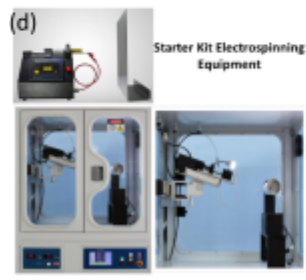

ESR200RD model

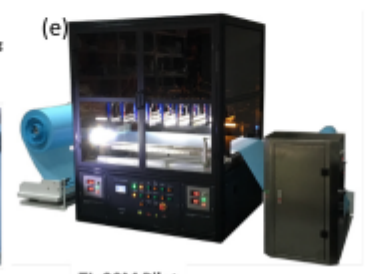

TL-20M Pilot

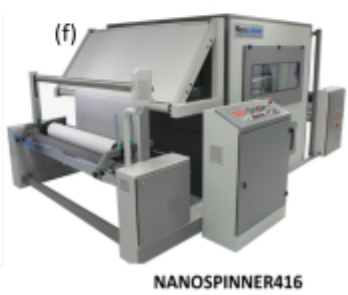

The nanofibers obtained by this technique can be aligned, can be produced continuously, and have high surface-tovolume ratios (Wang et al., 2017). These advantages make the electrospinning technique highly interesting for both academic and industrial applications. A huge number of reports have been published on this technique, as shown in Figure 6 b, and production on an industrial scale (i.e. $2000 \mathrm{~m}^{2} /$ day capacity on one production line) has been achieved (Figure 6c) (Ding, Hou, Zhao, Zhu \& Fong 2016). Furthermore, both lab- and industrial-scale electrospinning equipment is now available on the market (Figure 6d-f) (Elmarco, 2018; INOVENSO Co, 2018; LINARI NanoTech, 2018; Nadetech Innovations, 2018; NanoNC, 2018; TONG LI TECH, 2018).

One of the main advantages of the electrospinning technique is that the nanofiber morphology can be controlled by several parameters. The main parameters that can be used to optimize the electrospinning process are divided into three categories: solution parameters, process parameters, and environmental conditions. The most critical parameters and their effects are summarized in Figure 7.

Figure 7. Diagram shows the main parameters affecting the morphology of the prepared nanofibers.

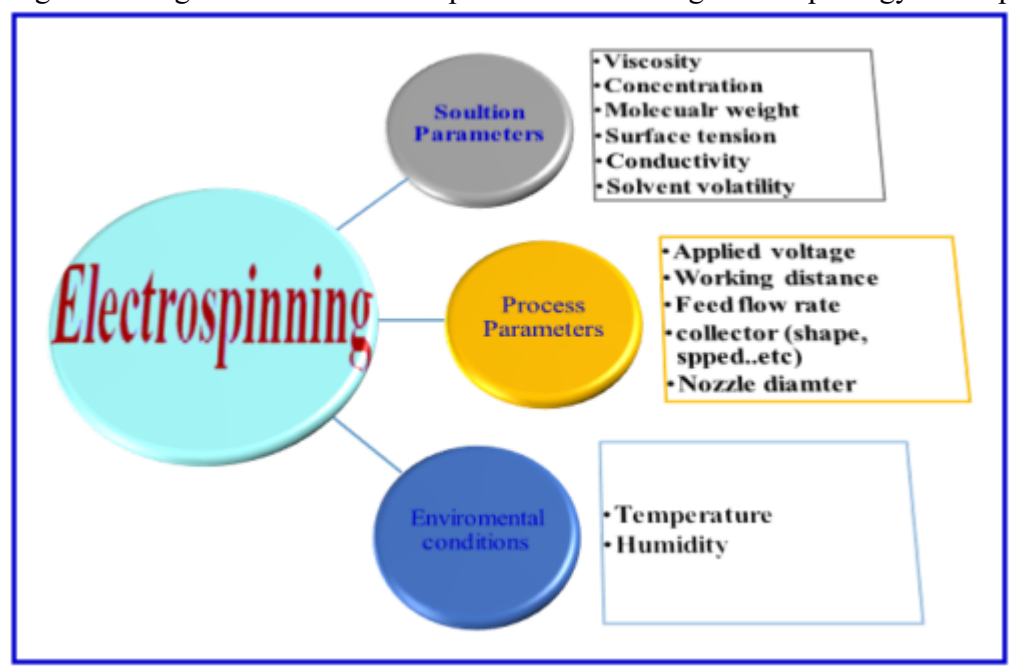

\subsection{Solution parameters}

The main solution parameters are density, molecular weight, viscosity, concentration, surface tension, and conductivity. It is worth mentioning that solution concentration and viscosity are related to each other, i.e., a high viscosity corresponds to a high concentration. Although the polymer molecular weight, properties of the solvent, and solution temperature have an effect on the viscosity, the solution concertation considers the key factor affecting the viscosity 
as well as the fiber formation (Ding \& Yu, 2014). Generally, when the solution concentration is increased the fiber diameter could be increased. If the concentration is too low, a spray or beads are formed and if the concentration is too high, ribbons are formed (Jacobs, Anandjiwala \& Maaza, 2010; Yang et al., 2004). On other words, at low viscosities, smooth nanofibers are not produced, whereas if the viscosity is too high, the polymer is not ejected (Lee et al., 2004; Neo, Ray, Easteal, Nikolaidis \& Quek, 2012; Zhao, Yang, Lu, Wang \& Wei, 2005). Typically, at viscosity lower than 1 poise and minimum concertation, the surface tension would be the dominant factor and electrospray occurs producing drops instead of fibers, while, when the viscosity of the solution is greater than 20 poise, its flow through the needle tip is hampered (Deitzel, Kleinmeyer, Harris \& Tan, 2001). On other words, based on the relative solution concentration $\mathrm{c} / \mathrm{c}^{*}$, the polymer concentration can be divided into three regions; dilute $\left(\mathrm{c} / \mathrm{c}^{*}<1\right)$, semi-dilute unentangled $\left(1<\mathrm{c} / \mathrm{c}^{*}<3\right)$, and semi-dilute entangled $\left(\mathrm{c} / \mathrm{c}^{*}>3\right)$, and the nanofibers can be produced from the semi-dilute entangled polymer solution only, whereas aerosol and stretched beads are formed from electrospinning of dilute and semi-dilute unentangled solution, respectively (Arinstein, 2017).

Therefore, a suitable concentration (suitable viscosity and surface tension) is required to obtain smooth nanofibers. For instance, at low PVDF/DMF solution concentration (5 wt.\%) electrospray occurred and no fibers were observed, while by increasing the concentration to $10 \mathrm{wt} \%$ smooth nanofibers were obtained, and further increase in the concentration to $15 \mathrm{wt}$ \% resulted in an increase of the fiber diameters (Costa, Bretas, \& Gregorio, 2010). Also, Zhang reported an increase of the nanofiber diameters from $60-90 \mathrm{~nm}$ to $110-150 \mathrm{~nm}$ when Nylon 6 solution concentration increased from 10 to 15 wt.\% (Zhang, Shim, Kim \& Design, 2009). For the PLLA dissolved in DCM/pyridine, it turns out that a minimum concentration to produce uniform electrospun nanofibers is $1 \mathrm{wt} . \%$, while the use of concentration lower than $1 \mathrm{wt}$ \% results in the formation of beaded fibers (Tan, Inai, Kotaki \& Ramakrishna, 2005).

The molecular weight of the polymer affects the entanglement of the polymer chains, as well as influence the solution viscosity. Using high molecular weight PVA, at a fixed concentration, resulted in forming smooth nanofibers, while lowering its molecular weight produced beads instead of fibers (Koski, Yim \& Shivkumar, 2004). Tan et.al found that an increase of the PLLA molecular weight from $100 \mathrm{~K} \mathrm{~g} / \mathrm{mole}$ (LM-PLLA) to $300 \mathrm{~K} \mathrm{~g} / \mathrm{mole}$ (HM-PLLA) resulted in a decrease of the minimum spinnable concentration of PLLA solution (required to produce bead-free fibers) from 9 wt.\% to 4.5 wt.\%, respectively (Tan, Inai, Kotaki \& Ramakrishna, 2005). Although increase of the molecular weight can result in an increase of fiber diameters, some reports find out that the oligomers with adequate intermolecular interaction can be electrospun and produce smooth fiber, and the high molecular weight is not essential in such cases (Burger, Hsiao \& Chu, 2006; McKee, Layman, Cashion \& Long, 2006).

Both of the solution conductivity and surface tension affects the Talyor cone formation, where the solution must have adequate charges which make the repulsive forces overcome the surface tension. Increasing the conductivity results in the formation of thinner nanofibers, and decreasing the surface tension can eliminate the formation of beads, while the high surface tension inhibits the electrospinning process (Angammana \& Jayaram, 2011; Huang et al., 2006). However, at low solution conductivity, no fiber will produce because no charge to form a Taylor cone. Many factors can affect the solution conductivity, such as solvent, polymer type and adding of salts. For example, by raising the polymer solution conductivity from 1.53 to $10.5 \mathrm{mS} / \mathrm{cm}^{2}$ (using sodium chloride ( $\mathrm{NaCl}$ ) from 0.05 to $0.2 \%$ ), the diameter of produced nanofibers was decreased from 214 to $159 \mathrm{~nm}$, respectively (Zhang, Yuan, Wu, Han \& Sheng, 2005). Using Lithium bromide ( $\mathrm{LiBr}$ ) salt as additives, the fiber diameters of styrene-butadiene-styrene (SBS) decreased from 1480 to $480 \mathrm{~nm}$ when the $\mathrm{LiBr}$ concentration increased from 0.0001 to $0.2 \mathrm{wt} . \%$ (Fan, Xu, Zhou, Chen \& Fu, 2018). However, some studied showed that raise of the salt concentration can result in significant increase in the viscosity, as a result, increase the fiber diameters instead of decrease, thus figure out the adequate concentration of salt is critical (Mit-uppatham, Nithitanakul, \& Supaphol, 2004, Balas, Manzano, Horcajada \& ValletRegí, 2006).

\subsection{Process parameters}

The applied voltage is a critical process parameter which induces the required charges on the electrospun solution and it directly affects the droplets shape and surface charge on the droplets, as a result, morphology of the produced fibers, and to produce smooth nanofibers, it must exceed that required to form a Taylor cone (Haider, Haider \& Kang, 2018). However, no clear conclusion for the effect of the applied voltage on the fiber diameter and bead formation. Where, some researchers found that the increase of the voltage provides a decrease in the fiber diameters (Haider, Haider \& Kang, 2018; Katti, Robinson, Ko, \& Laurencin, 2004). In contrast, other groups figure out that the fiber 
diameters were increased by raising the applied voltage ( Reneker \& Chun, 1996, Okutan, Terzi \& Altay, 2014 ). This can be explained that increase of the applied voltage has two effects; (1) enhance the stretching of the droplets which ultimately favors the thinning of the produced fibers, and (2) increase the jet velocity and ejects more solution in a jet, encouraging beads formation and increasing the fiber diameters.

The feeding flow rate of the solution influences the jet velocity and the polymer transfer rate, generally, the lower flow rate is more recommended to give the polymeric solution and the solvent sufficient time for the polarization and evaporation, respectively. Increasing the flow rate tends to rise fiber diameters, and further increase results in thick or beaded fibers, as there is insufficient time for polarization or solidification (Buchko, Chen, Shen \& Martin, 1999; Zargham, Bazgir, Tavakoli, Rashidi \& Damerchely, 2012; Zuo et al., 2005). Furthermore, increasing the nozzle diameter (orifice radius) has the same effect as increasing the flow rate, as these parameters are related to each other. Katti et al. found a significant decrease in the fiber diameters (from 250 to $125 \mathrm{~nm}$ ) when the needle orifice radii reduced from 0.59 to $0.29 \mathrm{~mm}$ ) (Katti et al., 2004).

Changing the distance between the tip and collector influences the flight (fibers drying) time and the strength of the electric field. If the distance is too short, unsolidified fibers are formed, whereas if the distance is too long, beaded fibers are formed (Yuan, Zhang, Dong \& Sheng, 2004, Cramariuc et al., 2013), thus the minimum distance is necessary to provide enough time for the fibers to dry before reaching the collector (Min et al., 2004). However, increase of the needle tip/collector distance (in at appropriate limit) tends to decrease the fiber diameters, i.e. increase of the spinning distance from 4 to $18 \mathrm{~cm}$, decreased the Nylon-6 average fiber diameters from 230 to $140 \mathrm{~nm}$ (Sun et al., 2014).

\subsection{Environmental conditions}

Both the temperature and humidity are important ambient conditions for electrospinning. Humidity controls the solidification process of the jet, and the nature of the polymer plays an important role. In case of polymer dissolved in a volatile solvent, the low humidity tends to fast solvent evaporation, resulting in rapid dryness for the fibers, and if the dryness (evaporation rate) is so fast (very low humidity) this leads to clogging of the needle tip and stops the electrospinning process (Ding \& Yu, 2014). Conversely, the solvent evaporation rate (polymer solidification) become slower if the humidity is relatively high, forming thinner fibers, owing to expose the jet to voltage induce stretching for a long time. For example, increase the relative humidity from $4 \%$ to $60 \%$ decreased the PVA fiber diameters from 667 to $161 \mathrm{~nm}$, and PEO fiber diameters were decreased from 252 to $130 \mathrm{~nm}$ when the humidity increased from $4 \%$ to $40 \%$ (Pelipenko, Kristl, Janković, Baumgartner \& Kocbek, 2013). Although many researchers reported that decrease of the fiber diameters with increasing the humidity, some reports exhibited the opposite trend. Where, it was found that the fiber diameters of PAN, PSf, and CA were increased by increasing the relative humidity (De Vrieze et al., 2009; Huang, Bui, Manickam \& McCutcheon, 2011). The authors attributed this increase in the diameters to the presence of more water vapor between the tip needle and collector (at high humidity) which decreases the electric field intensity.

Furthermore, the humidity exhibited an effect on the creation of pores on the fiber surface, where the small circular pores on the PS surface were obtained when the humidity increased, and a further increase in the humidity results in more pores (Casper, Stephens, Tassi, Chase \& Rabolt, 2004).

It is worth mentioning that the affection of humidity on the fiber diameter and morphology significantly depends on many factors, such as solvent volatility, polymer/water solubility, the interaction between polymer/solvent and water vapor, and etc. For example, at very high humidity, the hydrophobic polymers will be solidified on the needle tip, producing beads or blocking the tip, which is attributed to the occurring of phase separation at the solution droplet on the needle tip. Where the presence of more water vapor (nonsolvent for the hydrophobic polymer) surrounded the needle tip, facilitates the precipitation of the polymer on the needle tip. On the other hand, the hydrophilic polymers are precipitated as a film or beaded-film at very high humidity, where the fibers are fused (De Vrieze et al., 2009; Pelipenko, Kristl, Janković, Baumgartner \& Kocbek, 2013).

The temperature has two opposite effects; increase the solvent evaporation rate and decrease the solution viscosity, but overall increasing the temperature favors the formation of thinner nanofibers (Ki et al., 2007; Kim et al., 2006).

The possibility of incorporating or blending different materials or components makes electrospinning a powerful technique for producing nanofibers with remarkable features, such as unique mechanical, physical, chemical proper- 
ties (Jia et al., 2014; Wang, Ding, Yu \& Wang, 2011; Wang, Wang, Ding, Yu \& Sun, 2012). Numerous studies have been carried out to explore the effective application of electrospinning in various fields. Owing to their unique advantages, ENs have been applied in a wide range of applications, including membrane systems, filtration, catalysis, sorbent materials, energy conversion/storage devices, optical and electronic devices, and biomedical uses (Gopal et al., 2006; Lim, Hwang, Chang \& Kim, 2010; Lu, Wang \& Wei, 2009; Obaid et al., 2017; Peng et al., 2015; Ramakrishna et al., 2006; Shang et al., 2012; Wang, Ding \& Li, 2013; Zhu, Qiu, Jiang, Wu \& Zhang, 2011). Interestingly, the high permeability of the electrospun nanofiber membranes strongly recommends them to be utilized as substrates for TFC membranes or as a membrane with high flux.

\section{Progress in ENs-supported TFC-FO membranes}

This section provides a summary of all TFC-FO membranes supported by ENs substrates reported from when these membranes were first developed until April 2018. Specifically, it focuses on the development of ENs substrates over time, the fabrication and modification of ENs substrates based on different polymers and inorganic/polymer matrices, and the fabrication of ENs-supported TFC-FO membranes. Moreover, calculations are also included to allow reasonable comparisons of the various studies.

TFC-FO membranes based on ENs substrates are relatively new in comparison to those based on PI substrates. The innovations and breakthroughs in the fabrication and modification of ENs-supported TFC-FO membranes are summarized in Figure 8. Each advancement is discussed in detail in the following sections.

Figure 8. Timeline of important breakthroughs in the fabrication, and modification of all ENs supported TFC-FO membranes from the first report until April 2018, different colors meaning different polymer types or additives. All of these data are discussed in the following sections.

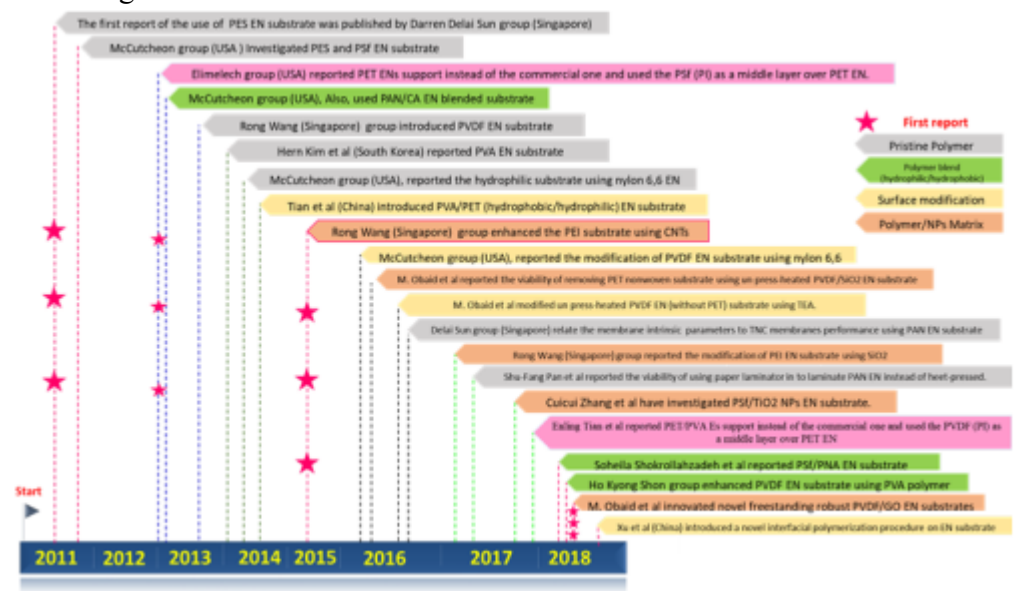

\subsection{Pristine polymers as ENs substrates for TFC-FO membranes}

In 2011, the first ENs-supported TFC membrane for an FO process was fabricated by Song et al. (Song, Liu \& Sun, 2011). The ENs substrate showed remarkable advantages over the sponge-like structure of conventional substrate fabricated via PI, as it was thinner and had a high porosity and low tortuosity (Figure 9a and b). They successfully polymerized a PA layer $(370 \mathrm{~nm})$ on a polyethersulfone (PES) ENs substrate to fabricate a TFC-FO membrane (designated as NC-FO), as shown in Figure 9c. This membrane was compared with a TFC-FO membrane supported by an in-house-made PI substrate (PI-FO: PI substrate supported TFC-FO, Figure 9d) and a commercial HTI-FO (TFC-FO) membrane. The water permeability coefficient (A) of the NC-FO membrane was found to be approximately 0.4 and 3.5 times higher than those of TFC-membranes; namely PI-FO and HTI-FO membranes, respectively. Furthermore, the $S$ values were found to decrease in the following order: $620 \mu \mathrm{m}$ (HTI-FO, $50 \mu \mathrm{m}$ thick, 40\% porosity) $>450 \mu \mathrm{m}$ (PI-FO, $100 \mu \mathrm{m}$ thick, $81 \%$ porosity) $>160 \mu \mathrm{m}$ (\#2 NC-FO, $70 \mu \mathrm{m}$ thick, 83\% porosity) $>80 \mu \mathrm{m}$ (\#1 NCFO, $50 \mu \mathrm{m}$ thick, $83 \%$ porosity). However, it is important to mention that the difference of the membrane thickness (100 $\mu \mathrm{m}$ for PI vs. $70 \mu \mathrm{m}$ for NC) is high to be ignored since the substrate thickness directly affects the $\mathrm{S}$ value.

Figure 9. (a) Schematic of the synthetic steps for preparing a conventional PES substrate using the PI method and a cross-sectional SEM image showing the tortuous sponge-like structure, (b) schematic of the synthetic steps for preparing a PES ENs substrate and 
an overview SEM image, (c) cross-sectional image of the NC-FO membrane, suggesting that the polyamide active layer is about $370 \pm 20 \mathrm{~nm}$ thick, (d) cross-sectional image of the PI-FO membrane, suggesting that the polyamide active layer is about

$260 \pm 10 \mathrm{~nm}$ thick, (e) comparison of the salt concentration profiles for the NC-FO (left) and PI-FO (right) membranes, and (f) water fluxes of various FO membranes as a function of salt concentration, where the FS is DI water and the draw solute is $\mathrm{NaCl}$. The SEM images and water flux data were adopted from (Song, Liu \& Sun 2011).

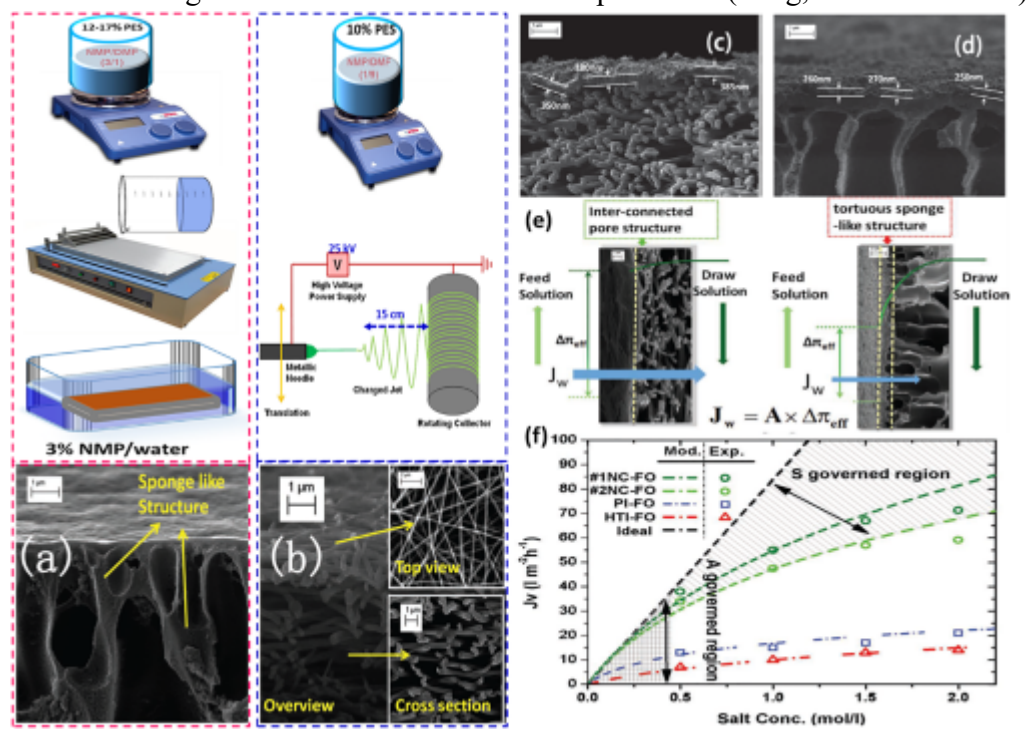

The unique structure of the nanofiber substrate guarantees direct paths for salt and water diffusion, which could provide a good solution for eliminating the ICP bottleneck in FO membranes (Figure 9e). As a result, the FO water flux was enhanced in the inverse order to that observed for the $\mathrm{S}$ value: $6.5 \mathrm{~L} / \mathrm{m}^{2}$.h (abbreviated as LMH) (HTI-FO) $<$ 13.4 LMH (PI-FO) < 33.9 LMH (\#2 NC-FO) < 37.8 LMH (\#1 NC-FO) when 0.5 M NaCl was used as the DS against deionized (DI) water as the FS for AL-FS mode, Figure 9f.

Despite the excellent water flux of the NC-FO membrane, no data were presented about the salt permeability coefficient (B) or the reverse salt flux $\left(\mathrm{J}_{\mathrm{S}}\right)$. Because of the interesting water flux and because this breakthrough work shifted the focus of FO substrates towards nanofibers-based substrates, we calculated the $B$ value using Eq. (5) (Cath, Childress \& Elimelech, 2006) and the $J_{S}$ value using Eq. (6) (Shaffer, Werber, Jaramillo, Lin \& Elimelech, 2015).

$B=\frac{(1-R)^{*} A^{*}(\Delta P-\Delta \pi)}{R}(5)$

where $A$ is $1.7 \mathrm{~L} / \mathrm{m}^{2} \cdot \mathrm{h} \cdot$ bar, $R$ is $97 \%, \Delta \pi$ is 2.48 bar $(50 \mathrm{mM} \mathrm{NaCl}$ feed $)$, and the difference in the hydraulic pressure, $\Delta P$, is 24 bar (the data were taken from their report). The calculated $B$ value was $1.13 \mathrm{~L} / \mathrm{m}^{2} \cdot \mathrm{h}$, which indicated a high salt permeability. Furthermore, this value was used to calculate the reverse salt flux $\left(J_{S}, \mathrm{~mol} / \mathrm{m}^{2} \cdot \mathrm{h}\right) \mathrm{using}$ the van't Hoff equation (Eq. (2)):

$J_{S}=\frac{J_{v}{ }^{*} B}{A^{*} n^{*} R_{g}{ }^{*} T}{ }^{(6)}$

where $J_{v}\left(J_{w}\right)$ is the FO water flux of \#1 NC-FO (37.8 LMH, from their report), $B$ is the salt permeability coefficient, which was calculated using Eq. (5) $\left(1.13 \mathrm{~L} / \mathrm{m}^{2} \cdot \mathrm{h}\right), A$ is $1.7 \mathrm{~L} / \mathrm{m}^{2} \cdot \mathrm{h} \cdot \mathrm{bar}, n$ is the number of dissolved species created by the draw solute $\left(2\right.$ for $\mathrm{NaCl}$ ), $T$ is the absolute temperature in $\mathrm{K}$, and $R_{g}$ is the ideal gas constant $(0.083 \mathrm{~L} \cdot \mathrm{bar} / \mathrm{mol} \cdot \mathrm{K})$. 
The NC-FO membrane showed an extremely high reverse salt flux $\left(0.57 \mathrm{~mol} / \mathrm{m}^{2} \cdot \mathrm{h}\right.$ or $\left.33 \mathrm{gMH}\left(\mathrm{g} / \mathrm{m}^{2} . \mathrm{h}\right)\right)$ with a specific reverse solute flux (SRSF) " $\mathrm{J}_{\mathrm{S}} / \mathrm{J}_{\mathrm{W}}$ " of $0.87 \mathrm{~g} / \mathrm{L}$, which reflects the low selectivity of the introduced membrane. This behavior may be attributed to defects in the PA layer or delamination of the PA from the substrate. Importantly, in the same year (2011), Bui, Lind, Hoek \& McCutcheon (2011) reported poor adhesion and delamination of the PA layer from the PES ENs substrate, as shown in Figure 10. In contrast, they found that the adhesion between a polysulfone (PSf) ENs substrate and the PA layer was stronger than that between a PES ENs substrate and the PA. They attributed this difference in adhesion to the chemical interactions between PES or PSf ENs substrates and the PA layer, as they hypothesized that the presence of the bisphenol moiety in PSf enhanced the adhesion between the PA and PSf ENs substrate.

Figure 10. SEM images of (a) a PES ENs substrate and (b-d) PES-based TFC membranes at magnifications of (a) $2.2 \mathrm{kx}$, (b) 0.46 $\mathrm{kx}$, (c) $8.85 \mathrm{kx}$, and (d) $5.75 \mathrm{kx}$. Images (c) and (d) show poor adhesion between the PA layer and the PES ENs substrate. (e-g) SEM images and focused ion beam (FIB) images of a PSf ENs-supported TFC polyamide membrane (Bui, Lind, Hoek \& McCutcheon 2011a).

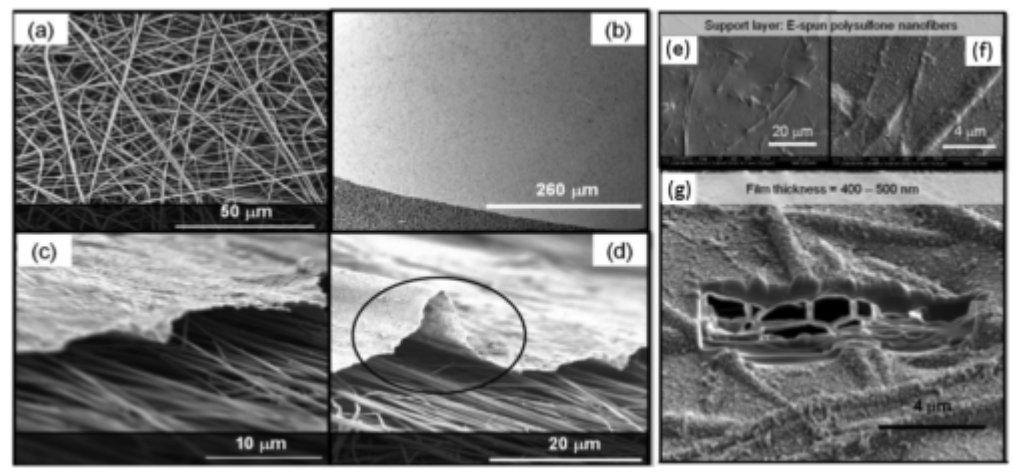

Therefore, TFC membranes based on PSf ENs substrates were used for both FO modes (AL-FS and AL-DS). Moreover, they studied the substrates without and with PET nonwoven supports. The imprint of the PSf ENs under the PA layer was observed (Figure 10e and f), and the application of a focused ion beam to etch a small area of the PA layer revealed that the underlying nanofibers had very high surface porosity (Figure 10g). Compared to the commercial membrane (CTA-HTI), they found that the $\mathrm{PSf}^{\mathrm{n}}$ (TFC-FO membrane supported with PSf ENs substrate without PET) and PSf ${ }^{\mathrm{n}}$-PET (TFC-FO membrane supported by PSf ENs substrate and PET nonwoven) membranes showed approximately 2 times higher in A value, while B value for $\mathrm{PSf}^{\mathrm{n}}$ was higher than CTA-HTI by 91 times. However, the wetting of the substrate using $1 \mathrm{mM}$ of sodium dodecyl sulfate (SDS) strongly increased both the water and reverse salt fluxes. These results were attributed to the diffusivity of the solute through the effectively wetted porous structure of the support layer (McCutcheon \& Elimelech, 2008). These results highlighted the importance of the wettability of the substrate and introduced a new concept of effective porosity (a wetted area or wetted porosity).

The feasibility of using hydrophobic polyvinylidene fluoride (PVDF) ENs substrates for TFC-FO membrane was explored by Tian et al. (Tian, Qiu, Liao, Chou \& Wang, 2013). By controlling the electrospinning parameters of applied voltage and working distance, they produced two different PVDF ENs substrates, namely, ES-1\# (smaller pore size) and ES-2\# (larger pore size) (Figure 11a). Moreover, they investigated the effect of the pore size of the ENs substrate and the ratio of $m$-phenylenediamine (MPD)/1,3,5-benzenetricarbonyl trichloride (TMC) monomers on the formation of the PA layer, as well as the overall performance of the TFC membrane. A PA layer was successfully fabricated over each substrate. In addition, they observed that the formation of a denser and rough PA layer (membrane with high selectivity) is easier on the ENs substrate with a smaller pore size (ES-1\#), as shown in Figure 11a. Further, an increase in the MPD/TMC ratio produced a denser PA layer, resulting in an increase in salt rejection and a decrease in water permeability (Figure $11 \mathrm{~b}$ and c) owing to an enhanced degree of crosslinking (Roh, Greenberg \& Khare, 2006). Highly permeable TFC membranes could be produced by increasing the pore size of the ENs substrate. However, the increase of the pore size of the substrate resulting in increased both of the water and reverse salt fluxes.

Figure 11. (a) Diagram of the electrospinning process for the fabrication of PVDF ENs substrates under different conditions, SEM images of the top surfaces of ENs substrates (S1 and S2), schematic diagram of the polyamide layers formed on the different supports, and AFM images of the two ENs-based TFC membranes (TFC-1\# and TFC-2\#). Influence of the concentrations of (b) MPD 
(at a fixed TMC concentration of $0.15 \mathrm{wt} . \%$ ) and (c) TMC (at a fixed MPD concentration of $5 \mathrm{wt} . \%$ ) on the intrinsic separation properties of the TFC membranes. Experimental conditions: cross-flow RO testing conditions using $1000 \mathrm{ppm} \mathrm{NaCl}$ as the $\mathrm{FS}$ at an applied pressure of 5 bar and $23^{\circ} \mathrm{C}$; the statistical average of the data for three samples of each substrate. Adapted from (Tian, Qiu, Liao, Chou \& Wang 2013).
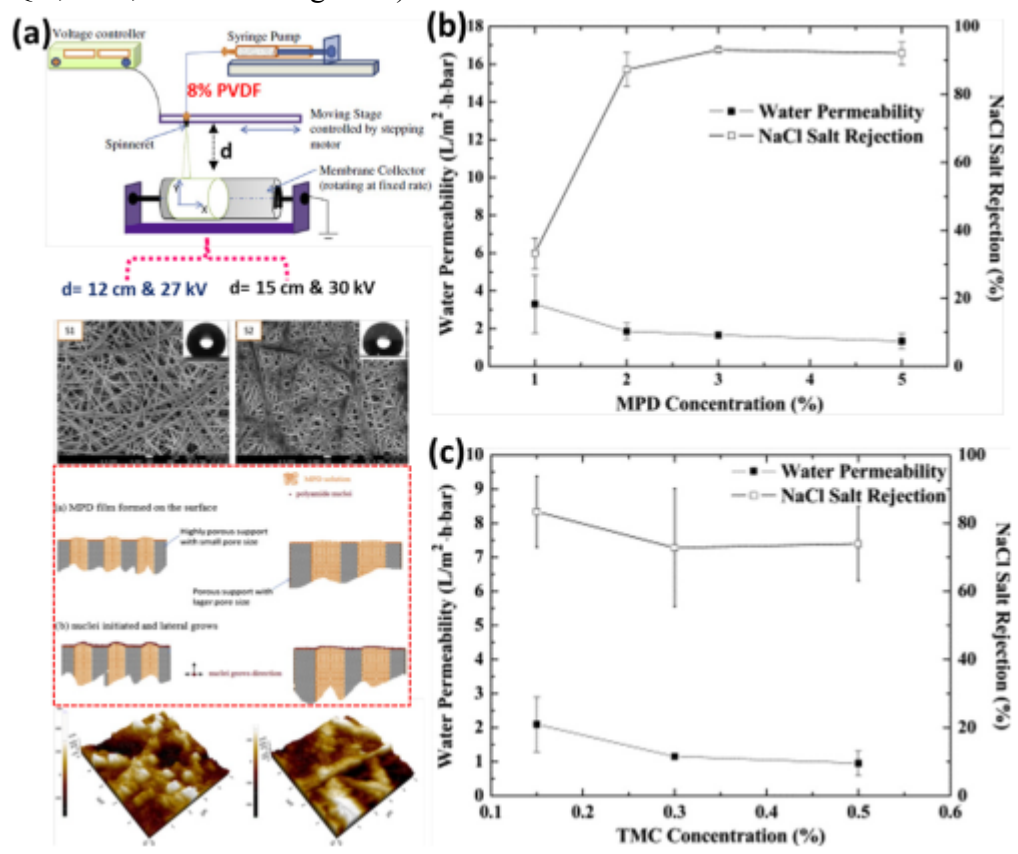

To diminish the pore size $(1.27 \mu \mathrm{m})$ of hydrophobic polyimide (PI) microporous ENs substrate for the formation of the PA layer, a novel IP procedure was introduced by Xu (Chi, Zhang, Guo \& Xu, 2018). They added the ethanol as a co-solvent with different concentrations $(25-100 \%)$ to MPD aqueous phase and the IP procedure was carried out in two steps. The purpose of the first IP producer is to decrease the pore size, in which the TMC organic phase was poured on the substrate surface, followed by MPD aqueous phase (co-solvent ethanol-water). While, the purpose of the second IP producer is to synthesis the PA layer with the conventional technique, where the MPD aqueous phase (co-solvent ethanol-water) came first, then the TMC organic phase, to address delamination of the PA layer, a modified IP process was used (Kong, Kanezashi, Yamomoto, Shintani \& Tsuru, 2010). When the modified IP process (namely, cosolvent-assisted IP (Kong, Shintani, Kamada, Freger \& Tsuru, 2011)) was applied, less dense PA layer (CAIP-TFC) was produced. This change in the PA morphology was attributed to reaction zone broadening in the case of CAIP (Freger, 2005), resulting in an increase in the permeability and a decrease in the selectivity with increasing concentrations of cosolvent. As a result, the FO water flux increased with sacrifice selectivity by increasing the cosolvent concentration.

Because of concerns about the high tendency for fouling of hydrophobic membrane materials, some researchers have used hydrophilic polymers as ENs substrates. Huang and McCutcheon (Huang \& McCutcheon, 2014) fabricated TFC membranes based on a hydrophilic nylon 6,6 ENs substrate. The produced nylon 6,6 ENs and ENs-based TFC membranes showed excellent mechanical properties in terms of tensile strength and modulus, with comparable results to PI substrates (Han, Chung, Toriida \& Tamai, 2012). However, the swelling of the introduced substrate increased owing to its high hydrophilicity (water contact angle $(\mathrm{WCA})=38^{\circ}$ ), which dramatically reduced the mechanical properties of the wetted membranes and enhanced delamination of the PA from the nylon 6,6 ENs substrate. As another hydrophilic polymer, polyvinyl alcohol (PVA) was used by Puguan et al. to fabricate an ENs substrate for TFCFO membranes (Puguan, Kim, Lee \& Kim, 2014). The nascent PVA ENs substrate showed high porosity $(93 \% \pm$ $0.77 \%$ ) and remarkable hydrophilicity $\left(52.48^{\circ}\right.$ to $0^{\circ}$ after $\left.2.188 \mathrm{~s}\right)$, resulting in low tortuosity and a low structural parameter $(1.2$ and $66 \pm 7.9 \mu \mathrm{m})$. The TFC membrane based on this substrate (named NC-PVA/PA) exhibited A value of $1.69 \mathrm{~L} /\left(\mathrm{m}^{2} \cdot \mathrm{h} \cdot\right.$ bar $)$ and a B value of $0.24 \mathrm{~L} /\left(\mathrm{m}^{2} \cdot \mathrm{h}\right)$. In addition, the water flux of NC-PVA/PA was $27.74 \mathrm{LMH}$ with $0.5 \mathrm{M} \mathrm{NaCl}$ as the DS and DI water as the FS in AL-FS mode. It is important to note that, under the same conditions 
$(0.5 \mathrm{M} \mathrm{NaCl}$ as the DS and DI water as the FS in Al-FS mode), the NC-FO membrane (TFC membrane based on PES ENs, first report) (Song, Liu \& Sun, 2011) showed a higher water flux than this TFC membrane (NC-PVA/PA). Compared with the PVA substrate, the PES substrate had lower hydrophilicity and a higher $S$ value, in addition to similar A values for their TFC-membranes, but the NC-FO membrane exhibited a $38 \%$ higher water flux. This result was unexpected, as many reports have proven that increasing the hydrophilicity and decreasing of the tortuous path of the substrate (or S value) significantly enhances FO membrane performance (Emadzadeh, Lau, Matsuura, Ismail \& Rahbari-Sisakht, 2014; Han, Chung, Toriida \& Tamai, 2012; Park et al., 2015). Thus, the above results can be explained by defects or delamination of the PA layer in the NC-FO membrane. Based on the above calculation for the $\mathrm{B}$ and $\mathrm{J}_{\mathrm{s}}$ values, the NC-FO membrane showed low selectivity with $B$ and $J_{S}$ values of $1.13 \mathrm{~L} / \mathrm{m}^{2} \cdot \mathrm{h}$ and $33 \mathrm{gMH}$, respectively. These values are significantly higher than those of the NC-PVA-PA membrane by 5.3 and 7 times for B and $\mathrm{J}_{\mathrm{S}}$ (was calculated using Eq. (6)), respectively. Furthermore, to effective comparison, the SRSF was calculated and it was found to be $0.17 \mathrm{~g} / \mathrm{L}$ for NC-PVA-PA compared to $0.87 \mathrm{~g} / \mathrm{L}$ for NC-FO membrane, which reflects the lower selectivity of NC-FO. These results pointed out defects in the PA or delamination of the PA from the substrate in case of NCFO, was also confirmed by Bui et al. who using also PES ENs as a substrate (Bui, Lind, Hoek \& McCutcheon, 2011).

Song and Prince (2016) used polyacrylonitrile (PAN) to fabricate an ENs substrate for TFC-FO membranes. Moreover, they investigated the effect of various modification techniques on the water/solute permeability. These techniques involved modifying the substrate using $1.5 \mathrm{M} \mathrm{NaOH}$, adding additives during the IP process $(1.1 \%$ Triethylamine, TEA, and 2.3\% camphor sulfonic acid, CAS), posttreatment of the PA layer with chlorine (1000 and $2000 \mathrm{ppm}$ $\mathrm{NaClO}$ ), and removal of nonwoven PET substrates. They also systematically analyzed the relationship between the B and A values using the following empirical equation: $B=0.025^{*} A^{3}$ for TFC membranes based on ENs substrates. The results showed that modification of the ENs substrate by $\mathrm{NaOH}$ or removal of PET slightly increased the A value by $13 \%$ and $16 \%$, respectively, relative to the pristine TFC membrane. Additionally, adding TEA-CAS during the IP process facilitated the reaction and enhanced crosslinking, resulting in a decrease in both the $\mathrm{A}$ and $\mathrm{B}$ values relative to the pristine TFC membrane. In contrast, chorine modification significantly increased the A and B values. In addition, PAN was used as a hydrophilic ENs substrate to fabricate a TFC-FO membrane (PA/PAN-eTFC) (Pan, Dong, Zheng, Zhong \& Yuan, 2017). The fabricated membrane was investigated in an FO system and in an FO-membrane distillation (FO-MD) hybrid system to treat simulated tetracycline (TC) wastewater.

Generally, the mechanical properties of the ENs substrate is low, thus the PET support (backing layer) or posttreatment of the ENs substrate, using the heat-press method, in which the nanofibers melted and bonded to each other (Gopal et al., 2006; Na, Zhao, Zhao, Zhao \& Yuan, 2008) were used to enhance the mechanical properties. Furthermore, the paper's laminator was used to enhance the mechanical properties of the PAN ENs substrate (Figure 12) (Pan, Dong, Zheng, Zhong \& Yuan, 2017). Compared with pristine PAN ENs, the laminated substrate exhibited higher mechanical properties and superior wettability (Figure 12).

Figure 12. Schematic diagram of the preparation of a PAN ENs-supported TFC membrane. (Left) Fabrication of the ENs substrate: (a) photograph of the laminator, (b) FE-SEM image, and (ci-ciii) dynamic WCAs of laminated PAN ENs substrate. (Right) Synthesis of PA via an IP process: (a) optical photograph of the TFC membrane and (b-d) SEM images of the TFC membrane crosssection, top surface, and the bottom substrate surface, respectively. Adapted from (Pan, Dong, Zheng, Zhong \& Yuan 2017). 


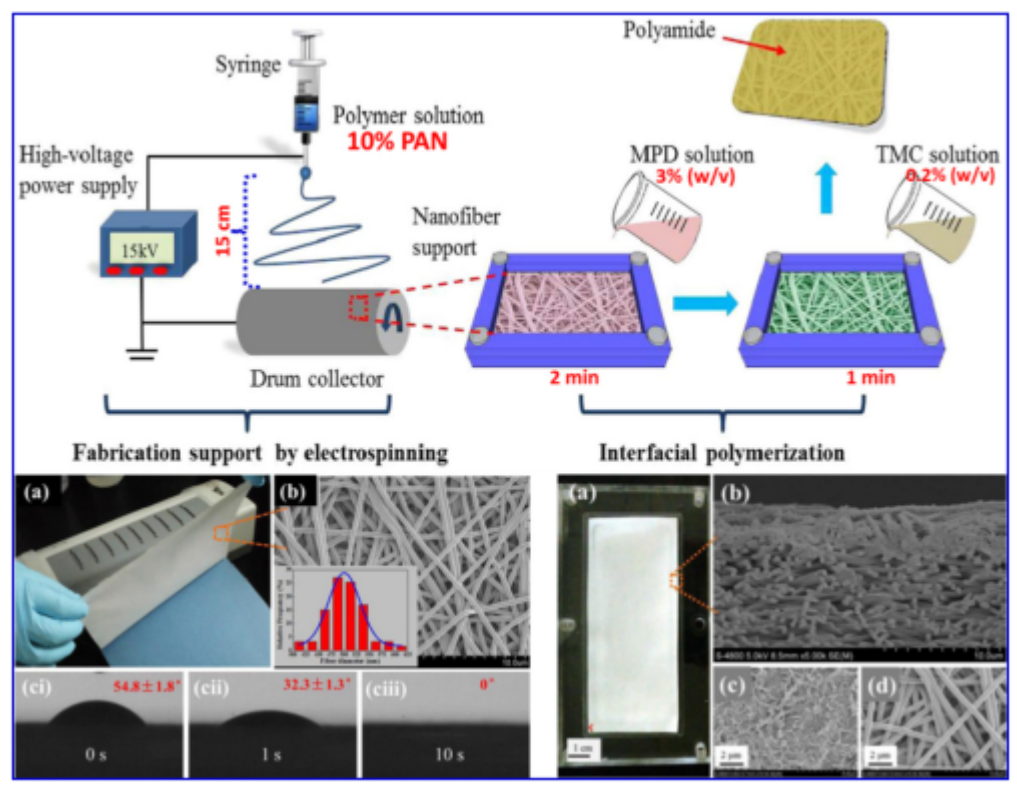

\subsection{Modification of ENs substrates by surface coating or blending with hydrophilic polymers}

Modification of polymeric substrates by blending or chemical modification can be used to achieve polymeric substrates with new properties (Reddy \& Patel, 2008). Incomplete wetting of the hydrophobic substrates in TFC-FO membranes during the FO process results in decrease the performance (Zhang, Xiao \& Hu, 2013). However, although hydrophilicity is a desired feature for the substrates of TFC-FO membranes, swelling of hydrophilic nanofibers (Muta, Miwa \& Satoh, 2001) may become a major challenge for FO applications. Therefore, the modification or blending of hydrophobic polymers with hydrophilic polymers can be used to enhance membrane performance without affecting the mechanical properties.

Some researchers have addressed the challenges of swelling and hydrophobicity by surface modification or blending with hydrophilic polymers. For example, Bui and McCutcheon (Bui \& McCutcheon, 2013) developed a hydrophilic ENs substrate for TFC-FO membranes via blending cellulose acetate (CA) with PAN as a hydrophilic polymer (Bui \& McCutcheon, 2013). They studied the effect of PAN/CA ratio on the morphology, wettability, mechanical properties, and membrane performance in FO (AL-FS and AL-DS modes). Pure CA did not form nanofibers, but smooth nanofibers were observed when PAN was blended with CA. Increasing the PAN/CA ratio resulted in increasing fiber diameters, hydrophilicity, and elongation, whereas the elasticity modulus and strength decreased (Figure $13 \mathrm{~A})$.

Figure 13. (A) Schematic for the blending strategy using different PAN/CA ratios and corresponding FE-SEM images (1 kx magnification) of the obtained PAN/CA blended substrates. (B) Performance of TFC membranes in AL-DS and AL-FS modes: (a) water flux and (b) reverse salt flux. Tests conditions: $1.5 \mathrm{M} \mathrm{NaCl}$ as the DS, DI water as the FS, crossflow velocity of $15.82 \mathrm{~cm} / \mathrm{s}$, and temperature of $25 \pm 0.5^{\circ} \mathrm{C}$ on both sides of the membrane. The SEM images, water flux data, and reverse salt flux data are adapted from (Bui \& McCutcheon 2013).

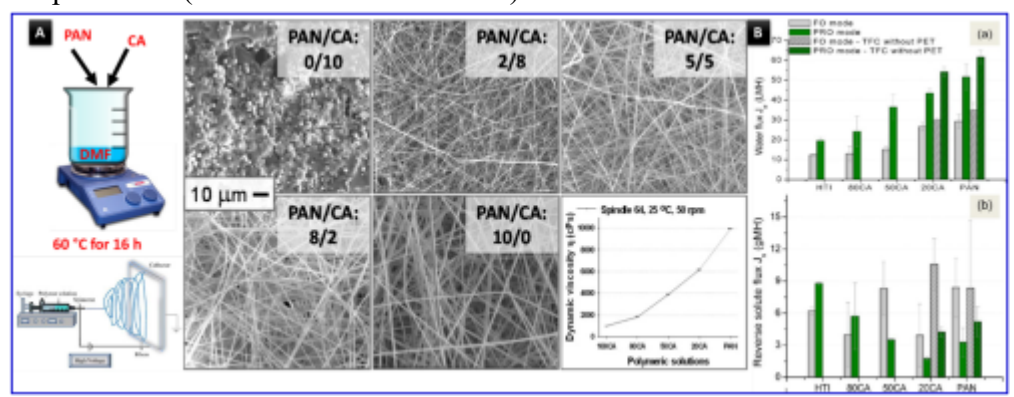

C Copyrights 2018 
The A value of the PAN/CA TFC membrane was higher than that of BW30 RO and lower than that of HTI-CTA, i.e., the A values of various membranes decrease in the order: HTI-CTA $>$ PAN/CA-TFC $>$ BW30. In contrast, the reverse order was observed for the B value: BW30 $>$ PAN/CA TFC $>$ HTI-CTA. However, this was not the case for the CA/PAN-TFC membrane with a PAN/CA ratio of 80:20 (80CA), which showed the lowest salt selectivity. Increasing the PAN concentration resulted in higher A value and water flux (AL-FS and Al-DS modes) owing to the increased wettability of the substrates, the roundness of the PA layer, and the substrate pore size.

A hydrophobic/hydrophilic (PET/PVA) composite ENs substrate was fabricated to enhance the wettability (Tian, Zhou, Ren, Wang \& Xiong, 2014). The hydrophilicity of the substrate increased as the PET/PVA ratio decreased, with the WCA decreasing from $134.8^{\circ}$ for PET to $38.9^{\circ}$ for a PET/PVA ratio of $1 / 4$. This increase in hydrophilicity could increase the effective porosity and the available pathways for water, resulting in an increased water flux for FO, as shown in Figure 14.

Figure 14. Schematic of the synthetic steps for fabricating PET/PVA ENs, FE-SEM images of the prepared ENs substrates, and water and reverse solute fluxes of the corresponding TFC membranes. Experimental conditions: volumetric flow rate of $184 \mathrm{~mL} / \mathrm{min}$ for the FS and DS, DI water as the FS, $0.5 \mathrm{M} \mathrm{NaCl}$ as the DS, the temperature of $23 \pm 1^{\circ} \mathrm{C}$, and AL-DS mode. The SEM images, water flux data, and reverse salt flux data are adopted from (Tian, Zhou, Ren, Wang \& Xiong 2014).

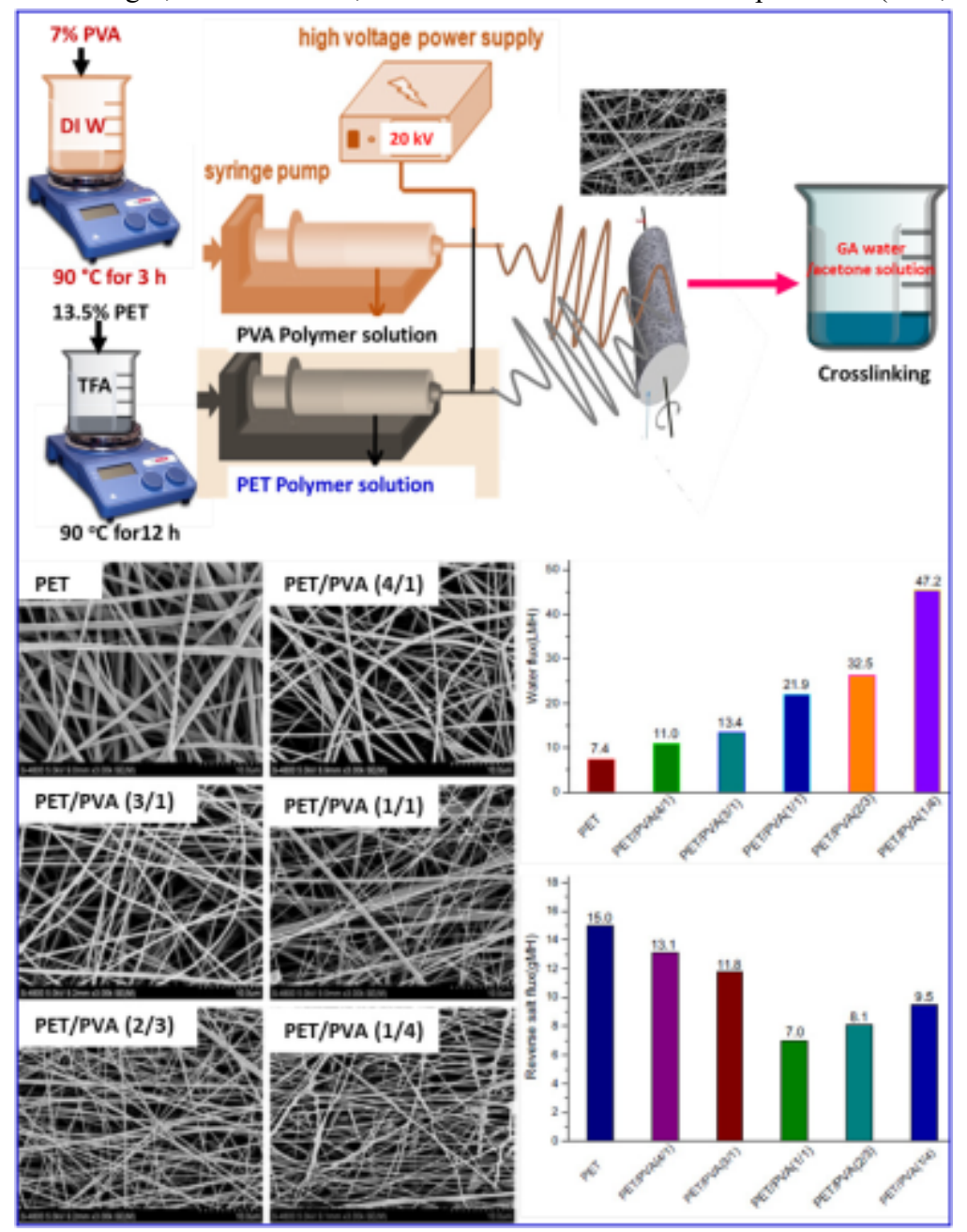

Enhancing both of the wettability ad mechanical properties of the PVDF ENs substrate was carried out using nylon 6,6 (Huang, Arena \& McCutcheon, 2016). Nylon 6,6 was formed directly onto PVDF ENs via in-situ IP using 1,6-hexane diamine/hexane and adipoyl chloride/toluene solutions. Subsequent IP using MPD/water and TMC/ hexane was used to form a PA (rejection) layer on the substrate surface and obtain a TFC-FO membrane. The modification method enhanced the wettability of the PVDF ENs substrate, with the WCA decreasing from $151^{\circ}$ for unmodi- 
fied PVDF to $48^{\circ}$ for the modified PVDF (Figure 15a and b). This enhancement in the wettability was attributed to the formation of hydrophilic nylon 6,6 on and between the PVDF EN substrate, as shown in Figure 15b-d.

Figure 15. (a) Top view and (c) cross-sectional FE-SEM images of the unmodified PVDF ENs substrate (the inset shows the WCA). (b) Top view and (d) cross-sectional FE-SEM images of the nylon 6,6-modified PVDF EN substrate (inset shows the WCA).
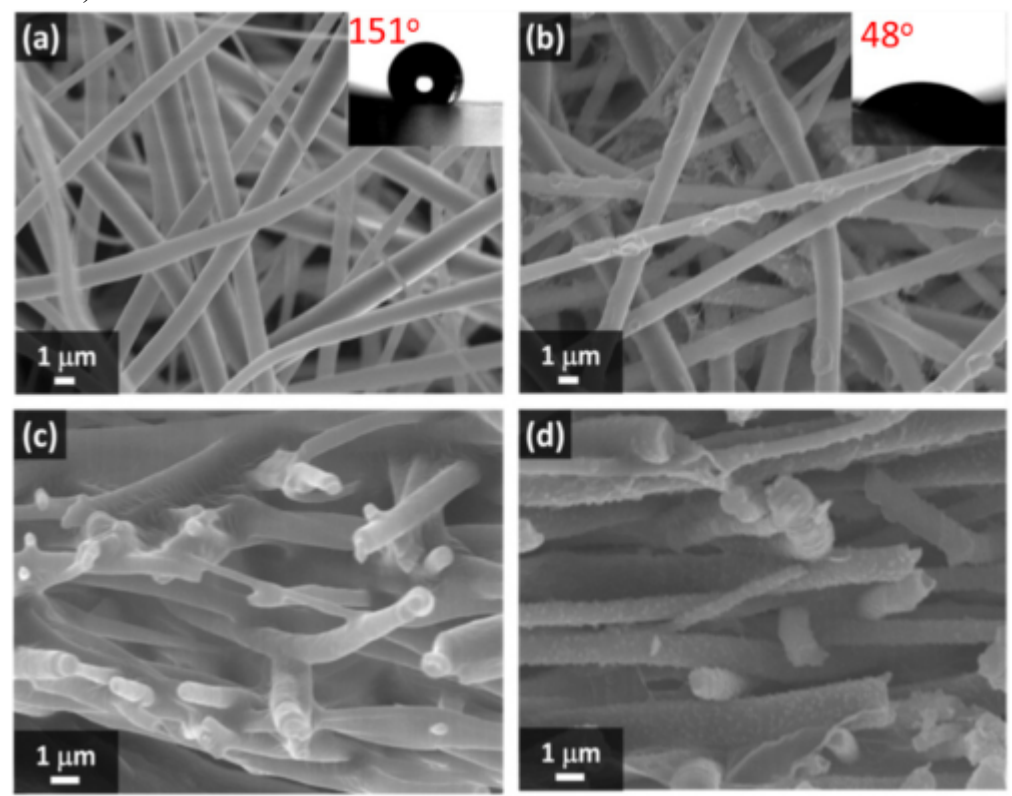

As a result, the modified TFC membrane had a smaller structural parameter than the unmodified TFC membrane (193 and $2410 \mu \mathrm{m}$, respectively), resulting in a significant increase in the water flux for the modified TFC membrane. On the other hand, the mechanical properties of the modified PVDF were enhanced comparative to pristine PVDF, as the modulus increased 6-fold (from 4.2 to $26.1 \mathrm{MPa}$ ) and the tensile strength increased slightly (from 2.88 to 3.11 MPa).

Notably, when the unmodified TFC membrane was prewetted with a 50\% isopropyl alcohol (IPA)/water solution for a short time $(0.5 \mathrm{~min})$ a superior FO performance was obtained and the $\mathrm{S}$ value was decreased from 2410 to $163 \mu \mathrm{m}$ relative to that for the modified TFC membrane $(193 \mu \mathrm{m})$. These results highlight the influence of hydrophilicity and the prewetting of the ENs substrates, and more work is needed to correlate the hydrophilicity and prewetting to the $S$ value and ICP phenomena in ENs substrates.

Similarly, the wettability and mechanical properties of heat-pressed PVDF ENs substrates have been enhanced via PVA dip-coating followed by chemical crosslinking (Park, Gonzales, Abdel-Wahab, Phuntsho \& Shon, 2018). Compared with pristine PVDF ENs, a significant increase was obtained in the hydrophilicity of the modified PVDF-PVA substrate, with the WCA decreasing from $138.15^{\circ}$ for PVDF to $66.15^{\circ}$ for PVDF-PVA. As a result, the water absorption capacity (water uptake) increased significantly from $2.5 \%$ for PVDF to $159 \%$ for PVDF-PVA. Additionally, the mechanical properties of the heat-pressed PVDF-PVA substrate were found to be superior to those of heat-pressed PVDF and non-heat-pressed PVDF, with the tensile strength and elongation at break decreasing in the order: heatpressed PVDF-PVA $>$ heat-pressed PVDF > non-heat-pressed PVDF. Furthermore, the FO performance of the PVDF-PVA TFC membrane (TFC-PVDF-PVA) was compared with those of the PVDF TFC membrane (TFCPVDF), prewetted TFC-PVDF (prewetted with 50\% IPA/water for $1 \mathrm{~min}$ before the FO test), and the commercial CTA-HTI membrane. Among the tested membranes, TFC-PVDF-PVA exhibited the highest FO water flux (24.8 and 32.6 LMH in AL-FS and AL-DS mode, respectively). Interestingly, also prewetting of the TFC-PVDF membrane before the FO test was found to significantly enhance the water flux. These results also emphasized the importance of the wettability of the substrates. 
However, the difference in the A values of TFC-PVDF $\left(1.81 \mathrm{~L} / \mathrm{m}^{2} \cdot \mathrm{h} \cdot \mathrm{bar}\right)$ and prewetted TFC-PVDF (1.86 L/ $\mathrm{m}^{2} \cdot \mathrm{h} \cdot$ bar) calculated in RO mode (A-RO) was negligible. In contrast, a significant difference was observed between the A values calculated in FO mode (A-FO), with values of 0.73 and $2.26 \mathrm{~L} /\left(\mathrm{m}^{2} \cdot \mathrm{h} \cdot \mathrm{bar}\right.$ ) for TFC-PVDF and prewetted TFC-PVDF, respectively. Notably, the A-RO value $\left(1.81 \mathrm{~L} /\left(\mathrm{m}^{2} \cdot \mathrm{h} \cdot \mathrm{bar}\right)\right.$ was 2.5 times higher than the A-FO value $\left(0.73 \mathrm{~L} /\left(\mathrm{m}^{2} \cdot \mathrm{h} \cdot\right.\right.$ bar $)$ for the TFC-PVDF membrane. This result may be acceptable, where the decrease in the A value (A-FO) attributed to ICP phenomena during the FO process. In contrast, the A-FO value for prewetted TFC-PVDF was higher than the A-RO value, which is questionable. In our opinion, prewetting of PVDF could sharply increase the water uptake (from $2.48 \%$ to $176.36 \%$ ), which may result in swelling and delamination of the PA from the PVDF substrate, especially if the low adhesion between the PVDF ENs substrate (high hydrophobicity) and the PA layer was considered. Such defects in the PA layer would increase both the water and salt permeability, and thus the salt permeability (B value) increased from 0.08 to $0.26 \mathrm{~L} / \mathrm{m}^{2} \cdot \mathrm{h}$ after the wetting process. Similar behavior was observed by Bui, Lind, Hoek \& McCutcheon (2011) when SDS was added to the feed solution. Consequently, critical and full studies for the effect of prewetting on the delamination of the PA layer as well as the FO performance are required. However, the difference in the $S$ values of the TFC-PVDF membranes with and without prewetting confirms the importance of the hydrophilicity of the substrates, with the $S$ values decreasing 3-fold after prewetting from $1380 \mu \mathrm{m}$ (TFC-PVDF) to $431 \mu \mathrm{m}$ (prewetted TFC-PVDF). Because the performance of the substrate relied heavily on the hydrophilicity, the lowest $S$ value was obtained for TFC-PVDF-PVA $(154 \mu \mathrm{m})$.

Shokrollahzadeh and Tajik (2018) blended PAN with PSf to fabricate PSf/PAN ENs substrates (PSf/PAN ${ }^{\mathrm{n}}$ ) for TFC-FO membranes and compared the performance of these membranes with an in-house-made PI PSf/PAN substrate. Compared with PSf/PAN PI, the PSf/PAN ${ }^{\mathrm{n}}$ substrate showed higher porosity, higher wettability, and superior mechanical properties. Furthermore, the membrane based on the PSf/PAN ${ }^{\mathrm{n}}$ ENs substrate (NTFC) exhibited higher A and B values than the membrane based on the PI PSf/PAN substrate (TFC). Moreover, the $S$ value of the NTFC membrane was 2.8 times lower than that of the TFC membrane. Similarly, the wettability of a PVDF ENs substrate was enhanced by using a simple and effective method that involved TEA posttreatment before the IP process (Obaid, Mohamed, Yasin, Fadali, Khalil, Kim \& Barakat, 2016). Compared with unmodified TFC-PVDF, the $S$ value of the modified TFC-PVDF-TEA membrane decreased by $67 \%$, resulting in a decrease of ICP by $45 \%$ and the enhancement of the FO water flux (Figure 16)

Figure 16. (A) Decrease in osmotic pressure differences owing to ICP, (B) theoretical, experimental, and calculated (based on the ICP) water fluxes at different DS concentrations, and (C) concentration profiles of TFC-PVDF and TFC-PVDF-TEA membranes with the numerical osmotic pressure profile (experimental conditions: $2 \mathrm{M} \mathrm{NaCl}$ as the DS and DI waster as the FS in FO mode) (Obaid, Mohamed, Yasin, Fadali, Khalil, Kim \& Barakat 2016).

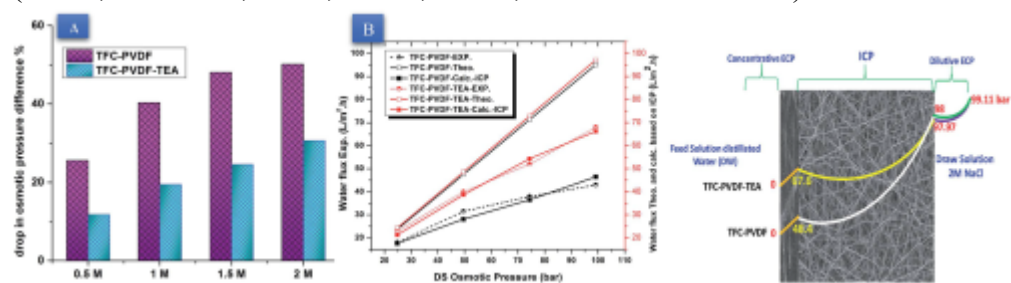

\subsection{Modification of ENs-supported TFC-FO membranes by addition of inorganic nanoparticles}

The incorporation of $\mathrm{SiO}_{2}$ nanoparticles (NPs) extracted from rice husk into PVDF ENs substrates, to enhance the substrate properties, was successfully investigated (Obaid, Ghouri, Fadali, Khalil, Almajid \& Barakat, 2016). The influence of $\mathrm{SiO}_{2}$ NPs loading $(0,0.5,1,2$, and $5 \mathrm{wt} . \%)$ on the substrate and TFC-FO membrane performance was studied. The TFC membrane based on PVDF-0.5 $\mathrm{SiO}_{2} \mathrm{NPs}$ exhibited the optimal properties and highest FO performance, with a water flux of $83 \mathrm{LMH}$ and a SRSF value of $0.9 \mathrm{~g} / \mathrm{L}$ using $2 \mathrm{M} \mathrm{NaCl}$ as the DS and DI water as the FS. These results were attributed to the low $S$ value of approximately $30 \mu \mathrm{m}(69 \%$ of the values for the pristine membrane), which mitigates the severe effects of ICP, as shown in Figure 17. However, this membrane had very poor mechanical properties (worse than those of the pristine membrane), which was attributed to the absence of nonwoven PET support or a posttreatment process (heat-pressing). Furthermore, increasing the content of $\mathrm{SiO}_{2} \mathrm{NPs}$ to 5 wt.\% 
resulted in a membrane that was not suitable for FO, as the reverse salt flux value of $1651 \mathrm{~mol} / \mathrm{m}^{2} \cdot \mathrm{h}$ was unacceptable.

Figure 17. Three-dimensional schematic diagram showing the ICP mechanism and the effect of tortuosity on ICP. $\mathrm{C}_{\mathrm{b}}, \mathrm{C}_{\mathrm{m}}$, and $\mathrm{C}_{\mathrm{i}}$ represent the bulk, membrane, and interfacial salt concentrations, respectively. (A) Salt concentration gradient at high tortuosity (TFC-PVDF), (B) salt concentration gradient at low tortuosity (TFC-PVDF-0.5 $\mathrm{SiO}_{2} \mathrm{NPs}$ ), and effect of $\mathrm{SiO}_{2} \mathrm{NPs}_{\text {on }}$ the water fluxes and tortuosities of the membranes (Obaid, Ghouri, Fadali, Khalil, Almajid \& Barakat 2016).

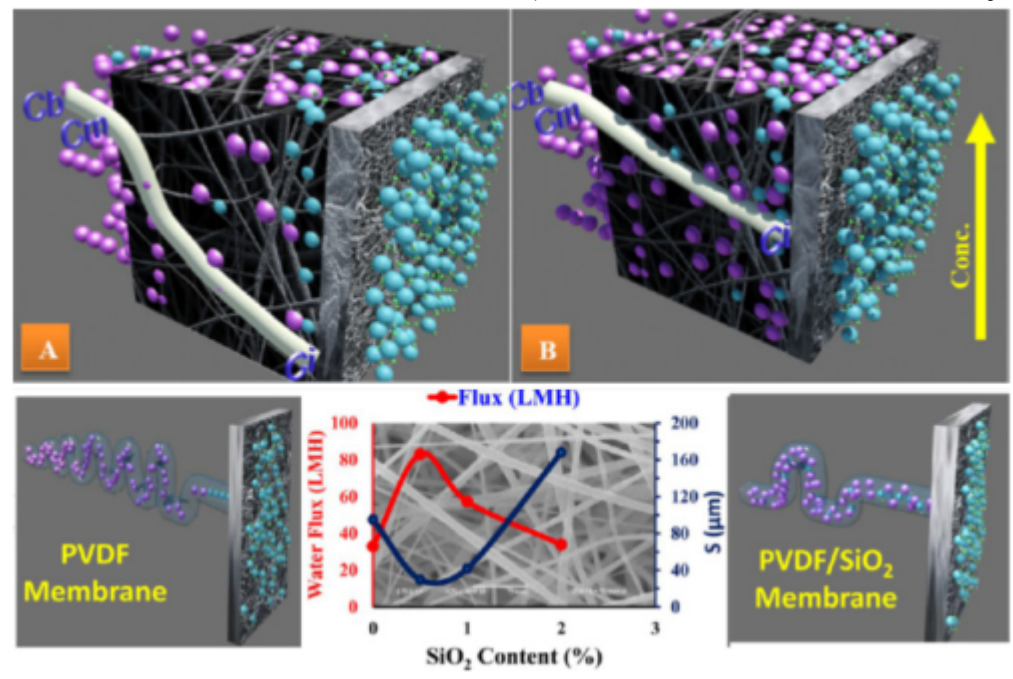

Recently, our group also innovated novel freestanding robust ENs substrates, where we successfully fabricated robust freestanding graphene oxide (GO) incorporated PVDF ENs substrates to support the thin-film nanocomposite (TFN) membranes (Obaid et al., 2018). Notably, these ENs substrates were used without heat-press treatment and without PET supports. The results showed that the incorporation of GO (1-15 wt \%) remarkably changes the porosity, chemical structure, morphology, wettability, and mechanical properties of the substrate, resulting in an augmentation in the performance of the TFN membranes. As a result, the membrane having 5\% GO (TFN5) exhibited the strongest behavior, with outstanding flexibility and strength even compared with some flat sheet membranes fabricated with a PI method. Remarkably, this membrane showed the lowest S value (low ICP), resulting in a strangely highest FO water flux with a comparable a SRSF value of $0.41 \mathrm{~g} / \mathrm{L}$.

Functionalized multiwalled carbon nanotubes (f-CNTs) was used by Tian, Wang \& Wang (2015) to reinforce a polyetherimide (PEI) ENs substrate. By controlling the electrospinning conditions, they fabricated two f-CNT-filled substrates (CNT-PEI and CNT-PEI-L, where L indicates larger pores) with two different pore sizes. A low concentration of f-CNTs $(0.3 \mathrm{wt} . \%$ based on the weight of PEI) enhanced the distribution of f-CNTs on the macro- and nanoscopic scale, as shown in Figure 18a and c, which increased the tensile strength and modulus of the CNT-PEI substrate by 1.8 and 1.5 times, respectively, relative to the pristine substrate (PEI-0). Although the larger pore size and higher porosity (Figure 18) of CNT-PEI-L slightly decreased its mechanical properties compared with CNT-PEI, the mechanical properties of CNT-PEI-L were still superior to those of PEI-0.

Figure 18. Characterization of PEI ENs substrates. (a) Photographic images of PEI-0 (left) and CNT-PEI (right). FE-SEM images of (b) PEI-0, (c) CNT-PEI (inset shows a TEM image), and (d) CNT-PEI-L. 


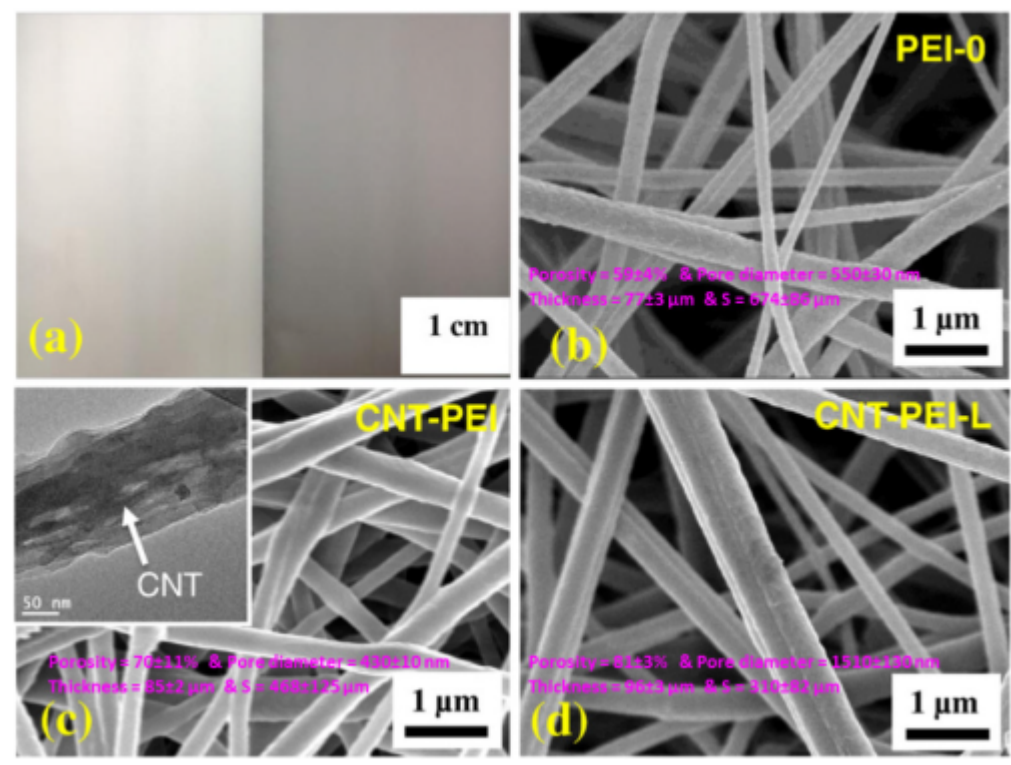

However, the higher porosity, larger pore size, and lower structural parameter of the CNT-PEI-L substrate (Figure 18) made the TFN membrane based on this substrate (TFN-2) the best among the three PEI ENs-based membranes, with the highest $\mathrm{A}$ and $\mathrm{B}$ values. In another study, the same group studied the effect of embedding $\mathrm{SiO}_{2} \mathrm{NPs}_{(0.16}$, 0.8 , an $1.6 \%$ ) in a PEI ENs substrate on the performance of the corresponding TFC-FO membranes (Tian, Wang, Wang \& Fane, 2017). Increasing the content of $\mathrm{SiO}_{2}$ NPs resulted in an increase in pore size and porosity, leading to a decrease in the $\mathrm{S}$ value. Although the presence of $\mathrm{SiO}_{2} \mathrm{NPs}$ did not change the fiber diameter (similar ENs diameters) or pore sizes on the substrate surface, the mean pore size increased with increasing $\mathrm{SiO}_{2}$ content. This change in pore size was attributed to the high resistance of the $\mathrm{SiO}_{2}$-based ENs substrate, compared with that of the control, owing to thermal compaction during the heat-press step, which produced a large gap between the nanofiber layers in the z-direction. This hypothesis was supported by the increase in the overall thickness of the substrate during the heat-press step. Furthermore, water permeability increased with increasing $\mathrm{SiO}_{2}$ content. TFN\#3 (the substrate with the highest $\mathrm{SiO}_{2}$ content of $1.6 \%$ ) was found to have the highest water permeability, as the substrate had the smallest $S$ value $(174 \mu \mathrm{m})$ owing to its porosity of $83 \%$. However, the hydrophobicity (WCA $>127^{\circ}$ ) of the substrates negatively affected the FO water flux, where the FO water flux was slightly increased from 42 LMH to 49 LMH when the DS concentration raised from 1 to $2 \mathrm{M}$. This result indicated that doubling the osmotic pressure achieved only a slight increase $(16 \%)$ in the FO water flux. This behavior could be attributed to a decrease in the effective porosity, resulting in a decrease in available pathways for the solute and water within the substrate, and hence, increasing ICP (Puguan, Kim, Lee \& Kim, 2014; Tian, Zhou, Ren, Wang \& Xiong, 2014).

Titanium dioxide NPs $\left(\mathrm{TiO}_{2} \mathrm{NPs}\right)$ was added to PSf ENs substrate and the effect of $\mathrm{TiO}_{2} \mathrm{NPs}(0,0.25,0.5$, and $0.75 \%$ ) on the pore size, porosity, hydrophilicity, and mechanical properties of the substrates, as well as on the corresponding TFN membranes have been studied (Zhang, Huang, Meng, Li and Cai 2017). Compared with the PSf substrate, the addition of $0.75 \% \mathrm{TiO}_{2}$ NPs (TFN-0.75) resulted in an increase in wettability (WCA decreased from $112.6^{\circ}$ to $90.4^{\circ}$ ), thickness (from 141 to $216 \mu \mathrm{m}$ ), and fiber diameter (from 396 to $502 \mathrm{~nm}$ ). In FO processes, the TFN-0.25 membrane achieved the highest water flux (19\% higher than TFC), but adding more $\mathrm{TiO}_{2} \mathrm{NPs}_{\text {increased }}$ the SRSF with a water flux similar to that of TFN-0.25. These results may be attributed to the increase in the pore size of the substrate with increasing $\mathrm{TiO}_{2}$ content, where an increase in fiber diameter resulted in an increase of pore size. Thus, the PA layer (rejection layer) would be more vulnerable, resulting in increased salt ion transport. Additionally, the increase in the support layer thickness (with increase $\mathrm{TiO}_{2}$ ) and decrease in the porosity results in an increased $S$ value (increased ICP), which decreases the water flux of the membrane.

\subsection{Using the ENs substrates as a nonwoven backing support}


Instead of using PET backing fabric, the ENs substrates were used to support the TFC-FO membranes. In which TFC-FO membrane constitutes of three layers; ENs as support (bottom) followed by substrate fabricated by PI in the middle and PA layer on the top. Figure 19 showed the different places for ENs substrates, where the ENs can be sandwiched between PET and PA layer (left image), can be supported PA after heat-press modification (middle image), or supported PI and PA layer (right image).

Figure 19. Different configurations of ENs substrates in TFC-FO membranes. The first three-dimensional image shows the ENs sandwiched between PET and PA layers, the middle image illustrates a heat-pressed ENs substrate with a PA layer, and the third image shows a PI layer sandwiched between an ENs support layer (nonwoven backing support) and a PA layer.

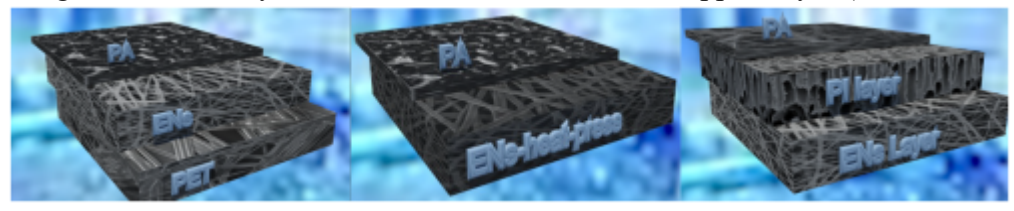

For the first time, Hoover et al. (Hoover, Schiffman \& Elimelech, 2013) investigated the replacement of the PET nonwoven backing fabric with PET ENs (ePET), on above it a PSf-PI layer was casted (Figure 19 (right) and Figure 20). The morphologies, fiber diameters, mechanical properties, and performance of the TFC membrane based on ePET (eTFC) were compared with those of commercial wet-laid PET (wlTFC). The ePET support had a thinner fiber diameter of $0.348 \pm 0.08 \mu \mathrm{m}$, which is nearly two orders of magnitude smaller than the wlPET fiber diameter $(21 \pm 3.8 \mu \mathrm{m})$, resulting in enmeshment between the ePET and PSf layers (Figure 20). This could structurally integrate the ePET and PSf layers, preventing the delamination at the interface against tangential shear forces (cross-flow velocity), while the thicker fiber diameter of the wlPET caused internally delamination at the wlPET-PSf interface, as shown in Figure 20 (right side). Although the smaller diameter of ePET enhanced the mechanical integrity, the TFC based ePET exhibited higher $\mathrm{S}$ value $(651 \pm 33.5 \mu \mathrm{m})$, as a result, lower FO water flux, compared to TFC based wlPET membrane. This is attributed to the increase of the transport resistance in the intertwining region of ePET.

Figure 20. SEM images of (A) a cross-section of a wlTFC membrane and (B) a cross-section of an eTFC membrane. Magnified views of (C) the dense, sponge-like morphology near the top surface of the eTFC membrane and (D) ePET enmeshed with PSf at the ePET-PSf interface. Digital photographs of the wITFC membrane after testing the response to shear stress induced by a moderate crossflow velocity. Delamination at the PET-PSf interface is seen from (upper) the top surface (the PA layer) and (lower) the bottom surface (PET fabric). The shown delamination occurred in a cell with a countercurrent flow of DI water at crossflow velocities that were gradually increased to $26 \mathrm{~cm} / \mathrm{s}$ (Hoover, Schiffman \& Elimelech 2013).

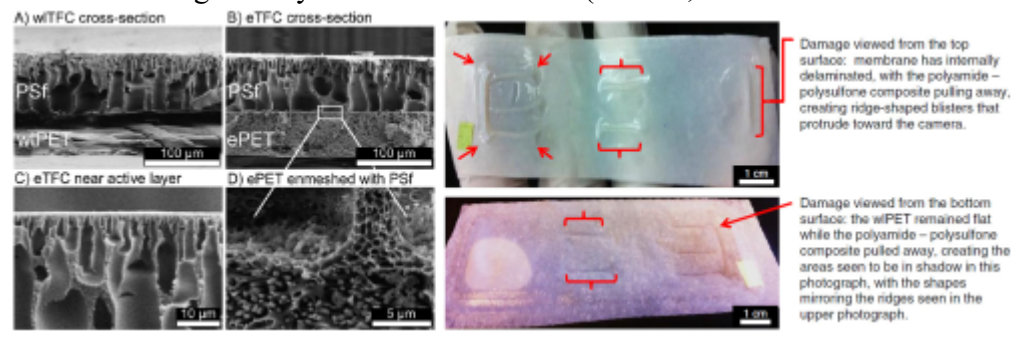

A flat TFC-FO membrane with a three-layer structure also was fabricated (Tian, Wang, Zhao \& Ren, 2017), namely, an electrospun hydrophobic/hydrophilic (PET/PVA) interpenetrating network of composite nanofibers (HH-IPN$\mathrm{CNF}$ ) as a bottom layer, a microporous PVDF-PI substrate (middle), and a top PA layer formed by IP. The effects of the casting parameters for the PVDF middle layer, such as PVDF concentration (7-15\%), composition of coagulation bath (solvent/nonsolvent ratios of 0/100, 30/70, and 50/50), and casting blade height (35, 70, and $105 \mu \mathrm{m})$, on the PET/PVA EN bottom layer was investigated. The bottom ENs substrate (thickness of $30 \mu \mathrm{m}$ and WCA of $21.9^{\circ}$ ) was found to be enmeshed with the pores of the PVDF matrix. Remarkably, the PVDF middle layer significantly reduced the roughness compared with the ENs substrate, resulting in enhanced adhesion between the PA layer and the support layer (Han, Zhang, Li, Widjojo \& Chung, 2012). However, they investigated the casting parameters of the PVDF middle layer, instead of the ENs support, which does not show the influence of the ENs on the TFC membrane performance, as well no comparison to the commercial PET backing fabric was provided. 
Overall, from the abovementioned two studies about replacing the PET backing fabric with the ENs mat, it can be concluded that the thin fiber diameters of the ENs could be enmeshed well with the PI porous layer (middle), enhancing the delamination resistance at the PI-ENs layers interface. On the other hand, as is known, thinning of nanofiber diameters results in a decrease of the pore size (distance between nanofibers), as well as increase the $\mathrm{S}$ value. In addition to the increase of the transport resistance because of the existence of several layers of nanofibers in its thickness, which substituted one or two fibers in the depth or thickness of commercial PET fabric, at the same thickness. Overall, in addition to a decrease of the mechanical properties, using ENs support as a backing layer instead of PET backing fabric reduces the TFC membrane performance.

\subsection{Commercial nonwoven nanofibers as substrates for TFC-FO membranes}

Chowdhury, Huang and McCutcheon (2017) investigated commercial unsupported nonwoven PES nanofibers (DuPont) as a support layer for TFC-FO membranes. A thin active layer (PA) of 150-200 nm was successfully fabricated on DuPont PES nanofibers (mean fiber diameter of $450 \mathrm{~nm}$ ). As well as being commercially available, this substrate has superior mechanical properties. FO tests (FO and PRO modes using $1 \mathrm{M} \mathrm{NaCl}$ as the DS) revealed that the DuPont PES TFC membrane exhibited 200\% and 130\% higher water fluxes than the commercial HTI-TFC-FO membrane in FO and PRO modes, respectively.

A comparison of all the fabricated ENs-supported TFC-FO membranes is summarized in Table 1. In addition, some commercial membranes are included in the table. Overall, ENs-supported TFC-FO membranes exhibit very small $S$ values, resulting in outstanding water fluxes compared with those of commercial membranes.

Table 1. Comparison of the performance of all EN-supported TFC-FO membranes (from the first report until April, 2018), commercial membranes, and selected membranes fabricated by PI methods (the feed water is DI).

\begin{tabular}{|c|c|c|c|c|c|c|c|c|c|c|}
\hline $\begin{array}{l}\text { Membrane } \\
\text { (support layer) }\end{array}$ & $P^{s}(\%)$ & $t^{s}(\mu \mathrm{m})$ & $W C A^{S}\left({ }^{o}\right)$ & $F D^{s}(n m)$ & $\begin{array}{l}P W P^{s} \\
(L M H)\end{array}$ & $\begin{array}{c}S^{s} \\
(\mu \mathrm{m})\end{array}$ & $\begin{array}{c}\mathrm{DS} \\
(\mathrm{NaCl})\end{array}$ & $\begin{array}{c}J_{w}(\mathrm{LMH}) \\
\mathrm{AL}-\mathrm{FS} / \mathrm{AL}- \\
\text { DS }\end{array}$ & $\begin{array}{c}J_{S} / J_{w} \\
(\mathrm{~g} / \mathrm{L}) \mathrm{AL}- \\
\text { FS/AL- } \\
\text { DS }\end{array}$ & Ref. \\
\hline \multicolumn{11}{|c|}{ EN-based FO membranes } \\
\hline $\begin{array}{l}\text { 1\# NC-FO } \\
\text { (PES) }\end{array}$ & $83 \pm 1$ & $50 \pm 6$ & - & $50-150$ & $1139 \pm 45$ & $80 \pm 6$ & $0.5 \mathrm{M}$ & $37.8 /--$ & $0.87 \mathrm{a} /-$ & $\begin{array}{l}\text { (Song, } \\
\text { Liu \& } \\
\text { Sun } \\
2011)\end{array}$ \\
\hline PSf $^{\mathrm{n}}$ & --- & --- & $139 \pm 10$ & 250 & --- & --- & $1.5 \mathrm{M}$ & $--/ 24$ & $--/ 0.36$ & $\begin{array}{l}\text { (Bui, } \\
\text { Lind, } \\
\text { Hoek \& } \\
\text { McCutch- } \\
\text { eon 2011) }\end{array}$ \\
\hline PAN & --- & $10-15^{c}$ & $69.8 \pm 15.8$ & --- & --- & 290.7 & $1.5 \mathrm{M}$ & $29 / 52$ & $0.29 / 0.06$ & $\begin{array}{l}\text { (Bui \& } \\
\text { McCutch- } \\
\text { eon 2013) }\end{array}$ \\
\hline eTFC & --- & $30 \pm 20$ & --- & $340 \pm 80$ & --- & 651 & $1 \mathrm{M}$ & $12.9 /--$ & --- & (Hoover, \\
\hline wITFC & --- & $28 \pm 5.1$ & --- & $21000 \pm 3800$ & --- & 500 & $1 \mathrm{M}$ & $16.69 /--$ & --- & $\begin{array}{l}\text { Schiff- } \\
\text { man \& } \\
\text { Elimelech } \\
\text { 2013) }\end{array}$ \\
\hline
\end{tabular}




\begin{tabular}{|c|c|c|c|c|c|c|c|c|c|c|}
\hline $\begin{array}{l}\text { Membrane } \\
\text { (support layer) }\end{array}$ & $P^{S}(\%)$ & $t^{s}(\mu \mathrm{m})$ & $W C A^{S}\left({ }^{o}\right)$ & $F D^{s}(n m)$ & $\begin{array}{l}P W P^{S} \\
(L M H)\end{array}$ & $\begin{array}{c}S^{S} \\
(\mu \mathrm{m})\end{array}$ & $\begin{array}{c}\mathrm{DS} \\
(\mathrm{NaCl})\end{array}$ & $\begin{array}{c}J_{w}(\mathrm{LMH}) \\
\mathrm{AL}-\mathrm{FS} / \mathrm{AL}- \\
\text { DS }\end{array}$ & $\begin{array}{c}J_{S} / J_{w} \\
(\mathrm{~g} / \mathrm{L}) \mathrm{AL}- \\
\text { FS/AL- } \\
\text { DS }\end{array}$ & Ref. \\
\hline TFC-1\# & $67 \pm 2$ & $63.8 \pm 9$ & $137.8 \pm 2.1$ & --- & 1267 & 812 & $1 \mathrm{M}$ & $11.6 / 30.4$ & $0.3 / 0.21$ & (Tian, \\
\hline $\begin{array}{l}\text { TFC-2\# } \\
\text { (PVDF) }\end{array}$ & $57 \pm 8$ & $67.2 \pm 8$ & $135.8 \pm 2.4$ & --- & 1938 & 325 & $1 \mathrm{M}$ & $28 / 47.6$ & $0.46 / 0.45$ & $\begin{array}{l}\text { Qiu, } \\
\text { Liao, } \\
\text { Chou \& } \\
\text { Wang } \\
\text { 2013) }\end{array}$ \\
\hline $\begin{array}{l}\text { TFC-0.75 (ny- } \\
\text { lon } 6,6)\end{array}$ & --- & $\begin{array}{c}8-10^{c} \text { or } \\
70\end{array}$ & 38 & 270 & $7632 \pm 177$ & --- & $1 \mathrm{M}$ & $21 / 27$ & $0.24 / 0.44$ & $\begin{array}{l}\text { (Huang \& } \\
\text { McCutch- } \\
\text { eon 2014) }\end{array}$ \\
\hline $\begin{array}{l}\text { PET/PVA } \\
(1 / 4)\end{array}$ & --- & 57 & 38.9 & --- & --- & --- & $0.5 \mathrm{M}$ & $--/ 47.2$ & $--/ 0.2$ & $\begin{array}{l}\text { (Tian, } \\
\text { Zhou, } \\
\text { Ren, } \\
\text { Wang \& } \\
\text { Xiong } \\
2014)\end{array}$ \\
\hline $\begin{array}{l}\text { NC-PVA/PA } \\
\text { (crosslinked } \\
\text { PVA) }\end{array}$ & 93 & $51 \pm 7.8^{\mathrm{c}}$ & $\begin{array}{c}52 \rightarrow 0 \text { after } \\
2 \mathrm{~s}\end{array}$ & $260 \pm 61$ & --- & 66 & $0.5 \mathrm{M}$ & 27.24/-- & -- & $\begin{array}{l}\text { (Puguan, } \\
\text { Kim, Lee } \\
\& \text { Kim } \\
2014)\end{array}$ \\
\hline $\begin{array}{l}\text { TFN-2 (PEI/ } \\
\text { MWCNTs) }\end{array}$ & $81 \pm 3$ & $96 \pm 3$ & --- & --- & $2045 \pm 272$ & 310 & $1 \mathrm{M}$ & $32.8 / 61.3$ & $0.07 / 0.12$ & $\begin{array}{l}\text { (Tian, } \\
\text { Wang \& } \\
\text { Wang } \\
2015)\end{array}$ \\
\hline $\begin{array}{l}\text { modified-TFC } \\
\text { (PVDF modi- } \\
\text { fied with ny- } \\
\text { lon } 6,6 \text { ) }\end{array}$ & --- & $\begin{array}{c}15.2 \pm 2^{\mathrm{c}} \\
\text { or } 50\end{array}$ & $48 \pm 10$ & $930 \pm 280$ & --- & 193 & $1 \mathrm{M}$ & $22 / 31$ & $0.17 / 0.43$ & $\begin{array}{l}\text { (Huang, } \\
\text { Arena \& } \\
\text { McCutch- } \\
\text { eon 2016) }\end{array}$ \\
\hline $\begin{array}{l}\text { TFC-PVDF- } \\
\text { TEA (PVDF } \\
\text { modified with } \\
\text { TEA) }\end{array}$ & --- & --- & 39.56 & --- & --- & 29.5 & $2 \mathrm{M}$ & 68/-- & 0.03 & $\begin{array}{l}\text { (Obaid, } \\
\text { Mo- } \\
\text { hamed, } \\
\text { Yasin, } \\
\text { Fadali, } \\
\text { Khalil, } \\
\text { Kim \& } \\
\text { Barakat } \\
\text { 2016) }\end{array}$ \\
\hline $\begin{array}{l}\text { TFC- } \\
\text { PVDF- } 0.5 \mathrm{SiO}_{2} \\
\left(\mathrm{PVDF} / \mathrm{SiO}_{2}\right. \\
\mathrm{NPs})\end{array}$ & 77 & --- & 96 & 460 & --- & 29.7 & $1 \mathrm{M}$ & $52 /--$ & $0.67 /--$ & $\begin{array}{l}\text { (Obaid, } \\
\text { Ghouri, } \\
\text { Fadali, } \\
\text { Khalil, } \\
\text { Almajid } \\
\text { \& Bara- } \\
\text { kat 2016) }\end{array}$ \\
\hline
\end{tabular}




\begin{tabular}{|c|c|c|c|c|c|c|c|c|c|c|}
\hline $\begin{array}{l}\text { Membrane } \\
\text { (support layer) }\end{array}$ & $P^{s}(\%)$ & $t^{s}(\mu \mathrm{m})$ & $W C A^{s}\left({ }^{o}\right)$ & $F D^{s}(n m)$ & $\begin{array}{l}P W P^{S} \\
(L M H)\end{array}$ & $\begin{array}{c}S^{s} \\
(\mu \mathrm{m})\end{array}$ & $\begin{array}{c}\mathrm{DS} \\
(\mathrm{NaCl})\end{array}$ & $\begin{array}{c}J_{w}(\mathrm{LMH}) \\
\mathrm{AL}-\mathrm{FS} / \mathrm{AL}- \\
\mathrm{DS}\end{array}$ & $\begin{array}{l}J_{S} / J_{w} \\
(\mathrm{~g} / \mathrm{L}) \mathrm{AL}- \\
\text { FS/AL- } \\
\text { DS }\end{array}$ & Ref. \\
\hline $\begin{array}{l}\text { TFN\#3 } \\
\left(\mathrm{PEI} / \mathrm{SiO}_{2}\right. \\
\mathrm{NPs})\end{array}$ & $83 \pm 2$ & $93.7 \pm 8$ & $129 \pm 3$ & $249 \pm 38$ & --- & 174 & $1 \mathrm{M}$ & $42 / 72$ & $0.13 / 0.1$ & $\begin{array}{l}\text { (Tian, } \\
\text { Wang, } \\
\text { Wang \& } \\
\text { Fane } \\
2017)\end{array}$ \\
\hline $\begin{array}{l}\text { TFN-0.25 } \\
\left(\text { PSf/TiO }_{2}\right)\end{array}$ & $83.6 \pm 1$ & $150 \pm 7$ & $96.5 \pm 1.1$ & 417 & --- & -- & $1 \mathrm{M}$ & $49 / 57^{b}$ & $0.22 / 0.24^{b}$ & $\begin{array}{l}\text { (Zhang, } \\
\text { Huang, } \\
\text { Meng, Li } \\
\text { and Cai } \\
\text { 2017) }\end{array}$ \\
\hline $\begin{array}{l}\text { PA/PAN- } \\
\text { eTFC (PAN) }\end{array}$ & --- & $80 \pm 4$ & $\begin{array}{c}32.3 \pm 1.3 \rightarrow 0 \\
\text { after } 10 \mathrm{~s}\end{array}$ & $502 \pm 39$ & --- & 168 & $1 \mathrm{M}$ & $29.33 / 51.08$ & $0.24 / 0.33$ & $\begin{array}{l}\text { (Pan, } \\
\text { Dong, } \\
\text { Zheng, } \\
\text { Zhong \& } \\
\text { Yuan } \\
\text { 2017) }\end{array}$ \\
\hline $\begin{array}{l}\text { TFC-PVDF- } \\
\text { PVA (PVDF } \\
\text { modified with } \\
\text { PVA) }\end{array}$ & $75 \pm 1$ & $41.8 \pm 6$ & $66.15 \pm 4.7$ & $926 \pm 267$ & --- & 154 & $0.5 \mathrm{M}$ & $16 /-$ & $0.13 /--$ & $\begin{array}{l}\text { (Park, } \\
\text { Gonzales, } \\
\text { Abdel- } \\
\text { Wahab, } \\
\text { Phuntsho } \\
\text { \& Shon } \\
\text { 2018) }\end{array}$ \\
\hline $\begin{array}{l}\text { PAN/PSf } \\
\text { NTFC (PSf/ } \\
\text { PAN) }\end{array}$ & $84.3 \pm 3.6$ & $85.1 \pm 3.7$ & $59.7 \pm 1.7$ & $250-500$ & --- & 34 & $0.5 \mathrm{M}$ & $--/ 38.3$ & $--/ 0.4$ & $\begin{array}{l}\text { (Shokrol- } \\
\text { lahzadeh } \\
\text { \& Tajik } \\
\text { 2018) }\end{array}$ \\
\hline \begin{tabular}{|l|} 
TFN5 \\
(PVDF-5GO)
\end{tabular} & $88.3 \pm 2.5$ & 196 & $108.5 \pm 4.4$ & $206 \pm 21$ & --- & 85.5 & $2 \mathrm{M}$ & 80.9/-- & $0.41 /--$ & $\begin{array}{l}\text { (Obaid, } \\
\text { Kang, } \\
\text { Wang, } \\
\text { Yoon, } \\
\text { Kim, } \\
\text { Song \& } \\
\text { Kim } \\
2018)\end{array}$ \\
\hline PIN-2-0 & --- & --- & 108 & 531 & $2290 \pm 50$ & 350 & $1 \mathrm{M}$ & $13.6 / 20.3$ & $0.35 / 0.27$ & $\begin{array}{l}\text { (Chi, } \\
\text { Zhang, } \\
\text { Guo \& } \\
\text { Xu 2018) }\end{array}$ \\
\hline \multicolumn{11}{|c|}{ PI-based FO membranes } \\
\hline $\begin{array}{l}\text { TFNC-2 (PSf/ } \\
\text { LDH) }\end{array}$ & $80.6 \pm 1$ & $57.4 \pm 1.7$ & $75.7 \pm 1.4$ & & --- & $\sim 148$ & $1 \mathrm{M}$ & $18.1 / 34.6$ & $0.45 / 0.37$ & $\begin{array}{l}\text { (Lu, } \\
\text { Liang, } \\
\text { Qiu, Gao } \\
\text { \& Wang } \\
\text { 2016) }\end{array}$ \\
\hline
\end{tabular}




\begin{tabular}{|c|c|c|c|c|c|c|c|c|c|c|}
\hline $\begin{array}{l}\text { Membrane } \\
\text { (support layer) }\end{array}$ & $P^{S}(\%)$ & $t^{s}(\mu \mathrm{m})$ & $W C A^{S}\left({ }^{o}\right)$ & $F D^{S}(n m)$ & $\begin{array}{l}P W P^{S} \\
(L M H)\end{array}$ & $\begin{array}{c}S^{S} \\
(\mu \mathrm{m})\end{array}$ & $\begin{array}{c}\mathrm{DS} \\
(\mathrm{NaCl})\end{array}$ & $\begin{array}{c}J_{w}(\mathrm{LMH}) \\
\mathrm{AL}-\mathrm{FS} / \mathrm{AL}- \\
\mathrm{DS}\end{array}$ & $\begin{array}{c}J_{S} / J_{w} \\
(\mathrm{~g} / \mathrm{L}) \mathrm{AL}- \\
\text { FS/AL- } \\
\text { DS }\end{array}$ & Ref. \\
\hline TFC32 & $90 \pm 3.7$ & --- & $58 \pm 2.4$ & & $302.4 \pm 4.6$ & 525 & $2 \mathrm{M}$ & $25.4 / 43$ & $0.61 / 1.24$ & $\begin{array}{l}\text { (Liu, Yu, } \\
\text { Kang, Jie, } \\
\text { Jin \& } \\
\text { Cao } \\
2016)\end{array}$ \\
\hline TFN-0.08 & --- & 100 & $31^{b}$ & & --- & 242 & $0.5 \mathrm{M}$ & $26^{\mathrm{b} /--}$ & $0.185^{\mathrm{b}} /-$ & $\begin{array}{l}\text { (Zireh- } \\
\text { pour, Ra- } \\
\text { himpour } \\
\text { \& Ul- } \\
\text { bricht } \\
2017 \text { ) }\end{array}$ \\
\hline \multicolumn{11}{|c|}{ Commercial membranes } \\
\hline \begin{tabular}{|l} 
TFC1 (Oasys) \\
\end{tabular} & -- & -- & -- & & -- & 365 & $1 \mathrm{M}$ & 31.9/-- & $0.36 /--$ & \multirow{2}{*}{$\begin{array}{l}\text { (Coday, } \\
\text { Heil, Xu } \\
\text { \& Cath } \\
\text { 2013) }\end{array}$} \\
\hline $\begin{array}{l}\text { TFC2 (HTI- } \\
\text { TFC) }\end{array}$ & -- & -- & -- & & -- & 690 & $1 \mathrm{M}$ & 9.8/-- & $0.85 /--$ & \\
\hline HTI-NW & $58 \pm 1.2$ & $220 \pm 3.8$ & --- & & --- & 2092 & $0.5 \mathrm{M}$ & 3.69 & -- & $\begin{array}{l}\text { (Puguan, } \\
\text { Kim, Lee } \\
\text { \& Kim } \\
2014)\end{array}$ \\
\hline \multirow[t]{2}{*}{$\begin{array}{l}\text { HTI-FO } \\
(\text { CTA-HW) }\end{array}$} & \multirow[t]{2}{*}{$64 \pm 1$} & \multirow[t]{2}{*}{$60-90$} & \multirow[t]{2}{*}{$74 \pm 2$} & & \multirow[t]{2}{*}{--} & \multirow[t]{2}{*}{720} & $\begin{array}{l}0.5 \\
\mathrm{M}^{*}\end{array}$ & $9.03 / 15.4$ & $0.54 / 0.6$ & \multirow{2}{*}{$\begin{array}{l}\text { (Wei, } \\
\text { Qiu, } \\
\text { Tang, } \\
\text { Wang \& } \\
\text { Fane } \\
\text { 2011) }\end{array}$} \\
\hline & & & & & & & $2 \mathrm{M}^{*}$ & $18.3 / 35.9$ & & \\
\hline \multirow[t]{2}{*}{$\begin{array}{l}\text { HTI-FO } \\
(\text { CTA-W })^{\text {a }}\end{array}$} & \multirow[t]{2}{*}{$46 \pm 1$} & \multirow[t]{2}{*}{$20-44.7$} & \multirow[t]{2}{*}{$69 \pm 2$} & & \multirow[t]{2}{*}{--} & \multirow[t]{2}{*}{1000} & $\begin{array}{l}0.5 \\
\mathrm{M}^{*}\end{array}$ & $5 / 6.55$ & $1.06 / 0.73$ & \multirow{2}{*}{\begin{tabular}{|l} 
(Wei, \\
Qiu, \\
Tang, \\
Wang \& \\
Fane \\
2011)
\end{tabular}} \\
\hline & & & & & & & $2 \mathrm{M}^{*}$ & $12.1 / 22.9$ & & \\
\hline \multirow[t]{2}{*}{$\begin{array}{l}\text { HTI-FO } \\
(\text { CTA-NW) }\end{array}$} & \multirow[t]{2}{*}{$50 \pm 2$} & \multirow[t]{2}{*}{$144 \pm 24$} & \multirow[t]{2}{*}{$74 \pm 3$} & & \multirow[t]{2}{*}{--} & \multirow[t]{2}{*}{1380} & $\begin{array}{l}0.5 \\
\mathrm{M}^{*}\end{array}$ & $4.42 / 8.19$ & $0.66 / 0.34$ & \multirow{2}{*}{$\begin{array}{l}\text { (Wei, } \\
\text { Qiu, } \\
\text { Tang, } \\
\text { Wang \& } \\
\text { Fane } \\
2011)\end{array}$} \\
\hline & & & & & & & $2 \mathrm{M}^{*}$ & $8.51 / 21.8$ & & \\
\hline HTI-FO & $40 \pm 3$ & $50 \pm 12$ & --- & & -- & 620 & $0.5 \mathrm{M}$ & $6.5 /--$ & --- & $\begin{array}{l}\text { (Song, } \\
\text { Liu \& } \\
\text { Sun } \\
2011) \\
\end{array}$ \\
\hline
\end{tabular}




\begin{tabular}{|c|c|c|c|c|c|c|c|c|c|c|}
\hline $\begin{array}{l}\text { Membrane } \\
\text { (support layer) }\end{array}$ & $P^{s}(\%)$ & $t^{s}(\mu \mathrm{m})$ & $W C A^{S}\left({ }^{o}\right)$ & $F D^{s}(n m)$ & $\begin{array}{l}P W P^{S} \\
(L M H)\end{array}$ & $\begin{array}{c}S^{S} \\
(\mu \mathrm{m})\end{array}$ & $\begin{array}{c}\mathrm{DS} \\
(\mathrm{NaCl})\end{array}$ & $\begin{array}{c}J_{w}(\mathrm{LMH}) \\
\mathrm{AL}-\mathrm{FS} / \mathrm{AL}- \\
\mathrm{DS}\end{array}$ & $\begin{array}{c}J_{S} / J_{w} \\
(\mathrm{~g} / \mathrm{L}) \mathrm{AL}- \\
\text { FS/AL- } \\
\text { DS }\end{array}$ & Ref. \\
\hline RO (BW30) & $35 \pm 1$ & $152 \pm 4$ & $92 \pm 2^{\mathrm{d}}$ & & -- & 37500 & $\begin{array}{c}0.5 \\
\mathrm{M}^{*} \\
2 \mathrm{M}^{*}\end{array}$ & $\begin{array}{l}0.78 / 0.44 \\
0.48 / 1.59\end{array}$ & \begin{tabular}{|c|}
-- \\
--
\end{tabular} & $\begin{array}{l}\text { (Wei, } \\
\text { Qiu, } \\
\text { Tang, } \\
\text { Wang \& } \\
\text { Fane } \\
2011 \text { ) }\end{array}$ \\
\hline $\begin{array}{l}\text { RO (BW30- } \\
\text { o) }\end{array}$ & $49 \pm 1$ & $58.1 \pm 5.1$ & $92 \pm 2$ & & -- & 14000 & $\begin{array}{c}0.5 \\
\mathrm{M}^{*} \\
2 \mathrm{M}^{*}\end{array}$ & $\begin{array}{l}1.09 / 1.33 \\
1.9 / 2.18\end{array}$ & $\begin{array}{l}-- \\
--\end{array}$ & $\begin{array}{l}\text { (Wei, } \\
\text { Qiu, } \\
\text { Tang, } \\
\text { Wang \& } \\
\text { Fane } \\
2011)\end{array}$ \\
\hline
\end{tabular}

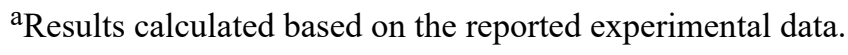

b Obtained from reported graphical data.

Ps Porosity of the substrate.

$t^{\mathrm{s}}$ Thickness of the substrate.

WCA $^{\mathrm{s}}$ Water contact angle of the substrate.

$\mathrm{FD}^{\mathrm{s}}$ Fiber diameter of the substrate.

PWPs pure water flux of the substrate.

${ }^{\mathrm{c}}$ The thickness is without PET non-woven support (only ENs thickness).

${ }^{d}$ It is BW30 after remove the non-woven fabric.

*It means the feed solution is $10 \mathrm{mM} \mathrm{NaCl}$ solution, otherwise, it was DI.

\section{Challenges}

\subsection{Membrane}

Regarding the membrane, one of the major challenges in FO processes is CP, especially ICP. As ICP occurs in the substrate, there is a critical need to fabricate substrates to meet the required criteria. Substrates can be tailored by choosing appropriate materials, controlling the fabrication conditions, changing the substrate design, or changing the fabrication method. Based on the previous reports, ENs are considered a feasible substrate for TFC-FO membranes, but more studies are needed to optimize these emerging substrates. In addition, there is a critical need for in-depth studies on ICP in ENs-supported TFC-FO membranes. Furthermore, ENs-supported TFC-FO membranes have some challenges that must be considered, such as:

$\rightarrow$ Delamination of the PA layer from the ENs substrate which is a considerable issue (Figure 21), as the nonuniform surface and high roughness of ENs mats enhance the delamination of the PA. To overcome this barrier, ENs substrates need to be fabricated with uniform fiber diameters, optimal pore sizes (related to fiber diameter) that are not too large or too small, and optimum wettability that considers the swelling of the introduced material. Moreover, posttreatment for the produced ENs substrate is important, such as using heat-pressed to decrease the surface roughness as well as enhance the mechanical properties.

Figure 21. FE-SEM images of the TFN- 0.25 ( $\mathrm{PSF} / 0.25 \% \mathrm{TiO}_{2} \mathrm{NPs}$ ) membrane: (a) cross-sectional structure of the TFN membrane and (b) cross-sectional structure of the PA active layer (Zhang, Huang, Meng, Li and Cai 2017). 
(a)

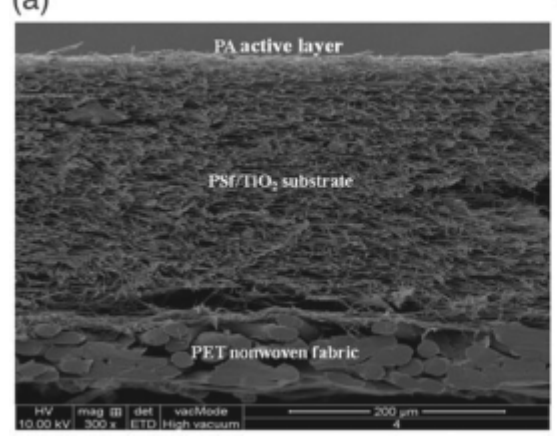

(b)

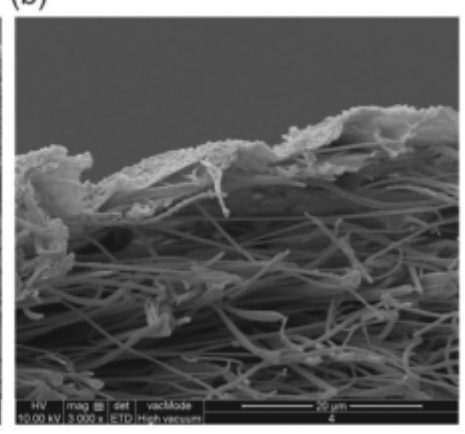

$\rightarrow$ The poor mechanical properties of polymeric ENs substrates is another obstacle for the large-scale implementation of ENs-supported TFC membranes. This weakness can be partially solved by heat-press posttreatment and reinforcement of the ENs substrate with PET nonwoven support. However, the former solution results in decreased porosity, whereas the latter solution increases the thickness of the whole membrane, leading to an increased $S$ value, which increases ICP. As no hydraulic pressure is used in FO processes, the produced substrates do not require exceptional mechanical properties. Therefore, it is crucial to explore ENs substrates with acceptable robustness by replacing the above two solutions with mixed matrix membranes (embedding inorganic NPs) and changing the fabrication parameters of electrospinning, with considering the wettability, porosity, and pore size. Regarding this challenge, our group successfully fabricated a novel freestanding robust ENs substrates (no PET and no heat-press) reinforced with GO nanosheets to overcome of the poor mechanical properties of the EN substrates and fabricate highly permeable thin-film nanocomposite FO membranes. Although this has some merits and may have a basis for further consideration, the results also showed that this cannot possibly be an endpoint and more studies are required.

$\rightarrow$ The wettability and swelling of the substrate must be considered. Highly hydrophobic polymers cannot be wetted, resulting in a decrease in available paths through the substrate (increased $S$ value), whereas highly hydrophilic polymers may undergo swelling and causes delamination of the PA layer. Therefore, there is a critical need to find appropriate materials with good wettability and very low swelling.

$\rightarrow$ The cost of the electrospinning process to fabricate the ENs substrate is rarely considered in the reports. To make a complete and effective comparison between the PI and ENs substrates, determination of the fabrication cost is important to consider as well as the effect of each process on the environment. Where the fabrication cost of the substrates definitely will affect the cost of the whole TFC membrane.

\subsection{FO process}

Despite the many interesting prospective applications of the FO process, some technological obstacles have yet to be overcome. These challenges can be classified according to the DS (regeneration or reconcentration, development of efficient DSs, and reverse solute diffusion) and the membrane (CP and membrane fouling). It is worth mentioning that approximately $71-98 \%$ of the total energy in an FO process is expected to be consumed in the DS regeneration process (Zou, Yuan, Childress \& He, 2016). Although FO has been widely represented as an energy-efficient process for desalination, wastewater treatment, or pretreatment in integrated desalination processes when regeneration (reconcentration) of the DS is considered the actual total energy will be high. For example, the total energy required for an FO-RO hybrid system is higher than the total energy needed for RO alone if high concentrated DS is used.

To accurately calculate the total specific energy consumption (SEC) in FO processes, the energy needed for pretreatment of the inlet FS and DS, regeneration (reconcentration) of the DS, recirculation pumps, and treatment of the concentrated (outlet) FS should be considered. However, the energy consumption in FO processes has been rarely reported using different software models (Mazlan, Peshev \& Livingston, 2016; Zou, Yuan, Childress \& He, 2016). As shown in Table 2, the actual total energy (including recirculation and pretreatment) is in the range of 0.84$3.58 \mathrm{kWh} / \mathrm{m}^{3}$ when using lab-scale model software, but increases to $21 \mathrm{kWh} / \mathrm{m}^{3}$ when a pilot-scale model is used and DS is regenerated (McGinnis, Hancock, Nowosielski-Slepowron \& McGurgan, 2013). Thus, when regeneration of the DS is not required, such as in the case of dilution of commercial fertilizers (Zou \& He, 2016) or FO coupled with 
a microbial electrolysis cell (MEC) (Qin \& He, 2014), the SEC values were very low $\left(0.02-1.86\right.$ and $0.1 \mathrm{kWh} / \mathrm{m}^{3}$, respectively) (Qin \& He, 2014; Zou \& He, 2016).

Table 2. Total energy consumption in FO processes, including the energy required for pretreatment and regeneration of the DS.

\begin{tabular}{|c|c|c|c|c|c|c|}
\hline Status & $\begin{array}{l}\text { FS concen- } \\
\text { tration }(\mathrm{g} / \mathrm{L})\end{array}$ & DS concentration & Regeneration & $\begin{array}{l}\text { Recov- } \\
\text { ery }(\%)\end{array}$ & $\begin{array}{l}\text { Total SEC } \\
\left(\mathrm{kWh} / \mathrm{m}^{3}\right)^{\mathrm{a}}\end{array}$ & Ref. \\
\hline Pilot scale & $>70$ & $\begin{array}{l}5.5-6.0 \mathrm{M} \\
\left(\mathrm{NH}_{3} / \mathrm{CO}_{2}\right)\end{array}$ & $\begin{array}{l}\text { Thermal distil- } \\
\text { lation }\end{array}$ & $>64$ & 21 & $\begin{array}{l}\text { McGinnis, Hancock, Now- } \\
\text { osielski-Slepowron \& } \\
\text { McGurgan, 2013) }\end{array}$ \\
\hline \multirow{3}{*}{$\begin{array}{l}\text { AspenONE } \\
\text { model }\end{array}$} & \multirow[t]{3}{*}{35} & $\sim 1.8 \mathrm{M} \mathrm{MgSO}_{4}$ & Nanofiltration & $50 / 75$ & $2.4 / 3.3$ & \multirow{3}{*}{$\begin{array}{l}\text { (Mazlan, Peshev \& Living- } \\
\text { ston, 2016) }\end{array}$} \\
\hline & & Hydrophilic NPs & Ultrafiltration & 75 & 3.2 & \\
\hline & & 5 M CO2-NH3 & Distillation & 75 & 1.2 & \\
\hline HYSYS model & 35 & $5 \mathrm{M} \mathrm{CO}_{2}-\mathrm{NH}_{3}$ & Distillation & 75 & 0.84 & $\begin{array}{l}\text { (McGinnis \& Elimelech, } \\
\text { 2007) }\end{array}$ \\
\hline Model & 35 & $\begin{array}{l}78.5 \text { bar }(\sim 1.5 \mathrm{M} \\
\mathrm{NaCl})\end{array}$ & RO & 50 & 3.58 & $\begin{array}{l}\text { (McGovern and Lienhard, } \\
\text { 2014) }\end{array}$ \\
\hline Lab-scale & $\begin{array}{l}\text { Treated } \\
\text { wastewater }\end{array}$ & $\begin{array}{l}1 \mathrm{M} \text { commercial } \\
\text { fertilizer }\end{array}$ & Not used & & $0.02-1.86$ & (Zou \& He, 2016) \\
\hline
\end{tabular}

ancluding the energy for pretreatment and regeneration of the DS.

The total electricity consumption of desalination processes with different capacities, such as membrane, thermal distillation, and electrodialysis processes, was compared with that of FO processes, and the results are plotted in Figure 22.

Figure 22. Minimum and maximum energy consumption during the main desalination process for specific ranges of unit sizes. The data for FO is from Table 1, whereas the other data are taken from (Al-Karaghouli \& Kazmerski 2013, Abdelkareem, Assad, Sayed \& Soudan 2017). MSF: multistage flash distillation, MED: multieffect distillation, MVC: mechanical vapor compression, TVC: thermal vapor compression, SWRO: seawater reverse osmosis, BWRO: brackish water reverse osmosis, and ED: electrodialysis.

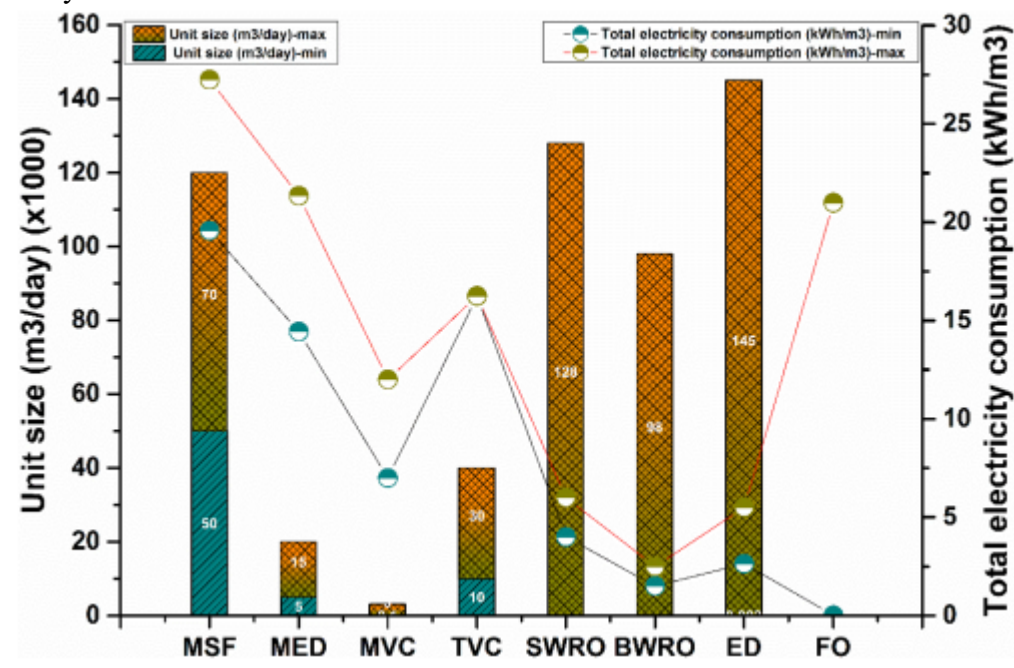

From Figure 22, the maximum SEC value for a pilot-scale FO process with a unit size capacity of $5.5-21.1 \mathrm{~m}^{3} / \mathrm{day}$ is $21 \mathrm{kWh} / \mathrm{m}^{3}$. This value is very high compared to the data obtained from the software's models (Table 2). Thus, current data available for the total SEC values of FO processes do not represent actual values for large-scale process- 
es. Instead, they are only examples to indicate the importance of considering the energy needed for DS regeneration, recirculation, etc. For example, the DS concentrations were assumed as $1.8 \mathrm{M} \mathrm{MgSO}_{4}$, and $1.5 \mathrm{M} \mathrm{NaCl}$ (Table 2) which are small compared with that are needed in the practical case. However, more studies are needed to calculate the exact and accurate SEC for the pilot and large-scale based on the real experimental results, where the modeling and simulation using assumptions that not match the real conditions giving rise to un-accurate SEC results.

\section{Practical considerations for implementing FO membranes}

For FO membranes to be employed in the field, there are a number of considerations and the primary concern is how to modulate the membranes to become the essential component of the water treatment process. There are two major types of FO elements: (1) spiral-wound (SW) and (2) plate and frame (PF). The primary purpose of using the FO process is to dilute the draw stream as efficient as possible within a given space in practical terms. One that plays a pivotal role out of important factors in the element design is the hydraulic pressure, one of the key considerations when membrane elements are employed.

The two modulation techniques illustrated in Figure 23 have pros and cons. SW-type follows the traditional approach for the RO membrane elements containing a series of membrane envelopes spirally packed by placing a permeate collection tube at the core. SW-type modulation is particularly beneficial when hydraulic pressure has to be accommodated because this modulation technique enables radially equivalent distribution of the hydraulic pressure (i.e. internal stress) inside the pressure vessel. On the other hand, PF-type modulation is relatively vulnerable to hydraulic pressure due to the localized internal stress at the center of the membrane envelope. Thus, SW-type element can be beneficial when operating pressure is high. However, PF-type element performs better, in general, than the SW-type element due to arguably more efficient use of the membranes. It was argued that the unique draw streamlines in the draw channel of the SW-type inflict the inefficient use of membranes at the corners of the membrane leaf, so-called the dead zones in Figure 23a, while such a phenomenon does not occur in the PF-type element (Lee \& Kim, 2018). This notion has been generally accepted in the academia but the presence of the dead zone has not been experimentally validated at this stage.

Figure 23. Characteristic flow patterns of (a) SW-type FO element and (b) PF-type FO element and (c) general membrane leaf composition. Blue sections in (a) and (b) represent glue lines. 

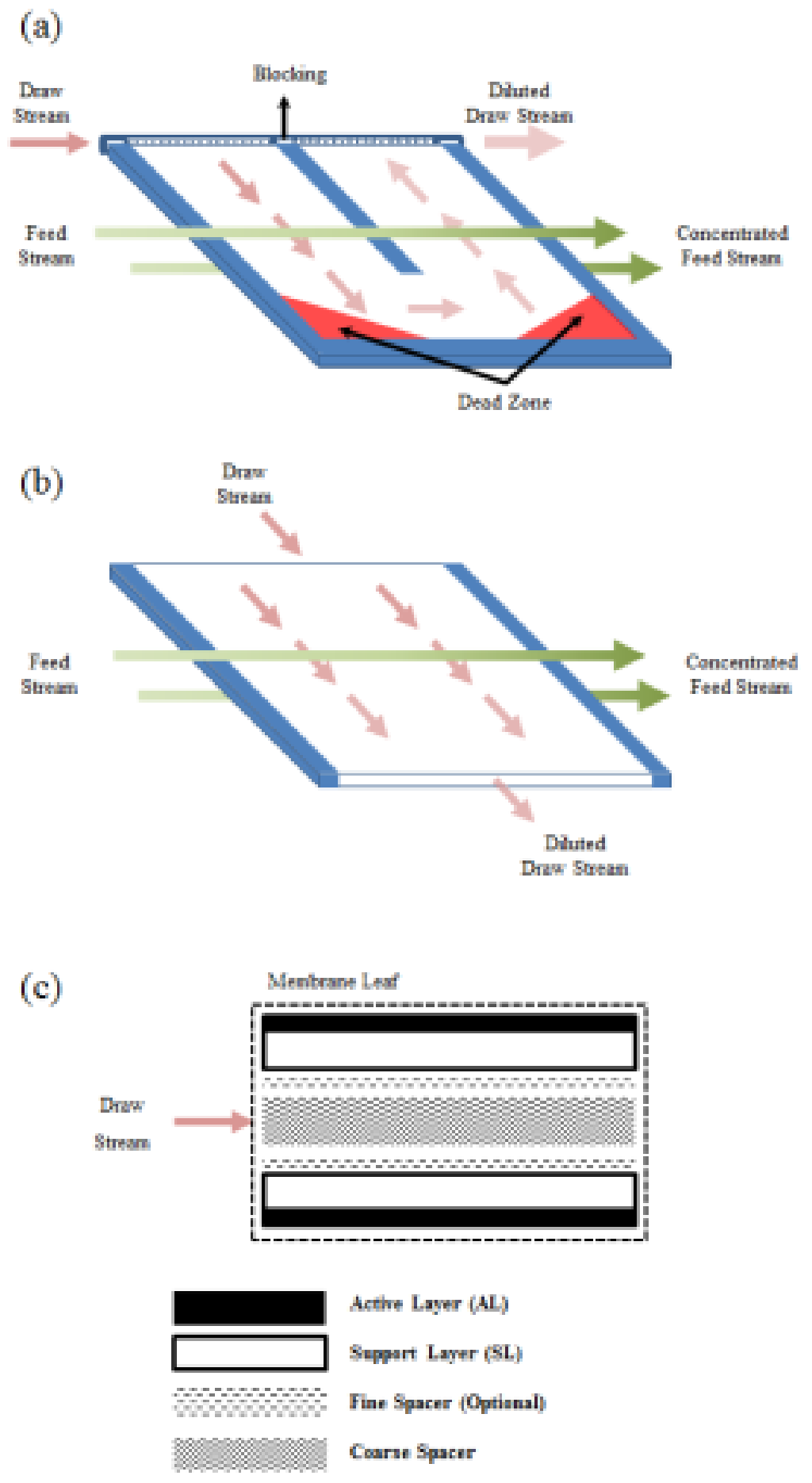

FO process has been conceptually perceived as a process that is not dependent on hydraulic pressure. However, this analogy can only be acceptable when the effective membrane area is small (e.g. lab-scale experiments with small membrane coupons). A number of previous studies covered the analyses on element-based FO performance and, without exception, hydraulic pressure build-ups at the inlet and the associated hydraulic pressure drops (i.e. hydraulic pressure difference between the inlet and outlet of both feed and draw channels) occurred (Attarde, Jain, Chaudhary \& Gupta, 2015; Im, Go, Lee, Park \& Jang, 2016; Kim, Blandin, Phuntsho, Verliefde, Le-Clech \& Shon, 2017; Kim \& Park, 2011). The hydraulic pressure build-up at the inlet of the membrane element is the result of structural resistance of the water channel against the initial water flow input to the system. The water channels must be occupied by chan- 
nel spacers to guarantee appropriate water flows through the channels since the spacers determine the structural resistance against the water flows yielding the pressure build-up. As such, when FO elements are employed in large scale to accommodate a set of feed and draw flowrates, hydraulic pressure inevitably becomes a dependent variable determined by the structural characteristics of the water channels with respect to the water inflows.

As far as the structural integrity of an FO membrane is concerned in large-scale operations, membrane deformation in association with the hydraulic pressure is one of the most critical factors. To ensure safe operation, it is recommended that any hydraulic pressure measured in the feed side should be higher than the hydraulic pressure in the draw side to prevent the membrane leaves from rupturing. This requirement can be satisfied by setting the feed outlet pressure equal to or higher than the draw inlet pressure. It is because of the unique characteristic of FO membrane leaves when an FO membrane element is manufactured. A membrane leaf is composed of draw channel spacers enveloped by two FO membranes in a way that the support layers (substrates) are facing the draw spacers as depicted in Figure 23c, while the edges of the membrane leaf are glued to ensure that the feed and draw streams do not make direct contact as shown in Figure 23a and 24b.

Figure 24. Estimated SECs of the PAFO-RO hybrid desalination depending on additional hydraulic pressures (Note: the figure is generated using the data sets for single FO element from (Kook, Lee, Nguyen, Lee, Shon \& Kim 2018)).

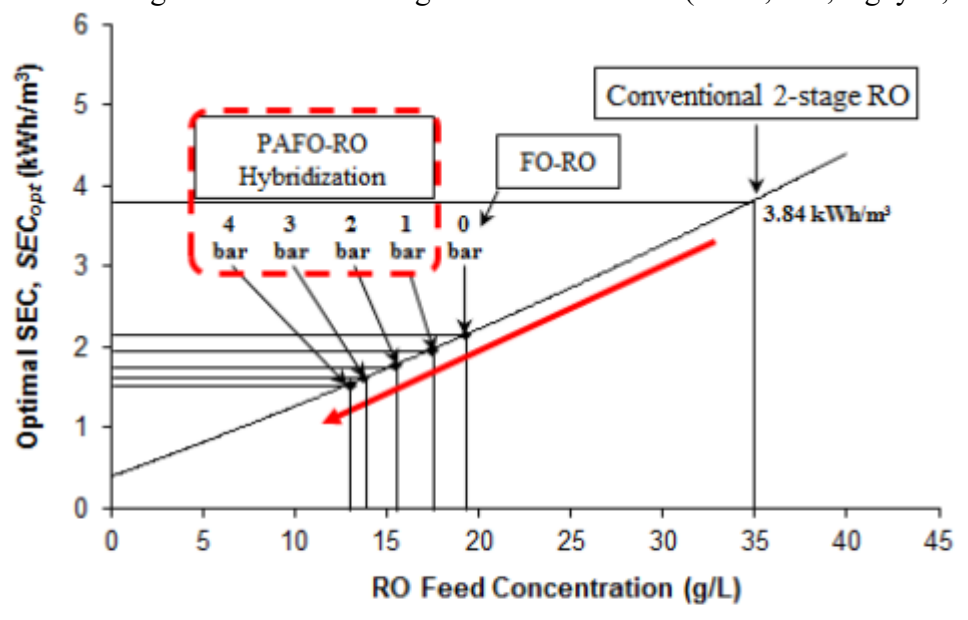

\begin{tabular}{l|lll|l|l}
\multicolumn{1}{c|}{ SEC } & 0 bar & 1 bar & 2 bar & 3 bar & 4 bar \\
\hline $\mathrm{SEC}_{\text {RO }}\left(\mathrm{kWh} / \mathrm{m}^{3}\right)$ & 2.170 & 1.958 & 1.762 & 1.618 & 1.525 \\
\hline $\mathrm{SEC}$ PAFO $\left(\mathrm{kWh} / \mathrm{m}^{3}\right)$ & 0.006 & 0.031 & 0.051 & 0.070 & 0.087 \\
\hline Total SEC & 2.176 & 1.989 & 1.813 & 1.688 & 1.612 \\
\hline
\end{tabular}

There are two important considerations in both scientific and engineering aspects. First of all, as hydraulic pressure in the feed side being always higher than the draw side for the safety reason discussed above, FO membranes deform toward the draw side resulting in a phenomenon called the draw channel contraction (Hidayat, Kook \& Kim, 2018; Lian, Blandin, Leslie \& Le-Clech, 2018). A previous study reported that the water and solute permeability coefficients of a CTA-based FO membrane were altered depending on the hydraulic pressure in the feed side and the types of draw channel spacers (Blandin, Verliefde, Tang, Childress \& Le-Clech, 2013). It is important to note from this study that minor changes on the permeability coefficients were observed for fine frit support, whereas significant alterations on the coefficients were observed for a coarser diamond-shaped draw spacer. This means the mass transport through an FO membrane is strictly dependent on the types of draw spacer in association with the structural integrity of the FO membrane. However, the data sets were analyzed based on the solution-diffusion theory which assumes that the hydraulic and osmotic pressures exhibit identical nature considering the membranes are in uniformity. This assumption was later elucidated in our recent study that the two pressure identities cannot be considered identical when FO membranes are operated under hydraulic pressure (Kook, Swetha, Lee, Lee, Fane \& Kim, 2018). This pioneering study offered a new insight on understanding the mass transports through FO membranes under hydraulic pressure as this study successfully validated a practically meaningful method that can quantitatively measure the 
proper operating hydraulic pressure limit for any FO membranes and possibly for all membranes categorized as nonporous. Nevertheless, this study only tested the FO membranes using 11 layers of fine RO permeate carriers as draw spacers and the hydraulic pressure limit is expected to be altered when coarse diamond-shaped draw spacers are employed, possibly lowering the limit due to severer membrane deformation. Secondly, when a specific initial draw flowrate should be accommodated, the contracted draw channel due to higher hydraulic pressure in the feed side than in the draw side inflicts higher energy requirement on the draw pump to overcome the worsened structural resistance of the draw channel (Hidayat, Kook \& Kim, 2018). Essentially, the energy cost is primarily determined by the input flow rate and the inlet hydraulic pressure accommodated by a pump (Blandin, Verliefde, Tang \& Le-Clech, 2015). Thus, it can be deduced that the electrical energy required for a draw pump is dependent on the hydraulic pressure in the feed side since the hydraulic pressures in both feed and draw sides are interconnected. As such, once a set of feed and draw flowrates is supplied to an FO element, the feed outlet pressure should be carefully controlled to ensure that the draw inlet pressure is equal or lower than the feed outlet for the FO unit process being safely operated; then the inlet pressures on both sides which directly affect the operating expenditure (OPEX) of the dilution process are accordingly determined.

As listed in Table 3, there have been efforts to understand the FO element performance and implications within a number of categories. Our recent study covered the economic feasibility of a hybrid desalination process which includes pressure-assisted forward osmosis (PAFO) as pretreatment for the following 2-stage RO process, namely PAFO-RO hybrid (Kook, Lee, Nguyen, Lee, Shon \& Kim, 2018). PAFO utilizes both hydraulic and osmotic pressures as active driving forces for water transport, thus has better dilution performance than FO (i.e. hydraulic pressure $=0$ ) (Blandin, Verliefde, Tang, Childress \& Le-Clech, 2013; Kook \& Kim, 2017; Oh, Lee, Elimelech, Lee \& Hong, 2014). we conducted a set of pilot-scale PAFO tests under varying feed and draw flowrates, the number of FO elements in series and the hydraulic pressure difference between the feed outlet and the draw inlet, ranging from $0-4$ bar, in order to estimate their economic impacts within the hybrid scheme. It was assumed that the PAFO unit process was added to an existing 2 -stage $\mathrm{RO}$ desalination plant.

Table 3. Element-based FO studies and their key aspects.

\begin{tabular}{|c|c|c|c|}
\hline Category & FO Element & Key Aspects & Ref. \\
\hline \multirow[t]{5}{*}{$\begin{array}{l}\text { Element Perform- } \\
\text { ance }\end{array}$} & $\begin{array}{l}\text { HTI } 2521 \text { (Hy- } \\
\text { drowell) }\end{array}$ & $\begin{array}{l}\text { - Estimation of concentration polarization in the element } \\
\text { (incorporating dilution effect) by conducting FO and PRO } \\
\text { operations }\end{array}$ & $\begin{array}{l}\text { (Xu, Peng, Tang, } \\
\text { Fu \& Nie, 2010) }\end{array}$ \\
\hline & HTI 4040 & $\begin{array}{l}\cdot \text { FO operations (non-circulating draw stream) } \bullet \text { Initial } \\
\text { draw flowrate found to govern the membrane performance }\end{array}$ & $\begin{array}{l}\text { (Kim \& Park, } \\
\text { 2011) }\end{array}$ \\
\hline & HTI 2521 & $\begin{array}{l}- \text { FO operations (two elements in series) } \bullet \text { Significant pres- } \\
\text { sure build-up observed throughout the draw channel }\end{array}$ & $\begin{array}{l}\text { (Im, Go, Lee, } \\
\text { Park \& Jang, } \\
\text { 2016) }\end{array}$ \\
\hline & $\begin{array}{l}\text { HTI } 8040 \text { Toray } \\
\text { FO } 8040\end{array}$ & $\begin{array}{l}\text { - Fouling reversibility quantified for osmotic backwashing } \\
\text { using batch operations }\end{array}$ & (Kim et al., 2017) \\
\hline & Toray FO 8040 & $\begin{array}{l}\text { - PAFO operations (single element) } \text { Impact of draw chan- } \\
\text { nel contraction on pressure build-up }\end{array}$ & $\begin{array}{l}\text { (Hidayat, Kook \& } \\
\text { Kim, 2018) }\end{array}$ \\
\hline
\end{tabular}




\begin{tabular}{|c|c|c|c|}
\hline Category & FO Element & Key Aspects & Ref. \\
\hline \multirow[t]{6}{*}{$\begin{array}{l}\text { Performance Esti- } \\
\text { mation via Simula- } \\
\text { tion }\end{array}$} & - & $\begin{array}{l}\text { - Computational fluid dynamics (CFD) simulations on flow } \\
\text { velocity and CPs } \bullet \text { ECP on the draw side cannot be neglec- } \\
\text { ted as the channel length increases. }\end{array}$ & $\begin{array}{l}\text { (Gruber et al., } \\
\text { 2011) }\end{array}$ \\
\hline & $\begin{array}{l}\text { Data adapted } \\
\text { from (Xu, Peng, } \\
\text { Tang, Fu \& Nie, } \\
\text { 2010) }\end{array}$ & $\begin{array}{l}\text { - Comparison of plate-and-frame and spiral-wound element } \\
\text { performances using CFD } \cdot \text { CPs are the major contributors } \\
\text { for determining the membrane performances }\end{array}$ & $\begin{array}{l}\text { (Gu, Kim, Kim \& } \\
\text { Yang, 2011) }\end{array}$ \\
\hline & - & $\begin{array}{l}\text { - FO performance estimation by two-dimensional FEM } \\
\text { model (Channel length: } 1 \mathrm{~m}) \cdot \text { Counter-current operation } \\
\text { showed slight performance enhancement. }\end{array}$ & $\begin{array}{l}\text { (Sagiv, Zhu, } \\
\text { Christofides, Co- } \\
\text { hen \& Semiat, } \\
\text { 2014) }\end{array}$ \\
\hline & HTI 2521 & $\begin{array}{l}\text { - Validation of experimental data of FO and PRO opera- } \\
\text { tions by a numerical parameter estimation }\end{array}$ & $\begin{array}{l}\text { (Attarde, Jain, } \\
\text { Chaudhary \& } \\
\text { Gupta, 2015) }\end{array}$ \\
\hline & HTI 2521 & $\begin{array}{l}\text { - Validation of experimental data of FO and PRO opera- } \\
\text { tions by Spiegler-Kedem model }\end{array}$ & $\begin{array}{l}\text { (Attarde, Jain \& } \\
\text { Gupta, 2016) }\end{array}$ \\
\hline & $\begin{array}{l}\text { HTI } 2521 \text { Pori- } \\
\text { fera PFO } 20\end{array}$ & $\begin{array}{l}\text { - Performance estimation using S-D theory } \bullet \text { SW-type and } \\
\text { PF-type FO elements tested }\end{array}$ & $\begin{array}{l}\text { (Lian, Blandin, } \\
\text { Leslie \& Le- } \\
\text { Clech, 2018) }\end{array}$ \\
\hline \multirow[t]{2}{*}{ Impact of Spacers } & $\begin{array}{l}\text { HTI CTA 8040- } \\
\text { CS and 8040-MS }\end{array}$ & $\begin{array}{l}\text { - The first study that reported the } 8040 \text { FO element per- } \\
\text { formance } \bullet \text { Comparison of element performances (corruga- } \\
\text { ted vs. diamond-shaped) }\end{array}$ & $\begin{array}{l}\text { (Kim, Phuntsho, } \\
\text { Lotfi \& Shon, } \\
\text { 2015) }\end{array}$ \\
\hline & $\begin{array}{l}\text { HTI CTA } \\
\text { 2521FO-MS Por- } \\
\text { ifera PFO } 20\end{array}$ & $\begin{array}{l}\text { - Impact of draw channel contraction on pressure build-up } \\
\text { and pressure drop using both SW-type and PF-type ele- } \\
\text { ments }\end{array}$ & $\begin{array}{l}\text { (Lian, Blandin, } \\
\text { Leslie \& Le- } \\
\text { Clech, 2018) }\end{array}$ \\
\hline $\begin{array}{l}\text { Fertilizer Drawn } \\
\text { FO }\end{array}$ & $\begin{array}{l}\text { HTI CTA } 8040- \\
\text { 2EA (Parallel } \\
\text { connection) }\end{array}$ & $\begin{array}{l}- \text { FDFO-NF pilot testing to treat saline groundwater at a } \\
\text { coal mine } \bullet \text { Failed to meet the fertigation standard } \rightarrow \text { Need } \\
\text { element with higher selectivity. }\end{array}$ & $\begin{array}{l}\text { (Phuntsho et al., } \\
\text { 2016) }\end{array}$ \\
\hline \multirow[t]{4}{*}{$\begin{array}{l}\text { Economic Feasibil- } \\
\text { ity Assessment }\end{array}$} & $\begin{array}{l}\text { Data adapted } \\
\text { from (Phuntsho, } \\
\text { Kim, Johir, } \\
\text { Hong, Li, Ghaf- } \\
\text { four, Leiknes \& } \\
\text { Shon 2016) } \\
\end{array}$ & $\begin{array}{l}\cdot \text { Life cycle assessment (LCA) conducted for FDFO-NF } \\
\text { hybrid } \bullet \text { Comparison with MF-RO and UF-RO }\end{array}$ & (Kim et al., 2017) \\
\hline & Toray FO 8040 & $\begin{array}{l}\text { - Single element-based FO testing for serial connection up } \\
\text { to } 4 \text { elements } \cdot \text { Non-linear regression adopted for simulat- } \\
\text { ing up to } 8 \text { elements }\end{array}$ & $\begin{array}{l}\text { (Kim, Phuntsho, } \\
\text { Ali, Choi \& Shon, } \\
\text { 2018) }\end{array}$ \\
\hline & $\begin{array}{l}\text { HTI }(0.5 \mathrm{~m} 2) \\
\text { Porifera }(7.0 \mathrm{~m} 2)\end{array}$ & $\begin{array}{l}\text { - Single element-based FO testing for serial connection up } \\
\text { to } 4 \text { elements } \bullet \text { Scale-up factors discussed for economics in } \\
\text { large scale }\end{array}$ & $\begin{array}{l}\text { (Im, Jeong \& } \\
\text { Jang, 2018) }\end{array}$ \\
\hline & Toray FO 8040 & $\begin{array}{l}\text { - Actual serial connection of } 8 \text {-inch FO elements in series } \\
\text { up to } 3 \text { elements } \bullet \text { Economic assessment based on the ex- } \\
\text { perimental data to suggest a practical method that can sug- } \\
\text { gest optimal operating conditions for field application }\end{array}$ & $\begin{array}{l}\text { (Kook, Lee, } \\
\text { Nguyen, Lee, } \\
\text { Shon \& Kim, } \\
\text { 2018) }\end{array}$ \\
\hline
\end{tabular}

The economic assessment results showed that the hybrid process could significantly reduce the energy cost of the hybrid process as depicted in Figure 24. Optimal SEC values of RO under varying diluted draw concentrations were adopted from (Kook et al., 2017) and the additional hydraulic pressure conditions defined in (Kook et al., 2018) were 
given depending on the diluted concentrations measured from the actual pilot-scale operations. The SECs for PAFO and $\mathrm{RO}$ were computed based on the final product (i.e. 100,000 $\mathrm{m}^{3} / \mathrm{d}$ ) specified in the work.

By taking the capital expenditure (CAPEX) of PAFO into account, it was found the FO-RO hybrid can only be beneficial only when a substantial unit FO element cost cut-down is guaranteed. On the other hand, employing PAFO instead of FO was found to efficiently improve the economic feasibility of the hybrid scheme, particularly when two FO elements are serially connected and 2 bar of hydraulic pressure difference was maintained between the feed outlet and the draw inlet of the last element in the serial configuration. However, membrane fouling was not covered in this study; the research team is planning to move the PAFO pilot system to a wastewater treatment plant on October 2018, to answer the question that FO and/or PAFO actually is an economically viable option considering membrane fouling in the PAFO-RO hybrid scheme.

\section{Conclusions}

The FO is a next-generation membrane system for various fields of science and engineering such as desalination of sea/brackish water, wastewater treatment, and food processing. Despite the significant increase in research of FO technology, implementation of the full-scale has been limited and scarce as well as the implemented pilot-scale systems have been incompletely reported. Several factors and parameters must be considered for the development of the FO for example; developing the draw solution that can be easily and economically recovered, nontoxic, cheap, and available, and optimizing the operation parameters and conditions, as well as synthesis of effective membranes with excellent performance, such as high water permeability, high salt rejection, high chemical stability, small ICP, and sufficient mechanical strength.

Although there have been extensive studies on TFC-FO membranes based on the PI substrates which resulted in many commercial FO membranes, the research of ENs supported TFC-FO membranes is still at its infant stage and the progress potential is still large. Unlike PI substrates, ENs substrates-supported TFC-FO membranes can provide significant potential in FO process owing to their low structural parameters. The unique structure of these ENs substrates guarantees direct paths for salt and water diffusion, which could provide a good solution for eliminating the ICP bottleneck in FO membranes. Nevertheless, more works are required to enhance their mechanical properties, optimize the pore size of ENs substrates, and overcome the PA layer delamination from the ENs substrates. Furthermore, the determination and study of the capital and operating costs of the electrospinning process, to fabricate ENs substrates, is important and critically needed, as well as its influence on the environmental, compared to the PI fabrication methods.

On the other hand, investigation of the SEC using the results from the various practical pilot-scale systems combining with modeling and simulation, considering the practical challenges and conditions, is critically required for the scale-up of the FO process, as well as to determine the optimum hybridization systems.

\section{References}

Abdelkareem, M. A., Assad, M. E. H., Sayed, E. T., \& Soudan, B. (2017). Recent progress in the use of renewable energy sources to power water desalination plants. Desalination. [AQ3]doi:10.1016/j.desal.2017.11.018

Achilli, A., Cath, T. Y., Marchand, E. A., \& Childress, A. E. (2009). The forward osmosis membrane [AQ4]bioreactor: A low fouling alternative to MBR processes. Desalination, 239(1-3), 10-21. doi:10.1016/j.desal.2008.02.022

Ahmed,[AQ5] F. E., Lalia, B. S., \& Hashaikeh, R. (2015). A review on electrospinning for membrane [AQ4]fabrication: Challenges and applications. Desalination, 356, 15-30. doi:10.1016/j.desal.2014.09.033

Al-Karaghouli, [AQ6]A., \& Kazmerski, L. L. (2013). Energy consumption and water production cost [AQ7]of conventional and renewable-energy-powered desalination processes. Renewable and Sustainable Energy Reviews, 24, 343-356. doi:10.1016/j.rser.2012.12.064

Angammana, [AQ8]C. J., \& Jayaram, S. H. (2011). Analysis of the effects of solution conductivity on[AQ9] electrospinning process and fiber morphology. IEEE Transactions on Industry Applications, 47(3), 1109-1117. doi:10.1109/ TIA.2011.2127431 
Arena, J. T.,[AQ10] McCloskey, B., Freeman, B. D., \& McCutcheon, J. R. (2011). Surface modification of thin film composite membrane support layers with polydopamine: Enabling use of [AQ11] reverse osmosis membranes in pressure retarded osmosis. Journal of Membrane Science, [AQ12]375(1-2), 55-62. doi:10.1016/j.memsci.2011.01.060

Arinstein, A. (2017). Electrospun polymer nanofibers. Jenny Stanford Publishing. Taylor\& Francis Group[AQ19]

Attarde, D., [AQ13]Jain, M., Chaudhary, K., \& Gupta, S. K. (2015). Osmotically driven membrane processes[AQ17] by using a spiral wound module - Modeling, experimentation and numerical parameter[AQ16] estimation. Desalination, 361, 81-94. doi:10.1016/j.desal.2015.01.025

Attarde, [AQ15]D., Jain, M., \& Gupta, S. K. (2016). Modeling of a forward osmosis and a pressure-retarded[AQ14] osmosis spiral wound module using the Spiegler-Kedem model and experimental validation. Separation and Purification Technology, 164, 182-197. doi:10.1016/j.seppur.2016.03.039

Baker, R. W. (2000). Membrane technology. Hoboken, NJ: Wiley Online Library.

Baker, R. W. (2004). Membrane technology and applications (pp. 96-103). Hoboken, NJ: John Wiley \& Sons, Ltd.

Balas, F., [AQ18]Manzano, M., Horcajada, P., \& Vallet-Regí, M. (2006). Confinement and controlled release of bisphosphonates on ordered mesoporous silica-based materials. Journal of the American Chemical Society, 128, 81168117. doi:10.1021/ja062286z

Blandin, G., Verliefde, A. R. D., Tang, C. Y., Childress, A. E., \& Le-Clech, P. (2013). Validation of assisted forward osmosis (AFO) process: Impact of hydraulic pressure. Journal of Membrane Science, 447, 1-11. doi:10.1016/ j.memsci.2013.06.002

Blandin, G., Verliefde, A. R. D., Tang, C. Y., \& Le-Clech, P. (2015). Opportunities to reach economic sustainability in forward osmosis-reverse osmosis hybrids for seawater desalination. Desalination, 363, 26-36. doi:10.1016/ j.desal.2014.12.011

Buchko, C. J., Chen, L. C., Shen, Y., \& Martin, D. C. (1999). Processing and microstructural characterization of porous biocompatible protein polymer thin films. Polymer, 40(26), 7397-7407. doi:10.1016/S0032-3861(98)00866-0

Bui, N.-N., Lind, M. L., Hoek, E. M. V., \& McCutcheon, J. R. (2011). Electrospun nanofiber supported thin film composite membranes for engineered osmosis. Journal of Membrane Science, 385-386, 10-19. doi:10.1016/ j.memsci.2011.08.002

Bui, N.-N., \& McCutcheon, J. R. (2013). Hydrophilic nanofibers as new supports for thin film composite membranes for engineered osmosis. Environmental Science \& Technology, 47, 1761-1769. doi:10.1021/es304215g

Burger, C., Hsiao, B. S., \& Chu, B. (2006). Nanofibrous materials and their applications. 36, 333-368. doi:10.1146/ annurev.matsci.36.011205.123537

Casper, C. L., Stephens, J. S., Tassi, N. G., Chase, D. B., \& Rabolt, J. F. J. M. (2004). Controlling surface morphology of electrospun polystyrene fibers: Effect of humidity and molecular weight in the electrospinning process. Macromolecules 37, 573-578. doi:10.1021/ma0351975

Cath, T. Y., Adams, D., \& Childress, A. E. (2005). Membrane contactor processes for wastewater reclamation in space: II. Combined direct osmosis, osmotic distillation, and membrane distillation for treatment of metabolic wastewater. Journal of Membrane Science, 257(1-2), 111-119. doi:10.1016/j.memsci.2004.07.039

Cath, T. Y., Childress, A. E., \& Elimelech, M. (2006). Forward osmosis: Principles, applications, and recent developments. Journal of Membrane Science, 281(1-2), 70-87. doi:10.1016/j.memsci.2006.05.048

Cath, T. Y., Elimelech, M., McCutcheon, J. R., McGinnis, R. L., Achilli, A., Anastasio, D., ... Hancock, N. T. (2013). Standard methodology for evaluating membrane performance in osmotically driven membrane processes. Desalination, 312, 31-38. doi:10.1016/j.desal.2012.07.005

Chen, S., Slattum, P., Wang, C., \& Zang, L. (2015). Self-assembly of perylene imide molecules into 1D nanostructures: Methods, morphologies, and applications. Chemical Reviews, 115(21), 11967-11998. doi:10.1021/acs.chemrev. $5 \mathrm{~b} 00312$ 
Chi, X.-Y., Zhang, P.-Y., Guo, X.-J., \& Xu, Z.-L. (2018). A novel TFC forward osmosis (FO) membrane supported by polyimide (PI) microporous nanofiber membrane. Applied Surface Science, 427, 1-9. doi:10.1016/ j.apsusc.2017.07.259

Chowdhury, M. R., Huang, L., \& McCutcheon, J. R. (2017). Thin film composite membranes for forward osmosis supported by commercial nanofiber nonwovens. Industrial \& Engineering Chemistry Research, 56, 1057-1063. doi:10.1021/acs.iecr.6b04256

Chun, Y., Mulcahy, D., Zou, L., \& Kim, I. (2017). A short review of membrane fouling in forward osmosis processes. Membranes, 7(2), 30. doi:10.3390/membranes7020030

Chung, T.-S., Li, X., Ong, R. C., Ge, Q., Wang, H., \& Han, G. (2012). Emerging forward osmosis (FO) technologies and challenges ahead for clean water and clean energy applications. Current Opinion in Chemical Engineering, 1(3), 246-257. doi:10.1016/j.coche.2012.07.004

Chung, T.-S., Zhang, S., Wang, K. Y., Su, J., \& Ling, M. M. (2012). Forward osmosis processes: Yesterday, today and tomorrow. Desalination, 287, 78-81. doi:10.1016/j.desal.2010.12.019

Coday, B. D., Heil, D. M., Xu, P., \& Cath, T. Y. (2013). Effects of transmembrane hydraulic pressure on performance of forward osmosis membranes. Environmental Science \& Technology, 47, 2386-2393. doi:10.1021/es304519p

Costa, L. M. M., Bretas, R. E. S., \& Gregorio, R. J. (2010). Effect of solution concentration on the electrospray/electrospinning transition and on the crystalline phase of PVDF. Materials Sciences and Applications, 1, 247.

doi:10.4236/msa.2010.14036

Cramariuc, B., Cramariuc, R., Scarlet, R., Manea, L. R., Lupu, I. G., \& Cramariuc, O. (2013). Fiber diameter in electrospinning process. Journal of Electrostatics, 71(3), 189-198. doi:10.1016/j.elstat.2012.12.018

De Vrieze, S., Van Camp, T., Nelvig, A., Hagström, B., Westbroek, P., \& De Clerck, K. (2009). The effect of temperature and humidity on electrospinning. Journal of Materials Science, 44, 1357-1362. doi:10.1007/ s10853-008-3010-6

Deitzel, J. M., Kleinmeyer, J., Harris, D., \& Tan, N. B. (2001). The effect of processing variables on the morphology of electrospun nanofibers and textiles. Polymer, 42, 261-272. doi:10.1016/S0032-3861(00)00250-0

Ding, Y., Hou, H., Zhao, Y., Zhu, Z., \& Fong, H. (2016). Electrospun polyimide nanofibers and their applications. Progress in Polymer Science, 61, 67-103. doi:10.1016/j.progpolymsci.2016.06.006

Ding, B., \& Yu, J. (2014). Electrospun nanofibers for energy and environmental applications. Springer. Springer Heidelberg New York Dordrecht London.[AQ20]

Dova, M. I., Petrotos, K. B., \& Lazarides, H. N. (2007). On the direct osmotic concentration of liquid foods. Part I: Impact of process parameters on process performance. Journal of Food Engineering, 78(2), 422-430. doi:10.1016/ j.jfoodeng.2005.10.010

Elmarco. (2018). Retreived from http://www.elmarco.com/.

Emadzadeh, D., Lau, W. J., Matsuura, T., Ismail, A. F., \& Rahbari-Sisakht, M. (2014). Synthesis and characterization of thin film nanocomposite forward osmosis membrane with hydrophilic nanocomposite support to reduce internal concentration polarization. Journal of Membrane Science, 449, 74-85. doi:10.1016/j.memsci.2013.08.014

Emadzadeh, D., Lau, W. J., Matsuura, T., Rahbari-Sisakht, M., \& Ismail, A. F. (2014). A novel thin film composite forward osmosis membrane prepared from $\mathrm{PSf}-\mathrm{TiO}_{2}$ nanocomposite substrate for water desalination. Chemical Engineering Journal, 237, 70-80. doi:10.1016/j.cej.2013.09.081

Emadzadeh, D., Lau, W. J., Rahbari-Sisakht, M., Ilbeygi, H., Rana, D., Matsuura, T., \& Ismail, A. F. (2015). Synthesis, modification and optimization of titanate nanotubes-polyamide thin film nanocomposite (TFN) membrane for forward osmosis (FO) application. Chemical Engineering Journal, 281, 243-251. doi:10.1016/j.cej.2015.06.035

Fan, L., Xu, Y., Zhou, X., Chen, F., \& Fu, Q. (2018). Effect of salt concentration in spinning solution on fiber diameter and mechanical property of electrospun styrene-butadiene-styrene tri-block copolymer membrane. Polymer, 153, 61-69. doi:10.1016/j.polymer.2018.08.008 
Fathizadeh, M., Aroujalian, A., \& Raisi, A. (2012). Effect of lag time in interfacial polymerization on polyamide composite membrane with different hydrophilic sub layers. Desalination, 284, 32-41. doi:10.1016/

j.desal.2011.08.034

Feng, C., Khulbe, K., Matsuura, T., Tabe, S., \& Ismail, A. (2013). Preparation and characterization of electro-spun nanofiber membranes and their possible applications in water treatment. Separation and Purification Technology, 102, 118-135. doi:10.1016/j.seppur.2012.09.037

Feng, C., Takeuchi, T., Abdelkareem, M. A., Tsujiguchi, T., \& Nakagawa, N. (2013). Carbon-CeO2 composite nanofibers as a promising support for a PtRu anode catalyst in a direct methanol fuel cell. Journal of Power Sources, 242, 57-64. doi:10.1016/j.jpowsour.2013.04.157

Freger, V. (2005). Kinetics of film formation by interfacial polycondensation. Langmuir, 21(5), 1884-1894. doi: $10.1021 / 1 \mathrm{a} 048085 \mathrm{v}$

Gao, Y., Wang, Y.-N., Li, W., \& Tang, C. Y. (2014). Characterization of internal and external concentration polarizations during forward osmosis processes. Desalination, 338, 65-73. doi:10.1016/j.desal.2014.01.021

Garg, K., \& Bowlin, G. L. (2011). Electrospinning jets and nanofibrous structures. Biomicrofluidics, 5(1), 013403. doi:10.1063/1.3567097

Ge, Q., \& Chung, T.-S. (2015). Oxalic acid complexes: Promising draw solutes for forward osmosis (FO) in protein enrichment. Chemical Communications, 51(23), 4854-4857. doi:10.1039/C5CC00168D

Ge, Q., Fu, F., \& Chung, T.-S. (2014). Ferric and cobaltous hydroacid complexes for forward osmosis (FO) processes. Water Research, 58, 230-238. doi:10.1016/j.watres.2014.03.024

Ge, Q., Ling, M., \& Chung, T.-S. (2013). Draw solutions for forward osmosis processes: Developments, challenges, and prospects for the future. Journal of Membrane Science, 442, 225-237. doi:10.1016/j.memsci.2013.03.046

Ghanbari, M., Emadzadeh, D., Lau, W., Riazi, H., Almasi, D., \& Ismail, A. (2016). Minimizing structural parameter of thin film composite forward osmosis membranes using polysulfone/halloysite nanotubes as membrane substrates. Desalination, 377, 152-162. doi:10.1016/j.desal.2015.09.019

Ghosh, A. K., \& Hoek, E. M. V. (2009). Impacts of support membrane structure and chemistry on polyamide-polysulfone interfacial composite membranes. Journal of Membrane Science, 336(1-2), 140-148. doi:10.1016/ j.memsci.2009.03.024

Gohil, J. M., \& Ray, P. (2017). A review on semi-aromatic polyamide TFC membranes prepared by interfacial polymerization: Potential for water treatment and desalination. Separation and Purification Technology, $181,159$. doi:10.1016/j.seppur.2017.03.020

Gopal, R., Kaur, S., Ma, Z., Chan, C., Ramakrishna, S., \& Matsuura, T. (2006). Electrospun nanofibrous filtration membrane. Journal of Membrane Science, 281(1-2), 581-586. doi:10.1016/j.memsci.2006.04.026

Gray, G. T., McCutcheon, J. R., \& Elimelech, M. (2006). Internal concentration polarization in forward osmosis: Role of membrane orientation. Desalination, 197(1-3), 1-8. doi:10.1016/j.desal.2006.02.003

Gruber, M. F., Johnson, C. J., Tang, C. Y., Jensen, M. H., Yde, L., \& Hélix-Nielsen, C. (2011). Computational fluid dynamics simulations of flow and concentration polarization in forward osmosis membrane systems. Journal of Membrane Science, 379(1-2), 488-495. doi:10.1016/j.memsci.2011.06.022

Gu, B., Kim, D. Y., Kim, J. H., \& Yang, D. R. (2011). Mathematical model of flat sheet membrane modules for FO process: Plate-and-frame module and spiral-wound module. Journal of Membrane Science, 379(1-2), 403-415. doi:10.1016/j.memsci.2011.06.012

Gwak, G., \& Hong, S. (2017). New approach for scaling control in forward osmosis (FO) by using an antiscalantblended draw solution. Journal of Membrane Science, 530, 95-103. doi:10.1016/j.memsci.2017.02.024

Haider, A., Haider, S., \& Kang, I.-K. J. (2018). A comprehensive review summarizing the effect of electrospinning parameters and potential applications of nanofibers in biomedical and biotechnology. Arabian Journal of Chemistry, 11, 1165-1188. doi:10.1016/j.arabjc.2015.11.015 
Han, G., Chung, T.-S., Toriida, M., \& Tamai, S. (2012). Thin-film composite forward osmosis membranes with novel hydrophilic supports for desalination. Journal of Membrane Science, 423-424, 543-555. doi:10.1016/ j.memsci.2012.09.005

Han, G., Liang, C.-Z., Chung, T.-S., Weber, M., Staudt, C., \& Maletzko, C. (2016). Combination of forward osmosis (FO) process with coagulation/flocculation (CF) for potential treatment of textile wastewater. Water Research, 91 , 361-370. doi:10.1016/j.watres.2016.01.031

Han, G., Zhang, S., Li, X., Widjojo, N., \& Chung, T.-S. (2012). Thin film composite forward osmosis membranes based on polydopamine modified polysulfone substrates with enhancements in both water flux and salt rejection. Chemical Engineering Science, 80, 219-231. doi:10.1016/j.ces.2012.05.033

Haupt, A., \& Lerch, A. J. M. (2018). Forward osmosis application in manufacturing industries. Membranes, 8, 47. doi:10.3390/membranes 8030047

Hidayat, M. A., Kook, S., \& Kim, I. S. (2018). Draw channel contraction of an 8040 spiral-wound forward osmosis membrane element in pressure-assisted forward osmosis (PAFO). Desalination and Water Treatment, 109, 17-27. doi:10.5004/dwt.2018.22152

Hilal, N., Ismail, A. F., \& Wright, C. (2015). Membrane fabrication. Boca Raton, FL: CRC Press.

Hoover, L. A., Schiffman, J. D., \& Elimelech, M. (2013). Nanofibers in thin-film composite membrane support layers: Enabling expanded application of forward and pressure retarded osmosis. Desalination, 308, 73-81. doi:10.1016/ j.desal.2012.07.019

Huang, L., Arena, J. T., \& McCutcheon, J. R. (2016). Surface modified PVDF nanofiber supported thin film composite membranes for forward osmosis. Journal of Membrane Science, 499, 352-360. doi:10.1016/ j.memsci.2015.10.030

Huang, L., Bui, N. N., Manickam, S. S., \& McCutcheon, J. R. (2011). Controlling electrospun nanofiber morphology and mechanical properties using humidity. Journal of Polymer Science Part B Polymer Physics, 49, $1734-1744$. doi:10.1002/polb.22371

Huang, L., Bui, N.-N., Meyering, M. T., Hamlin, T. J., \& McCutcheon, J. R. (2013). Novel hydrophilic nylon 6, 6 microfiltration membrane supported thin film composite membranes for engineered osmosis. Journal of Membrane Science, 437, 141-149. doi:10.1016/j.memsci.2013.01.046

Huang, M., Chen, Y., Huang, C.-H., Sun, P., \& Crittenden, J. (2015). Rejection and adsorption of trace pharmaceuticals by coating a forward osmosis membrane with $\mathrm{TiO}_{2}$. Chemical Engineering Journal, 279, 904-911. doi:10.1016/ j.cej.2015.05.078

Huang, C., Chen, S., Lai, C., Reneker, D. H., Qiu, H., Ye, Y., \& Hou, H. (2006). Electrospun polymer nanofibres with small diameters. Nanotechnology, 17(6), 1558. doi:10.1088/0957-4484/17/6/004

Huang, L., \& McCutcheon, J. R. (2014). Hydrophilic nylon 6, 6 nanofibers supported thin film composite membranes for engineered osmosis. Journal of Membrane Science, 457, 162-169. doi:10.1016/j.memsci.2014.01.040

Huang, L., \& McCutcheon, J. R. (2015). Impact of support layer pore size on performance of thin film composite membranes for forward osmosis. Journal of Membrane Science, 483, 25-33. doi:10.1016/j.memsci.2015.01.025

Im, S.-J., Go, G.-W., Lee, S.-H., Park, G.-H., \& Jang, A. (2016). Performance evaluation of two-stage spiral wound forward osmosis elements at various operation conditions. Desalination and Water Treatment, 57(51), 24583-24512. doi:10.1080/19443994.2016.1157989

Im, S.-J., Jeong, S., \& Jang, A. (2018). Feasibility evaluation of element scale forward osmosis for direct connection with reverse osmosis. Journal of Membrane Science, 549, 366-376. doi:10.1016/j.memsci.2017.12.027

INOVENSO Co. (2018). Retreived from http://inovenso.com/.

Ismail, A., Padaki, M., Hilal, N., Matsuura, T., \& Lau, W. (2015). Thin film composite membrane-recent development and future potential. Desalination, 356, 140-148. doi:10.1016/j.desal.2014.10.042 
Ito, Y., Takeuchi, T., Tsujiguchi, T., Abdelkareem, M. A., \& Nakagawa, N. (2013). Ultrahigh methanol electro-oxidation activity of $\mathrm{PtRu}$ nanoparticles prepared on TiO2-embedded carbon nanofiber support. Journal of Power Sources, 242, 280-288. doi:10.1016/j.jpowsour.2013.05.064

Jacobs, V., Anandjiwala, R. D., \& Maaza, M. (2010). The influence of electrospinning parameters on the structural morphology and diameter of electrospun nanofibers. Journal of Applied Polymer Science, 115(5), 3130-3136. doi:10.1002/app.31396

Jeong, B.-H., Hoek, E. M., Yan, Y., Subramani, A., Huang, X., Hurwitz, G., ... Jawor, A. (2007). Interfacial polymerization of thin film nanocomposites: A new concept for reverse osmosis membranes. Journal of Membrane Science, 294(1-2), 1-7. doi:10.1016/j.memsci.2007.02.025

Jia, C., Yu, D., Lamarre, M., Leopold, P. L., Teng, Y. D., \& Wang, H. (2014). Patterned electrospun nanofiber matrices via localized dissolution: Potential for guided tissue formation. Advanced Materials, 26(48), 8192-8197. doi:10.1002/adma.201403509

Kao, S. T., Teng, M. Y., Li, C. L., Kuo, C. Y., Hsieh, C. Y., Tsai, H. A., ... Lai, J. Y. (2008). Fabricating PC/PAN composite membranes by vapor-induced phase separation. Desalination , 233(1-3), 96-103. doi:10.1016/ j.desal.2007.09.031

Katti, D. S., Robinson, K. W., Ko, F. K., \& Laurencin, C. T. (2004). Bioresorbable nanofiber-based systems for wound healing and drug delivery: Optimization of fabrication parameters. Journal of Biomedical Materials Research, 70, 286-296. doi:10.1002/jbm.b.30041

Ki, C. S., Kim, J. W., Hyun, J. H., Lee, K. H., Hattori, M., Rah, D. K., \& Park, Y. H. (2007). Electrospun threedimensional silk fibroin nanofibrous scaffold. Journal of Applied Polymer Science, 106(6), 3922-3928. doi:10.1002/ app.26914

Kim, J., Blandin, G., Phuntsho, S., Verliefde, A., Le-Clech, P., \& Shon, H. J. D. (2017). Practical considerations for operability of an 8 "spiral wound forward osmosis module: Hydrodynamics, fouling behaviour and cleaning strategy. Desalination, 404, 249-258. doi:10.1016/j.desal.2016.11.004

Kim, D. I., Choi, J., \& Hong, S. (2018). Evaluation on suitability of osmotic dewatering through forward osmosis (FO) for xylose concentration. Separation and Purification Technology, 191, 225-232. doi:10.1016/ j.seppur.2017.09.036

Kim, C. H., Jung, Y. H., Kim, H. Y., Lee, D. R., Dharmaraj, N., \& Choi, K. E. (2006). Effect of collector temperature on the porous structure of electrospun fibers. Macromolecular Research, 14(1), 59-65. doi:10.1007/BF03219069

Kim, Y. C., \& Park, S. J. (2011). Experimental study of a 4040 spiral-wound forward-osmosis membrane module. Environmental Science \& Technology, 45(18), 7737-7745. doi:10.1021/es202175m

Kim, J. E., Phuntsho, S., Ali, S. M., Choi, J. Y., \& Shon, H. K. (2018). Forward osmosis membrane modular configurations for osmotic dilution of seawater by forward osmosis and reverse osmosis hybrid system. Water Research, 128, 183-192. doi:10.1016/j.watres.2017.10.042

Kim, J. E., Phuntsho, S., Lotfi, F., \& Shon, H. K. (2015). Investigation of pilot-scale 8040 FO membrane module under different operating conditions for brackish water desalination. Desalination and Water Treatment, 53(10), 2782-2791. doi:10.1080/19443994.2014.931528

Klaysom, C., Cath, T. Y., Depuydt, T., \& Vankelecom, I. F. (2013). Forward and pressure retarded osmosis: Potential solutions for global challenges in energy and water supply. Chemical Society Reviews, 42(16), 6959-6989. doi:10.1039/c3es60051c

Kong, C., Kanezashi, M., Yamomoto, T., Shintani, T., \& Tsuru, T. (2010). Controlled synthesis of high performance polyamide membrane with thin dense layer for water desalination. Journal of Membrane Science, 362(1-2), 76-80. doi:10.1016/j.memsci.2010.06.022

Kong, C., Koushima, A., Kamada, T., Shintani, T., Kanezashi, M., Yoshioka, T., \& Tsuru, T. (2011). Enhanced performance of inorganic-polyamide nanocomposite membranes prepared by metal-alkoxide-assisted interfacial polymerization. Journal of Membrane Science, 366(1-2), 382-388. doi:10.1016/j.memsci.2010.10.026 
Kong, C., Shintani, T., Kamada, T., Freger, V., \& Tsuru, T. (2011). Co-solvent-mediated synthesis of thin polyamide membranes. Journal of Membrane Science, 384(1-2), 10-16. doi:10.1016/j.memsci.2011.08.055

Kong, F-X., Yang, H-W., Wu, Y-Q., Wang, X-M., \& Xie, Y. F. (2015). Rejection of pharmaceuticals during forward osmosis and prediction by using the solution-diffusion model. Journal of Membrane Science, 476, 410-420. doi:10.1016/j.memsci.2014.11.026

Kook, S., \& Kim, I. S. (2017). Transport of trace organic contaminants (TrOCs) in pressure-assisted forward osmosis (PAFO). Desalination and Water Treatment, 82, 1-10. doi:10.5004/dwt.2017.21011

Kook, S., Kim, J., Kim, S.-J., Lee, J., Han, D., Phuntsho, S., ... Kim, I. S. (2017). Effect of initial feed and draw flowrates on performance of an 8040 spiral-wound forward osmosis membrane element. Desalination and Water Treatment, 72, 1-12. doi:10.5004/dwt.2017.20412

Kook, S., Lee, C., Nguyen, T. T., Lee, J., Shon, H. K., \& Kim, I. S. (2018). Serially connected forward osmosis membrane elements of pressure-assisted forward osmosis-reverse osmosis hybrid system: Process performance and economic analysis. Desalination, 448, 1-12. doi:10.1016/j.desal.2018.09.019

Kook, S., Swetha, C. D., Lee, J., Lee, C., Fane, T., \& Kim, I. S. (2018). Forward osmosis membranes under nullpressure condition: Do hydraulic and osmotic pressures have identical nature? Environmental Science \& Technology, 52(6), 3556-3566. doi:10.1021/acs.est.7b05265

Koski, A., Yim, K., \& Shivkumar, S. J. M. L. (2004). Effect of molecular weight on fibrous PVA produced by electrospinning. 58, 493-497. doi:10.1016/S0167-577X(03)00532-9

Kuang, W., Liu, Z., Yu, H., Kang, G., Jie, X., Jin, Y., \& Cao, Y. (2016). Investigation of internal concentration polarization reduction in forward osmosis membrane using nano- $\mathrm{CaCO}_{3}$ particles as sacrificial component. Journal of Membrane Science, 497, 485-493. doi:10.1016/j.memsci.2015.06.052

Lalia, B. S., Kochkodan, V., Hashaikeh, R., \& Hilal, N. (2013). A review on membrane fabrication: Structure, properties and performance relationship. Desalination, 326, 77-95. doi:10.1016/j.desal.2013.06.016

Lau, W., Gray, S., Matsuura, T., Emadzadeh, D., Chen, J. P., \& Ismail, A. (2015). A review on polyamide thin film nanocomposite (TFN) membranes: History, applications, challenges and approaches. Water Research, 80, 306-324. doi:10.1016/j.watres.2015.04.037

Lau, W. J., Ismail, A. F., Misdan, N., \& Kassim, M. A. (2012). A recent progress in thin film composite membrane: A review. Desalination, 287, 190-199. doi:10.1016/j.desal.2011.04.004

Lau, W., Ismail, A., Misdan, N., \& Kassim, M. (2012). A recent progress in thin film composite membrane: A review. Desalination, 287, 190-199. doi:10.1016/j.desal.2011.04.004

Lay, W. C., Zhang, J., Tang, C., Wang, R., Liu, Y., \& Fane, A. G. (2012). Factors affecting flux performance of forward osmosis systems. Journal of Membrane Science, 394, 151-168. doi:10.1016/j.memsci.2011.12.035

Lee, J. S., Choi, K. H., Ghim, H. D., Kim, S. S., Chun, D. H., Kim, H. Y., \& Lyoo, W. S. (2004). Role of molecular weight of atactic poly (vinyl alcohol)(PVA) in the structure and properties of PVA nanofabric prepared by electrospinning. Journal of Applied Polymer Science, 93(4), 1638-1646. doi:10.1002/app.20602

Lee, S., \& Kim, Y. C. (2017). Calcium carbonate scaling by reverse draw solute diffusion in a forward osmosis membrane for shale gas wastewater treatment. Journal of Membrane Science, 522, 257-266. doi:10.1016/ j.memsci.2016.09.026

Lee, S., \& Kim, Y. C. (2018). Performance analysis of plate-and-frame forward osmosis membrane elements and implications for scale-up design. Journal of Membrane Science, 550, 219-229. doi:10.1016/j.memsci.2017.12.080

Lee, K. H., Kim, H. Y., La, Y. M., Lee, D. R., \& Sung, N. H. (2002). Influence of a mixing solvent with tetrahydrofuran and N, N-dimethylformamide on electrospun poly (vinyl chloride) nonwoven mats. Journal of Polymer Science Part B: Polymer Physics, 40(19), 2259-2268. doi:10.1002/polb.10293

Li, N. N., Fane, A. G., Ho, W. W., \& Matsuura, T. (2011). Advanced membrane technology and applications. Hoboken, NJ: John Wiley \& Sons. 
Lian, B., Blandin, G., Leslie, G., \& Le-Clech, P. (2018). Impact of module design in forward osmosis and pressure assisted osmosis: An experimental and numerical study. Desalination, 426, 108-117. doi:10.1016/j.desal.2017.10.047

Liang, H.-Q., Hung, W.-S., Yu, H.-H., Hu, C.-C., Lee, K.-R., Lai, J.-Y., \& Xu, Z.-K. (2017). Forward osmosis membranes with unprecedented water flux. Journal of Membrane Science, 529, 47-54. doi:10.1016/j.memsci.2017.01.056

Lim, S. K., Hwang, S.-H., Chang, D., \& Kim, S. (2010). Preparation of mesoporous In 2 O 3 nanofibers by electrospinning and their application as a CO gas sensor. Sensors and Actuators B: Chemical, 149(1), 28-33. doi:10.1016/ j.snb.2010.06.039

LINARI NanoTech. (2018). Retreived from http://www.linaribiomedical.com/.

Liu, Z., Cui, Z., Zhang, Y., Qin, S., Yan, F., \& Li, J. (2017). Fabrication of polysulfone membrane via thermally induced phase separation process. Materials Letters, 195, 190-193. doi:10.1016/j.matlet.2017.02.070

Liu, S., Fukushima, K., Venkataraman, S., Hedrick, J. L., \& Yang, Y. Y. (2018). Supramolecular nanofibers self-assembled from cationic small molecules derived from repurposed poly (ethylene teraphthalate) for antibiotic delivery. Nanomedicine: Nanotechnology, Biology and Medicine, 14(1), 165-172. doi:10.1016/j.nano.2017.09.007

Liu, Q., Li, J., Zhou, Z., Xie, J., \& Lee, J. Y. (2016). Hydrophilic mineral coating of membrane substrate for reducing internal concentration polarization (ICP) in forward osmosis. Scientific Reports, 6(1), 19593. doi:10.1038/srep19593

Liu, Z., Yu, H., Kang, G., Jie, X., Jin, Y., \& Cao, Y. (2016). Investigation of internal concentration polarization reduction in forward osmosis membrane using nano- $\mathrm{CaCO}_{3}$ particles as sacrificial component. Journal of Membrane Science, 497, 485-493. doi:10.1016/j.memsci.2015.06.052

Loeb, S., Titelman, L., Korngold, E., \& Freiman, J. (1997). Effect of porous support fabric on osmosis through a Loeb-Sourirajan type asymmetric membrane. Journal of Membrane Science, 129(2), 243-249. doi:10.1016/ S0376-7388(96)00354-7

Lu, P., Liang, S., Qiu, L., Gao, Y., \& Wang, Q. (2016). Thin film nanocomposite forward osmosis membranes based on layered double hydroxide nanoparticles blended substrates. Journal of Membrane Science, 504, $196-205$. doi:10.1016/j.memsci.2015.12.066

Lutchmiah, K., Verliefde, A. R. D., Roest, K., Rietveld, L. C., \& Cornelissen, E. R. (2014). Forward osmosis for application in wastewater treatment: A review. Water Research, 58, 179-197. doi:10.1016/j.watres.2014.03.045

Lu, X., Wang, C., \& Wei, Y. (2009). One-dimensional composite nanomaterials: Synthesis by electrospinning and their applications. Small, 5(21), 2349-2370. doi:10.1002/smll.200900445

Ma, N., Wei, J., Liao, R., \& Tang, C. Y. (2012). Zeolite-polyamide thin film nanocomposite membranes. Journal of Membrane Science, 405, 149-157. doi:10.1016/j.memsci.2012.03.002

Ma, N., Wei, J., Qi, S., Zhao, Y., Gao, Y., \& Tang, C. Y. (2013). Nanocomposite substrates for controlling internal concentration polarization in forward osmosis membranes. Journal of Membrane Science, 441, 54-62. doi:10.1016/ j.memsci.2013.04.004

Mazlan, N. M., Peshev, D., \& Livingston, A. G. (2016). Energy consumption for desalination-A comparison of forward osmosis with reverse osmosis, and the potential for perfect membranes. Desalination, 377, $138-151$. doi:10.1016/j.desal.2015.08.011

McCutcheon, J. R., \& Elimelech, M. (2006). Influence of concentrative and dilutive internal concentration polarization on flux behavior in forward osmosis. Journal of Membrane Science, 284(1-2), 237-247. doi:10.1016/ j.memsci.2006.07.049

McCutcheon, J. R., \& Elimelech, M. (2007). Modeling water flux in forward osmosis: Implications for improved membrane design. AIChE Journal, 53(7), 1736-1744. doi:10.1002/aic.11197

McCutcheon, J. R., \& Elimelech, M. (2008). Influence of membrane support layer hydrophobicity on water flux in osmotically driven membrane processes. Journal of Membrane Science, 318(1-2), 458-466. doi:10.1016/ j.memsci.2008.03.021 
McGinnis, R. L., \& Elimelech, M. (2007). Energy requirements of ammonia-carbon dioxide forward osmosis desalination. Desalination, 207(1-3), 370-382. doi:10.1016/j.desal.2006.08.012

McGinnis, R. L., Hancock, N. T., Nowosielski-Slepowron, M. S., \& McGurgan, G. D. (2013). Pilot demonstration of the NH3/CO2 forward osmosis desalination process on high salinity brines. Desalination, 312, 67-74. doi:10.1016/ j.desal.2012.11.032

McGinnis, R., \& McGurgan, G. (2012). Forward osmosis membranes: Google Patents.

McGovern, R. K., \& Lienhard, J. H. (2014). On the potential of forward osmosis to energetically outperform reverse osmosis desalination. Journal of Membrane Science, 469, 245-250. doi:10.1016/j.memsci.2014.05.061

McKee, M. G., Layman, J. M., Cashion, M. P., \& Long, T. E. J. S. (2006). Phospholipid nonwoven electrospun membranes. Science, 311, 353-355. doi:10.1126/science.1119790

Min, B.-M., Lee, G., Kim, S. H., Nam, Y. S., Lee, T. S., \& Park, W. H. J. B. (2004). Electrospinning of silk fibroin nanofibers and its effect on the adhesion and spreading of normal human keratinocytes and fibroblasts in vitro. Biomaterials, 25, 1289-1297. doi:10.1016/j.biomaterials.2003.08.045

Misdan, N., Lau, W. J., Ismail, A. F., \& Matsuura, T. (2013). Formation of thin film composite nanofiltration membrane: Effect of polysulfone substrate characteristics. Desalination, 329, 9-18. doi:10.1016/j.desal.2013.08.021

Mit-Uppatham, C., Nithitanakul, M., \& Supaphol, P. (2004). Ultrafine electrospun polyamide-6 fibers: Effect of solution conditions on morphology and average fiber diameter. Macromolecular Chemistry and Physics, 205, 2327-2338. doi:10.1002/macp.200400225

Muta, H., Miwa, M., \& Satoh, M. (2001). Ion-specific swelling of hydrophilic polymer gels. Polymer, 42(14), 63136316. doi:10.1016/S0032-3861(01)00098-2

Na, H., Zhao, Y., Zhao, C., Zhao, C., \& Yuan, X. (2008). Effect of hot-press on electrospun poly(vinylidene fluoride) membranes. Polymer Engineering \& Science, 48, 934-940. doi:10.1002/pen.21039

Nadetech Innovations. (2018). Retreived from http://www.nadetech.com/index.php/en/.

Nain, A. S., Amon, C., \& Sitti, M. (2006). Proximal probes based nanorobotic drawing of polymer micro/nanofibers. IEEE Transactions on Nanotechnology, 5(5), 499-510. doi:10.1109/TNANO.2006.880453

NanoNC. (2018). Retreived from http://nanonc.co.kr/wordpress/.

Neo, Y. P., Ray, S., Easteal, A. J., Nikolaidis, M. G., \& Quek, S. Y. (2012). Influence of solution and processing parameters towards the fabrication of electrospun zein fibers with sub-micron diameter. Journal of Food Engineering, 109(4), 645-651. doi:10.1016/j.jfoodeng.2011.11.032

Obaid, M., Ghouri, Z. K., Fadali, O. A., Khalil, K. A., Almajid, A. A., \& Barakat, N. A. (2016). Amorphous $\mathrm{SiO}_{2}$ NP-incorporated poly (vinylidene fluoride) electrospun nanofiber membrane for high flux forward osmosis desalination. ACS Applied Materials \& Interfaces, 8, 4561-4574. doi:10.1021/acsami.5b09945

Obaid, M., Kang, Y., Wang, S., Yoon, M.-H., Kim, C.-M., Song, J-h., \& Kim, I. S. (2018). Fabrication of highly permeable thin-film nanocomposite forward osmosis membranes via design novel freestanding robust nanofiber substrates. Journal of Materials Chemistry A, 6(25), 11700. doi:10.1039/C7TA11320J

Obaid, M., Mohamed, H. O., Yasin, A. S., Fadali, O. A., Khalil, K. A., Kim, T., \& Barakat, N. A. (2016). A novel strategy for enhancing the electrospun PVDF support layer of thin-film composite forward osmosis membranes. RSC Advances, 6(104), 102762-102772. doi:10.1039/C6RA18153H

Obaid, M., Mohamed, H. O., Yasin, A. S., Yassin, M. A., Fadali, O. A., Kim, H., \& Barakat, N. A. (2017). Under-oil superhydrophilic wetted PVDF electrospun modified membrane for continuous gravitational oil/water separation with outstanding flux. Water Research, 123, 524-535. doi:10.1016/j.watres.2017.06.079

Oh, Y., Lee, S., Elimelech, M., Lee, S., \& Hong, S. (2014). Effect of hydraulic pressure and membrane orientation on water flux and reverse solute flux in pressure assisted osmosis. Journal of Membrane Science, 465, 159-166.

doi:10.1016/j.memsci.2014.04.008 
Okutan, N., Terzi, P., \& Altay, F. (2014). Affecting parameters on electrospinning process and characterization of electrospun gelatin nanofibers. Food Hydrocolloids, 39, 19-26. doi:10.1016/j.foodhyd.2013.12.022

Ong, R. C., Chung, T.-S., de Wit, J. S., \& Helmer, B. J. (2015). Novel cellulose ester substrates for high performance flat-sheet thin-film composite (TFC) forward osmosis (FO) membranes. Journal of Membrane Science, 473, 63-71. doi:10.1016/j.memsci.2014.08.046

Pan, S.-F., Dong, Y., Zheng, Y.-M., Zhong, L.-B., \& Yuan, Z.-H. (2017). Self-sustained hydrophilic nanofiber thin film composite forward osmosis membranes: Preparation, characterization and application for simulated antibiotic wastewater treatment. Journal of Membrane Science, 523, 205-215. doi:10.1016/j.memsci.2016.09.045

Park, S. Y., Ahn, H.-W., Chung, J. W., \& Kwak, S.-Y. (2016). Magnetic core-hydrophilic shell nanosphere as stability-enhanced draw solute for forward osmosis (FO) application. Desalination, 397, 22-29. doi:10.1016/ j.desal.2016.06.017

Park, M. J., Gonzales, R. R., Abdel-Wahab, A., Phuntsho, S., \& Shon, H. K. (2018). Hydrophilic polyvinyl alcohol coating on hydrophobic electrospun nanofiber membrane for high performance thin film composite forward osmosis membrane. Desalination, 426, 50-59. doi:10.1016/j.desal.2017.10.042

Park, M. J., Phuntsho, S., He, T., Nisola, G. M., Tijing, L. D., Li, X.-M., ... Shon, H. K. (2015). Graphene oxide incorporated polysulfone substrate for the fabrication of flat-sheet thin-film composite forward osmosis membranes. Journal of Membrane Science, 493, 496-507. doi:10.1016/j.memsci.2015.06.053

Pelipenko, J., Kristl, J., Janković, B., Baumgartner, S., \& Kocbek, P. (2013). The impact of relative humidity during electrospinning on the morphology and mechanical properties of nanofibers. International Journal of Pharmaceutics, 456, 125-134. doi:10.1016/j.ijpharm.2013.07.078

Peng, S., Li, L., Hu, Y., Srinivasan, M., Cheng, F., Chen, J., \& Ramakrishna, S. (2015). Fabrication of spinel onedimensional architectures by single-spinneret electrospinning for energy storage applications. ACS Nano, 9(2), 19451954. doi: $10.1021 / \mathrm{nn} 506851 \mathrm{x}$

Peng, J., Su, Y., Chen, W., Shi, Q., Jiang, Z. J. I., \& Research, E. C. (2010). Effects of coagulation bath temperature on the separation performance and antifouling property of poly (ether sulfone) ultrafiltration membranes. Industrial \& Engineering Chemistry Research, 49, 4858-4864. doi:10.1021/ie9018963

Persano, L., Camposeo, A., Tekmen, C., \& Pisignano, D. (2013). Industrial upscaling of electrospinning and applications of polymer nanofibers: A review. Macromolecular Materials and Engineering, 298(5), 504-520. doi:10.1002/ mame.201200290

Phuntsho, S., Kim, J. E., Johir, M. A. H., Hong, S., Li, Z., Ghaffour, N., ... Shon, H. K. (2016). Fertiliser drawn forward osmosis process: Pilot-scale desalination of mine impaired water for fertigation. Journal of Membrane Science, 508, 22-31. doi:10.1016/j.memsci.2016.02.024

Puguan, J. M. C., Kim, H.-S., Lee, K.-J., \& Kim, H. (2014). Low internal concentration polarization in forward osmosis membranes with hydrophilic crosslinked PVA nanofibers as porous support layer. Desalination, 336, $24-31$. doi:10.1016/j.desal.2013.12.031

Qasim, M., Darwish, N. A., Sarp, S., \& Hilal, N. (2015). Water desalination by forward (direct) osmosis phenomenon: A comprehensive review. Desalination, 374, 47-69. doi:10.1016/j.desal.2015.07.016

Qin, M., \& He, Z. (2014). Self-supplied ammonium bicarbonate draw solute for achieving wastewater treatment and recovery in a microbial electrolysis cell-forward osmosis-coupled system. Environmental Science \& Technology Letters, 1, 437-441. doi:10.1021/ez500280c

Ramakrishna, S., Fujihara, K., Teo, W.-E., Yong, T., Ma, Z., \& Ramaseshan, R. (2006). Electrospun nanofibers: Solving global issues. Materials Today, 9(3), 40-50. doi:10.1016/S1369-7021(06)71389-X

Rastogi, N. K. (2016). Opportunities and challenges in application of forward osmosis in food processing. Critical Reviews in Food Science and Nutrition, 56(2), 266-291. doi:10.1080/10408398.2012.724734 
Ray, S. S., Chen, S.-S., Li, C.-W., Nguyen, N. C., \& Nguyen, H. T. (2016). A comprehensive review: Electrospinning technique for fabrication and surface modification of membranes for water treatment application. RSC Advances, 6(88), 85495-85514. doi:10.1039/C6RA14952A

Reddy, A., \& Patel, H. R. (2008). Chemically treated polyethersulfone/polyacrylonitrile blend ultrafiltration membranes for better fouling resistance. Desalination, 22l(1-3), 318-323. doi:10.1016/j.desal.2007.01.089

Ren, J., \& McCutcheon, J. R. (2014). A new commercial thin film composite membrane for forward osmosis. Desalination, 343, 187-193. doi:10.1016/j.desal.2013.11.026

Reneker, D. H., \& Chun, I. (1996). Nanometre diameter fibres of polymer, produced by electrospinning. Nanotechnology, 7(3), 216.

Reneker, D. H., Yarin, A. L., Fong, H., \& Koombhongse, S. (2000). Bending instability of electrically charged liquid jets of polymer solutions in electrospinning. Journal of Applied Physics, 87(9), 4531-4547. doi:10.1063/1.373532

Roh, I. J., Greenberg, A. R., \& Khare, V. P. (2006). Synthesis and characterization of interfacially polymerized polyamide thin films. Desalination, 191(1-3), 279-290. doi:10.1016/j.desal.2006.03.004

Sagiv, A., Zhu, A., Christofides, P. D., Cohen, Y., \& Semiat, R. (2014). Analysis of forward osmosis desalination via two-dimensional FEM model. Journal of Membrane Science, 464, 161-172. doi:10.1016/j.memsci.2014.04.001

Sahebi, S., Phuntsho, S., Woo, Y. C., Park, M. J., Tijing, L. D., Hong, S., \& Shon, H. K. (2016). Effect of sulphonated polyethersulfone substrate for thin film composite forward osmosis membrane. Desalination, 389, 129-136. doi:10.1016/j.desal.2015.11.028

Sairam, M., Sereewatthanawut, E., Li, K., Bismarck, A., \& Livingston, A. G. (2011). Method for the preparation of cellulose acetate flat sheet composite membranes for forward osmosis - desalination using $\mathrm{MgSO}_{4}$ draw solution. Desalination, 273(2-3), 299-307. doi:10.1016/j.desal.2011.01.050

Sarbatly, R., Krishnaiah, D., \& Kamin, Z. (2016). A review of polymer nanofibres by electrospinning and their application in oil-water separation for cleaning up marine oil spills. Marine Pollution Bulletin, 106(1-2), 8-16. doi:10.1016/j.marpolbul.2016.03.037

Saud, P. S., Pant, B., Ojha, G. P., Kim, D.-U., Kuk, Y.-S., Park, S.-J., .. Kim, H.-Y. (2017). One-pot synthesis of $\mathrm{Ag}_{3} \mathrm{PO}_{4} / \mathrm{MoS}_{2}$ nanocomposite with highly efficient photocatalytic activity. Journal of Environmental Chemical Engineering, 5(6), 5521-5527. doi:10.1016/j.jece.2017.10.040

Sehaqui, H., Ezekiel Mushi, N., Morimune, S., Salajkova, M., Nishino, T., \& Berglund, L. A. (2012). Cellulose nanofiber orientation in nanopaper and nanocomposites by cold drawing. ACS Applied Materials \& Interfaces, 4, 10431049. doi:10.1021/am2016766

Shaffer, D. L., Werber, J. R., Jaramillo, H., Lin, S., \& Elimelech, M. (2015). Forward osmosis: Where are we now? Desalination, 356, 271-284. doi:10.1016/j.desal.2014.10.031

Shalini, H., \& Nayak, C. A. (2016). Forward osmosis membrane concentration of raw sugarcane juice. Recent Advances in Chemical Engineering- Select Proceedings of ICACE 2015 (pp.81-88). Springer.

Shang, Y., Si, Y., Raza, A., Yang, L., Mao, X., Ding, B., \& Yu, J. (2012). An in situ polymerization approach for the synthesis of superhydrophobic and superoleophilic nanofibrous membranes for oil-water separation. Nanoscale, 4(24), 7847-7854. doi:10.1039/c2nr33063f

Shannon, M. A., Bohn, P. W., Elimelech, M., Georgiadis, J. G., Mariñas, B. J., \& Mayes, A. M. (2008). Science and technology for water purification in the coming decades. Nature, 452(7185), 301-310. doi:10.1038/nature06599

Shao, C., Kim, H.-Y., Gong, J., Ding, B., Lee, D.-R., \& Park, S.-J. (2003). Fiber mats of poly(vinyl alcohol)/silica composite via electrospinning. Materials Letters, 57(9-10), 1579-1584. doi:10.1016/S0167-577X(02)01036-4

Shen, L., Xiong, S., \& Wang, Y. (2016). Graphene oxide incorporated thin-film composite membranes for forward osmosis applications. Chemical Engineering Science, 143, 194-205. doi:10.1016/j.ces.2015.12.029

Shi, L., Chou, S. R., Wang, R., Fang, W. X., Tang, C. Y., \& Fane, A. G. (2011). Effect of substrate structure on the performance of thin-film composite forward osmosis hollow fiber membranes. Journal of Membrane Science, 382(12), 116-123. doi:10.1016/j.memsci.2011.07.045 
Shirazi, A., Mahdi, M., Kargari, A., Ramakrishna, S., Doyle, J., Rajendrian, M., \& Babu, P. (2017). Electrospun membranes for desalination and water/wastewater treatment: A comprehensive review. Journal of Membrane Science and Research, 3, 209-227.

Shokrollahzadeh, S., \& Tajik, S. (2018). Fabrication of thin film composite forward osmosis membrane using electrospun polysulfone/polyacrylonitrile blend nanofibers as porous substrate. Desalination, 425, 68-76. doi:10.1016/ j.desal.2017.10.017

Singh, A. A., Geng, S., Herrera, N., \& Oksman, K. (2018). Aligned plasticized polylactic acid cellulose nanocomposite tapes: Effect of drawing conditions. Composites Part A: Applied Science and Manufacturing, 104, 101-107. doi:10.1016/j.compositesa.2017.10.019

Song, X., \& Prince, A. (2016). Relating water/solute permeability coefficients to the performance of thin-film nanofiber composite forward osmosis membrane. Journal of Membrane Science \& Technology, 6, 160. doi:10.4172/2155-9589.1000160

Song, X., Liu, Z., \& Sun, D. D. (2011). Nano gives the answer: Breaking the bottleneck of internal concentration polarization with a nanofiber composite forward osmosis membrane for a high water production rate. Advanced Materials, 23(29), 3256-3260. doi:10.1002/adma.201100510

Suh, C., \& Lee, S. (2013). Modeling reverse draw solute flux in forward osmosis with external concentration polarization in both sides of the draw and feed solution. Journal of Membrane Science, 427, 365-374. doi:10.1016/ j.memsci.2012.08.033

Sun, B., Long, Y., Zhang, H., Li, M., Duvail, J., Jiang, X., \& Yin, H. (2014). Advances in three-dimensional nanofibrous macrostructures via electrospinning. Progress in Polymer Science, 39, 862-890. doi:10.1016/j.progpolymsci.2013.06.002

Tang, C. Y., She, Q., Lay, W. C., Wang, R., \& Fane, A. G. (2010). Coupled effects of internal concentration polarization and fouling on flux behavior of forward osmosis membranes during humic acid filtration. Journal of Membrane Science, 354(1-2), 123-133. doi:10.1016/j.memsci.2010.02.059

Tang, C. Y., She, Q., Lay, W. C., Wang, R., Field, R., \& Fane, A. G. (2011). Modeling double-skinned FO membranes. Desalination, 283, 178-186. doi:10.1016/j.desal.2011.02.026

Tan, S.-H., Inai, R., Kotaki, M., \& Ramakrishna, S. (2005). Systematic parameter study for ultra-fine fiber fabrication via electrospinning process. Polymer, 46, 6128-6134. doi:10.1016/j.polymer.2005.05.068

Tan, C. H., \& Ng, H. Y. (2008). Modified models to predict flux behavior in forward osmosis in consideration of external and internal concentration polarizations. Journal of Membrane Science, 324(1-2), 209-219. doi:10.1016/ j.memsci.2008.07.020

Tan, C. H., \& Ng, H. Y. (2013). Revised external and internal concentration polarization models to improve flux prediction in forward osmosis process. Desalination, 309, 125-140. doi:10.1016/j.desal.2012.09.022

Tan, C., \& Ng, H. (2010). A novel hybrid forward osmosis-nanofiltration (FO-NF) process for seawater desalination: Draw solution selection and system configuration. Desalination and Water Treatment, 13(1-3), 356-361. doi:10.5004/dwt.2010.1733

Tao, S. L., \& Desai, T. A. (2007). Aligned arrays of biodegradable poly ( $€$-caprolactone) nanowires and nanofibers by template synthesis. Nano Letters, 7(6), 1463-1468. doi:10.1021/n10700346

Tian, M., Qiu, C., Liao, Y., Chou, S., \& Wang, R. (2013). Preparation of polyamide thin film composite forward osmosis membranes using electrospun polyvinylidene fluoride (PVDF) nanofibers as substrates. Separation and Purification Technology, 118, 727-736. doi:10.1016/j.seppur.2013.08.021

Tian, M., Wang, Y.-N., \& Wang, R. (2015). Synthesis and characterization of novel high-performance thin film nanocomposite (TFN) FO membranes with nanofibrous substrate reinforced by functionalized carbon nanotubes. Desalination, 370, 79-86. doi:10.1016/j.desal.2015.05.016 
Tian, M., Wang, Y.-N., Wang, R., \& Fane, A. G. (2017). Synthesis and characterization of thin film nanocomposite forward osmosis membranes supported by silica nanoparticle incorporated nanofibrous substrate. Desalination, 401, 142-150. doi:10.1016/j.desal.2016.04.003

Tian, E., Wang, X., Zhao, Y., \& Ren, Y. (2017). Middle support layer formation and structure in relation to performance of three-tier thin film composite forward osmosis membrane. Desalination, 421, 190. doi:10.1016/ j.desal.2017.02.014

Tian, E. L., Zhou, H., Ren, Y. W., Mirza, ZA., Wang, X. Z., \& Xiong, S. W. (2014). Novel design of hydrophobic/ hydrophilic interpenetrating network composite nanofibers for the support layer of forward osmosis membrane. Desalination, 347, 207-214. doi:10.1016/j.desal.2014.05.043

Tiraferri, A., Yip, N. Y., Phillip, W. A., Schiffman, J. D., \& Elimelech, M. (2011). Relating performance of thin-film composite forward osmosis membranes to support layer formation and structure. Journal of Membrane Science, 367(1-2), 340-352. doi:10.1016/j.memsci.2010.11.014

Tiraferri, A., Yip, N. Y., Straub, A. P., Castrillon, S. R.-V., \& Elimelech, M. (2013). A method for the simultaneous determination of transport and structural parameters of forward osmosis membranes. Journal of Membrane Science, 444, 523-538. doi:10.1016/j.memsci.2013.05.023

TONG LI TECH. (2018). Retreived from http://www.electro-spinning.com/index.html.

Volpin, F., Fons, E., Chekli, L., Kim, J. E., Jang, A., \& Shon, H. K. (2018). Hybrid forward osmosis-reverse osmosis for wastewater reuse and seawater desalination: Understanding the optimal feed solution to minimise fouling. Process Safety and Environmental Protection, 117, 523-532. doi:10.1016/j.psep.2018.05.006

Vyas, B., \& Ray, P. (2015). Preparation of nanofiltration membranes and relating surface chemistry with potential and topography: Application in separation and desalting of amino acids. Desalination, 362, 104-116. doi:10.1016/ j.desal.2015.02.013

Wang, X., Ding, B., \& Li, B. (2013). Biomimetic electrospun nanofibrous structures for tissue engineering. Materials Today, 16(6), 229-241. doi:10.1016/j.mattod.2013.06.005

Wang, X., Ding, B., Yu, J., \& Wang, M. (2011). Engineering biomimetic superhydrophobic surfaces of electrospun nanomaterials. Nano Today, 6(5), 510-530. doi:10.1016/j.nantod.2011.08.004

Wang, J., Dlamini, D. S., Mishra, A. K., Pendergast, M. T. M., Wong, M. C. Y., Mamba, B. B., ... Hoek, E. M. V. (2014). A critical review of transport through osmotic membranes. Journal of Membrane Science, 454, 516-537. doi:10.1016/j.memsci.2013.12.034

Wang, D.-M., \& Lai, J.-Y. (2013). Recent advances in preparation and morphology control of polymeric membranes formed by nonsolvent induced phase separation. Current Opinion in Chemical Engineering, 2, 229-237. doi:10.1016/ j.coche.2013.04.003

Wang, Y., Ou, R., Ge, Q., Wang, H., \& Xu, T. (2013). Preparation of polyethersulfone/carbon nanotube substrate for high-performance forward osmosis membrane. Desalination, 330, 70-78. doi:10.1016/j.desal.2013.09.028

Wang, Y., Ou, R., Wang, H., \& Xu, T. (2015). Graphene oxide modified graphitic carbon nitride as a modifier for thin film composite forward osmosis membrane. Journal of Membrane Science, 475, 281-289. doi:10.1016/ j.memsci.2014.10.028

Wang, J., Ouyang, Z., Ren, Z., Li, J., Zhang, P., Wei, G., \& Su, Z. (2015). Self-assembled peptide nanofibers on graphene oxide as a novel nanohybrid for biomimetic mineralization of hydroxyapatite. Carbon, 89, 20-30. doi:10.1016/ j.carbon.2015.03.024

Wang, R., Shi, L., Tang, C. Y., Chou, S., Qiu, C., \& Fane, A. G. (2010). Characterization of novel forward osmosis hollow fiber membranes. Journal of Membrane Science, 355(1-2), 158-167. doi:10.1016/j.memsci.2010.03.017

Wang, N., Wang, X., Ding, B., Yu, J., \& Sun, G. (2012). Tunable fabrication of three-dimensional polyamide-66 nano-fiber/nets for high efficiency fine particulate filtration. Journal of Materials Chemistry, 22(4), 1445-1452. doi:10.1039/C1JM14299B 
Wang, Y., Xu, S., Cheng, H., Liu, W., Chen, F., Liu, X., ... Hu, C. (2018). Oriented growth of polyaniline nanofiber arrays onto the glass and flexible substrates using a facile method. Applied Surface Science, 428, 315-321. doi:10.1016/j.apsusc.2017.09.087

Wang, G., Yu, D., Kelkar, A. D., \& Zhang, L. (2017). Electrospun nanofiber: Emerging reinforcing filler in polymer matrix composite materials. Progress in Polymer Science, 75, 73. doi:10.1016/j.progpolymsci.2017.08.002

Wang, X., Yu, J., Sun, G., \& Ding, B. (2016). Electrospun nanofibrous materials: A versatile medium for effective oil/water separation. Materials Today, 19(7), 403-414. doi:10.1016/j.mattod.2015.11.010

Wang, Y., Zhang, M., Liu, Y., Xiao, Q., \& Xu, S. (2016). Quantitative evaluation of concentration polarization under different operating conditions for forward osmosis process. Desalination, 398, 106-113. doi:10.1016/ j.desal.2016.07.015

Wang, S., Zhang, Y., Wang, W., Li, G., Ma, X., Li, X., ... Qian, Y. (2006). Template-assisted synthesis of porous molybdenum dioxide nanofibers and nanospheres by redox etching method. Journal of Crystal Growth, 290(1), 96102. doi:10.1016/j.jcrysgro.2005.10.149

Wei, J., Liu, X., Qiu, C., Wang, R., \& Tang, C. Y. (2011). Influence of monomer concentrations on the performance of polyamide-based thin film composite forward osmosis membranes. Journal of Membrane Science, 381(1-2), 110117. doi:10.1016/j.memsci.2011.07.034

Wei, J., Qiu, C., Tang, C. Y., Wang, R., \& Fane, A. G. (2011). Synthesis and characterization of flat-sheet thin film composite forward osmosis membranes. Journal of Membrane Science, 372(1-2), 292-302. doi:10.1016/ j.memsci.2011.02.013

Widjojo, N., Chung, T.-S., Weber, M., Maletzko, C., \& Warzelhan, V. (2011). The role of sulphonated polymer and macrovoid-free structure in the support layer for thin-film composite (TFC) forward osmosis (FO) membranes. Journal of Membrane Science, 383(1-2), 214-223. doi:10.1016/j.memsci.2011.08.041

Widjojo, N., Chung, T.-S., Weber, M., Maletzko, C., \& Warzelhan, V. (2013). A sulfonated polyphenylenesulfone (sPPSU) as the supporting substrate in thin film composite (TFC) membranes with enhanced performance for forward osmosis (FO). Chemical Engineering Journal, 220, 15-23. doi:10.1016/j.cej.2013.01.007

Xie, W., Geise, G. M., Freeman, B. D., Lee, H.-S., Byun, G., \& McGrath, J. E. (2012). Polyamide interfacial composite membranes prepared from m-phenylene diamine, trimesoyl chloride and a new disulfonated diamine. Journal of Membrane Science, 403, 152-161. doi:10.1016/j.memsci.2012.02.038

Xie, M., Luo, W., Guo, H., Nghiem, L. D., Tang, C. Y., \& Gray, S. R. (2018). Trace organic contaminant rejection by aquaporin forward osmosis membrane: Transport mechanisms and membrane stability. Water Research, 132, 90-98. doi:10.1016/j.watres.2017.12.072

Xu, Y., Peng, X., Tang, C. Y., Fu, Q. S., \& Nie, S. (2010). Effect of draw solution concentration and operating conditions on forward osmosis and pressure retarded osmosis performance in a spiral wound module. Journal of Membrane Science, 348(1-2), 298-309. doi:10.1016/j.memsci.2009.11.013

Yang, Q., Li, Z., Hong, Y., Zhao, Y., Qiu, S., Wang, C., \& Wei, Y. (2004). Influence of solvents on the formation of ultrathin uniform poly (vinyl pyrrolidone) nanofibers with electrospinning. Journal of Polymer Science Part B: Polymer Physics, 42(20), 3721-3726. doi:10.1002/polb.20222

Yeow, M., Liu, Y., \& Li, K. (2004). Morphological study of poly (vinylidene fluoride) asymmetric membranes: Effects of the solvent, additive, and dope temperature. Journal of Applied Polymer Science, 92, 1782-1789. doi:10.1002/app.20141

Yin, J., Zhu, G., \& Deng, B. (2016). Graphene oxide (GO) enhanced polyamide (PA) thin-film nanocomposite (TFN) membrane for water purification. Desalination, 379, 93-101. doi:10.1016/j.desal.2015.11.001

Yip, N. Y., Tiraferri, A., Phillip, W. A., Schiffman, J. D., \& Elimelech, M. (2010). High performance thin-film composite forward osmosis membrane. Environmental Science \& Technology, 44, 3812-3818. doi:10.1021/es1002555

Yip, N. Y., Phillip, W. A., Schiffman, J. D., \& Elimelech, M. (2015). High flux thin-film composite forward osmosis and pressure-retarded osmosis membranes. Google Patents. 
Yuan, H., Abu-Reesh, I. M., \& He, Z. (2015). Enhancing desalination and wastewater treatment by coupling microbial desalination cells with forward osmosis. Chemical Engineering Journal, 270, 437-443. doi:10.1016/ j.cej.2015.02.059

Yuan, X., Zhang, Y., Dong, C., \& Sheng, J. (2004). Morphology of ultrafine polysulfone fibers prepared by electrospinning. Polymer International, 53(11), 1704-1710. doi:10.1002/pi.1538

Zargham, S., Bazgir, S., Tavakoli, A., Rashidi, A. S., \& Damerchely, R. (2012). The effect of flow rate on morphology and deposition area of electrospun nylon 6 nanofiber. Journal of Engineered Fabrics \& Fibers (JEFF, ) 7

Zhang, F., Brastad, K. S., \& He, Z. (2011). Integrating forward osmosis into microbial fuel cells for wastewater treatment, water extraction and bioelectricity generation. Environmental Science \& Technology, 45(15), 6690-6696.

Zhang, B., Kang, F., Tarascon, J.-M., \& Kim, J.-K. (2016). Recent advances in electrospun carbon nanofibers and their application in electrochemical energy storage. Progress in Materials Science, 76, 319-380. doi:10.1016/j.pmatsci.2015.08.002

Zhang, S., Shim, W. S., Kim, J. J. M. \& Design, (2009). Design of ultra-fine nonwovens via electrospinning of Nylon 6: Spinning parameters and filtration efficiency. 30, 3659-3666. doi:10.1016/j.matdes.2009.02.017

Zhang, X., Xiao, C., \& Hu, X. (2013). Preparation and properties of polysulfone/polyacrylonitrile blend membrane and its modification with hydrolysis. Desalination and Water Treatment, 51(19-21), 3979-3987.

doi:10.1080/19443994.2013.800672

Zhang, C., Yuan, X., Wu, L., Han, Y., \& Sheng, J. (2005). Study on morphology of electrospun poly(vinyl alcohol) mats. European Polymer Journal, 41(3), 423-432. doi:10.1016/j.eurpolymj.2004.10.027

Zhao, X., Li, J., \& Liu, C. (2017). Improving the separation performance of the forward osmosis membrane based on the etched microstructure of the supporting layer. Desalination, 408, 102-109. doi:10.1016/j.desal.2017.01.021

Zhao, J., Luo, G., Wu, J., \& Xia, H. J. (2013). Preparation of microporous silicone rubber membrane with tunable pore size via solvent evaporation-induced phase separation. ACS Applied Materials \& Interfaces 5, 2040-2046. doi:10.1021/am302929c

Zhao, Y., Yang, Q., Lu, X.-F., Wang, C., \& Wei, Y. (2005). Study on correlation of morphology of electrospun products of polyacrylamide with ultrahigh molecular weight. Journal of Polymer Science Part B: Polymer Physics, 43(16), 2190-2195. doi:10.1002/polb.20506

Zhao, S., \& Zou, L. (2011). Relating solution physicochemical properties to internal concentration polarization in forward osmosis. Journal of Membrane Science, 379(1-2), 459-467. doi:10.1016/j.memsci.2011.06.021

Zhu, H., Qiu, S., Jiang, W., Wu, D., \& Zhang, C. (2011). Evaluation of electrospun polyvinyl chloride/polystyrene fibers as sorbent materials for oil spill cleanup. Environmental Science \& Technology, 45, 4527-4531. doi:10.1021/ es2002343

Zirehpour, A., Rahimpour, A., \& Ulbricht, M. (2017). Nano-sized metal organic framework to improve the structural properties and desalination performance of thin film composite forward osmosis membrane. Journal of Membrane Science, 531, 59-67. doi:10.1016/j.memsci.2017.02.049

Zou, S., \& He, Z. (2016). Enhancing wastewater reuse by forward osmosis with self-diluted commercial fertilizers as draw solutes. Water Research, 99, 235-243. doi:10.1016/j.watres.2016.04.067

Zou, S., Yuan, H., Childress, A., \& He, Z. (2016). Energy consumption by recirculation: A missing parameter when evaluating forward osmosis. Washington, D.C.: ACS Publications.

Zuo, W., Zhu, M., Yang, W., Yu, H., Chen, Y., \& Zhang, Y. J. (2005). Experimental study on relationship between jet instability and formation of beaded fibers during electrospinning. Polymer Engineering and Science 45, 704-709. doi:10.1002/pen.20304

Abbreviations

FO Forward osmosis

PRO Pressure retarded osmosis 


\begin{tabular}{|c|c|}
\hline RO & Reverse osmosis \\
\hline FS & Feed solution \\
\hline DS & Draw solution \\
\hline NF & Nanofiltration \\
\hline UF & Ultrafiltration \\
\hline MSF & Multi-stage flash distillation \\
\hline MED & Multi effect distillation \\
\hline MVC & Mechanical vapor compression \\
\hline TVC & Thermal vapor compression \\
\hline SWRO & Seawater reverse osmosis \\
\hline BWRO & Brackish water reverse osmosis \\
\hline ED & Electrodialysis \\
\hline SEC & Specific energy consumption \\
\hline TFC & Thin film composite \\
\hline CTA & Cellulose triacetate \\
\hline ENs & Electrospun nanofibers \\
\hline PI & Phase inversion \\
\hline IP & Interfacial polymerization \\
\hline $\mathrm{CP}$ & Concentration polarization \\
\hline ECP & External concentration polarization \\
\hline ICP & Internal concentration polarization \\
\hline PA & Polyamide \\
\hline $\mathrm{S}$ & Structural parameter \\
\hline $\mathrm{J}_{\mathrm{V}}=\mathrm{J}_{\mathrm{W}}$ & Water Flux (LMH) \\
\hline $\mathrm{LMH}$ & $\mathrm{L} /\left(\mathrm{m}^{2} \cdot \mathrm{h}\right)$ \\
\hline $\mathrm{J}_{\mathrm{S}}$ & Reverse salt flux (gMH) \\
\hline $\mathrm{gMH}$ & $\mathrm{g} /\left(\mathrm{m}^{2} \cdot \mathrm{h}\right)$ \\
\hline A & Water permeability coefficient $\left(\mathrm{L} /\left(\mathrm{m}^{2}\right.\right.$. h.bar $)$ \\
\hline $\mathrm{B}$ & Salt permeability coefficient $\left(\mathrm{L} /\left(\mathrm{m}^{2} . \mathrm{h}\right)\right.$ \\
\hline $\mathrm{J}_{\mathrm{S}} / \mathrm{J}_{\mathrm{W}}$ & Specific salt flux \\
\hline$\Delta \mathrm{P}$ & Hydraulic pressure difference \\
\hline$\Delta \pi$ & Osmotic pressure difference \\
\hline PES & Poly(ether sulfones) \\
\hline PET & Polyethylene terephthalate \\
\hline DMF & Dimethylformamide \\
\hline NMP & N-Methyl-2-pyrrolidone \\
\hline PSf & Polysulfone \\
\hline SDS & Sodium dodecyl sulfate \\
\hline MPD & m-Phenylenediamine \\
\hline TMC & 1,3,5-Benzenetricarbonyl Trichloride \\
\hline CAIP & Co-solvent assisted interfacial polymerization \\
\hline WCA & Water contact angle \\
\hline PVA & Polyvinyl alcohol \\
\hline PAN & Polyacrylonitrile \\
\hline TEA & Triethylamine \\
\hline $\mathrm{NaClO}$ & Sodium hypochlorite \\
\hline MD & Membrane distillation \\
\hline PVDF & Polyvinylidene fluoride \\
\hline PEI & polyetherimide \\
\hline CNT & Carbon nanotube \\
\hline
\end{tabular}




\section{AUthor QUeRIES}

Query: AQ0: Please review the table of contributors below and confirm that the first and last names are structured correctly and that the authors are listed in the correct order of contribution. This check is to ensure that your names will appear correctly online and when the article is indexed.

\begin{tabular}{|c|c|c|c|}
\hline Sequence & Prefix Given name(s) & Surname & Suffix \\
\hline 1 & M. & Obaid & \\
\hline 2 & Mohammad Ali & i Abdelkareem & \\
\hline 3 & Seungho & Kook & \\
\hline 4 & Hak-Yong & Kim & \\
\hline 5 & Nidal & Hilal & \\
\hline 6 & Noreddine & Ghaffour & \\
\hline 7 & $\ln S$. & Kim & \\
\hline
\end{tabular}

Response: Ok

Response: Ok

Query: AQ1: Please check whether the author names (first name followed by last name) and affiliations are correct as presented in the proofs.

Response: Answered within text

Query: AQ2: Please check and resupply corresponding author email address if the given is inaccurate.

Response: Ok

Response: Ok

Query: AQ3: References [Bui, N.-N., Lind, M. L., Hoek, E. M. V., \& McCutcheon, J. R. (2011). Electrospun nanofiber supported thin film composite membranes for engineered osmosis. Journal of Membrane Science, 385-386, 1019. // Bui, N.-N., Lind, M. L., Hoek, E. M., \& McCutcheon, J. R. (2011). Electrospun nanofiber supported thin film composite membranes for engineered osmosis. Journal of Membrane Science, 385, 10-19.] were duplicate. Please check.

Response: Ok

Response: Ok

Query: AQ4: References [Han, G., Chung, T.-S., Toriida, M., \& Tamai, S. (2012). Thin-film composite forward osmosis membranes with novel hydrophilic supports for desalination. Journal of Membrane Science, 423-424, 543-555]. // [Han, G., Chung, T.-S., Toriida, M., \& Tamai, S. (2012). Thin-film composite forward osmosis membranes with novel hydrophilic supports for desalination. Journal of Membrane Science, 423, 543-555.] were duplicate. Please check.

Response: Ok

Response: Ok

Query: AQ5: References [Lau, W., Gray, S., Matsuura, T., Emadzadeh, D., Chen, J. P., \& Ismail, A. (2015). A review on polyamide thin film nanocomposite (TFN) membranes: History, applications, challenges and approaches. Water Research, 80, 306-324.] // Lau, W., Gray, S., Matsuura, T., Emadzadeh, D., Chen, J. P., Ismail, A. J. W. \& R, (2015). A review on polyamide thin film nanocomposite (TFN) membranes: History, applications, challenges and approaches. 80, 306-324.] were duplicate. Please check.

Response: Ok

Response: OK

Query: AQ6: References [Ismail, A., Padaki, M., Hilal, N., Matsuura, T., \& Lau, W. (2015). Thin film composite membrane-recent development and future potential. Desalination, 356, 140-148.] // [Ismail, A., Padaki, M., Hilal, N., Matsuura, T., \& Lau, W. J. D. (2015). Thin film composite membrane-Recent development and future potential. 356, 140-148.] were duplicate. Please check. 


\section{Response: Ok}

Response: Ok

Query: AQ7: References [Ahmed, F. E., Lalia, B. S., \& Hashaikeh, R. (2015). A review on electrospinning for membrane fabrication: Challenges and applications. Desalination, 356, 15-30.] // [Ahmed, F. E., Lalia, B. S., \& Hashaikeh, R. (2015). A review on electrospinning for membrane fabrication: Challenges and applications. Desalination, 356, 15-30.] were duplicate. Please check.

\section{Response: Ok}

Response: Ok

Query: AQ8: References [Park, M. J., Phuntsho, S., He, T., Nisola, G. M., Tijing, L. D., Li, X.-M., ... Shon, H. K. (2015). Graphene oxide incorporated polysulfone substrate for the fabrication of flat-sheet thin-film composite forward osmosis membranes. Journal of Membrane Science, 493, 496-507.] // [Park, M. J., Phuntsho, S., He, T., Nisola, G. M., Tijing, L. D., Li, X.-M., ... Shon, H. K. (2015). Graphene oxide incorporated polysulfone substrate for the fabrication of flat-sheet thin-film composite forward osmosis membranes. Journal of Membrane Science, 493, 496-507.] were duplicate. Please check.

\section{Response: Ok}

Response: Ok

Query: AQ9: References [Emadzadeh, D., Lau, W. J., Matsuura, T., Ismail, A. F., \& Rahbari-Sisakht, M. (2014). Synthesis and characterization of thin film nanocomposite forward osmosis membrane with hydrophilic nanocomposite support to reduce internal concentration polarization. Journal of Membrane Science, 449, 74-85.] // [Emadzadeh, D., Lau, W., Matsuura, T., Ismail, A., \& Rahbari-Sisakht, M. (2014). Synthesis and characterization of thin film nanocomposite forward osmosis membrane with hydrophilic nanocomposite support to reduce internal concentration polarization. Journal of Membrane Science, 449, 74-85.] were duplicate. Please check.

\section{Response: Ok}

Response: Ok

Query: AQ10: References [Wang, Y., Zhang, M., Liu, Y., Xiao, Q., \& Xu, S. (2016). Quantitative evaluation of concentration polarization under different operating conditions for forward osmosis process. Desalination, 398, 106113.] // [Wang, Y., Zhang, M., Liu, Y., Xiao, Q., \& Xu, S. (2016). Quantitative evaluation of concentration polarization under different operating conditions for forward osmosis process. Desalination, 398, 106-113.] were duplicate. Please check.

Response: Ok

Response: Ok

Query: AQ11: References [Gray, G. T., McCutcheon, J. R., \& Elimelech, M. (2006). Internal concentration polarization in forward osmosis: Role of membrane orientation. Desalination, 197(1-3), 1-8.] // Gray, G. T., McCutcheon, J. R., \& Elimelech, M. (2006). Internal concentration polarization in forward osmosis: Role of membrane orientation. Desalination, 197(1-3), 1-8.] were duplicate. Please check.

Response: Ok

Response: Ok

Query: AQ12: References [Zirehpour, A., Rahimpour, A., \& Ulbricht, M. (2017). Nano-sized metal organic framework to improve the structural properties and desalination performance of thin film composite forward osmosis membrane. Journal of Membrane Science, 531, 59-67.] // [Zirehpour, A., Rahimpour, A., \& Ulbricht, M. (2017). Nanosized metal organic framework to improve the structural properties and desalination performance of thin film composite forward osmosis membrane. Journal of Membrane Science, 531, 59-67.] were duplicate. Please check.

Response: Ok

Response: Ok

Query: AQ13: References [Zhao, X., Li, J., \& Liu, C. (2017). Improving the separation performance of the forward osmosis membrane based on the etched microstructure of the supporting layer. Desalination, 408, 102-109.] // Zhao, X., Li, J., \& Liu, C. (2017). Improving the separation performance of the forward osmosis membrane based on the etched microstructure of the supporting layer. Desalination, 408, 102-109.] were duplicate. Please check.

Response: Ok 


\section{Response: Ok}

Query: AQ14: References [McGinnis, R. L., Hancock, N. T., Nowosielski-Slepowron, M. S., \& McGurgan, G. D. (2013). Pilot demonstration of the NH3/CO2 forward osmosis desalination process on high salinity brines. Desalination, 312, 67-74.] // [McGinnis, R. L., Hancock, N. T., Nowosielski-Slepowron, M. S., \& McGurgan, G. D. (2013). Pilot demonstration of the $\mathrm{NH} 3 / \mathrm{CO} 2$ forward osmosis desalination process on high salinity brines. Desalination, 312, 67-74.] were duplicate. Please check.

Response: Ok

Response: Ok

Query: AQ15: References [Kim, J., Blandin, G., Phuntsho, S., Verliefde, A., Le-Clech, P., \& Shon, H. J. D. (2017a). Practical considerations for operability of an 8 "spiral wound forward osmosis module: Hydrodynamics, fouling behaviour and cleaning strategy. 404, 249-258.] // [Kim, J., Blandin, G., Phuntsho, S., Verliefde, A., Le-Clech, P., \& Shon, H. (2017). Practical considerations for operability of an $8^{\prime \prime}$ spiral wound forward osmosis module: Hydrodynamics, fouling behaviour and cleaning strategy. Desalination, 404, 249-258.] were duplicate. Please check.

Response: Ok

Response: Ok

Query: AQ16: References [Kim, J. E., Phuntsho, S., Ali, S. M., Choi, J. Y., \& Shon, H. K. (2018). Forward osmosis membrane modular configurations for osmotic dilution of seawater by forward osmosis and reverse osmosis hybrid system. Water Research, 128, 183-192.] // [Kim, J. E., Phuntsho, S., Ali, S. M., Choi, J. Y., \& Shon, HKJWr. (2018a). Forward osmosis membrane modular configurations for osmotic dilution of seawater by forward osmosis and reverse osmosis hybrid system. 128, 183-192.] were duplicate. Please check.

Response: Ok

Response: Ok

Query: AQ17: References [Huang, L., \& McCutcheon, J. R. (2014). Hydrophilic nylon 6, 6 nanofibers supported thin film composite membranes for engineered osmosis. Journal of Membrane Science, 457, 162-169.] // Huang, L., \& McCutcheon, J. R. (2014). Hydrophilic nylon 6,6 nanofibers supported thin film composite membranes for engineered osmosis. Journal of Membrane Science, 457, 162-169.] were duplicate. Please check.

Response: Ok

Response: Ok

Query: AQ18: References [Dova, M. I., Petrotos, K. B., \& Lazarides, H. N. (2007a). On the direct osmotic concentration of liquid foods. Part I: Impact of process parameters on process performance. Journal of Food Engineering, 78(2), 422-430.] // [Dova, M. I., Petrotos, K. B., \& Lazarides, H. N. (2007b). On the direct osmotic concentration of liquid foods: Part II. Development of a generalized model. Journal of Food Engineering, 78(2), 431-437.] were duplicate. Please check.

Response: these are two referncees: Part I: Impact of process parameters on process performance. Journal of Food Engineering 78, 422-430Part II. Development of a generalized model. Journal of Food Engineering 78, 431-437

Query: AQ19: Please provide missing publisher location for ref. "Arinstein (2017)" in the reference list entry.

Response: Taylor\& Francis GroupPub. location: New YorkISBN 978-981-4745-27-7 (Hardcover)ISBN

978-1-315-36462-9 (eBook)Copyright (C) 2018 by Pan Stanford Publishing Pte. Ltd

Query: AQ20: Please provide the missing publisher name for ref. "Ding and $\mathrm{Yu}(2014)$ " in the reference list entry. Response: ISSN 1571-5744ISSN 2197-7976 (electronic)ISBN 978-3-642-54159-9 ISBN 978-3-642-54160-5 (eBook)DOI 10.1007/978-3-642-54160-5Springer Heidelberg New York Dordrecht London @ Springer-Verlag Berlin Heidelberg 2014

Query: AQ21: The funding information provided has been checked against the Open Funder Registry and we failed to find a match. Please check and resupply the funding details if necessary.

Response: This work was supported by the Korea Environment Industry \& Technology Institute (KEITI) through the Industrial Facilities \& Infrastructure Research Program, funded by the Korea Ministry of Environment (MOE)

(1485016274).

\section{COMMENTS}


C1 Author: United Kingdom;

C2 Author: This work was supported by the Korea Environment Industry \& Technology Institute (KEITI) through the Industrial Facilities \& Infrastructure Research Program, funded by the Korea Ministry of Environment (MOE)

(1485016274).;

C3 Author: for; 